\title{
LOS RETOS DEL PRESIDENTE BIDEN EN EL MEDIO ORIENTE TRAS LOS ¿ÉXITOS? OBTENIDOS POR EL EX - PRESIDENTE TRUMP. DE TRUMP A BIDEN: ¿RUPTURA O CONTINUIDAD?
}

\author{
Romualdo Bermejo García ${ }^{1}$ \\ Universidad de Leon
}

\begin{abstract}
La zona del Medio Oriente ha encontrado en los últimos tiempos unos vigorosos rayos de luz en las relaciones árabes-israelíes, como lo demuestran los ya conocidos Acuerdos de Abraham, liderados por el ya ex-presidente Donald Trump y por el también ya ex-primer ministro israelí Benjamin Netanyahu. Quedan, sin embargo, dos grandes temas muy importantes sin resolver: uno de ellos es el de Irán y los grupos armados apoyados masivamente por Teherán, como Hamás, Hezbolláh y otros que empiezan a tener una cierta relevancia tanto en Irak como en Siria, como lo pone de relieve la actualidad internacional; y el otro, que es más preciso, atañe a la cuestión del programa nuclear iraní, aspecto que se está tratando actualmente en las negociaciones nucleares de Viena, tras la retirada de los Estados Unidos del acuerdo nuclear de julio de 2015 por parte de Donald Trump. Esto pone de manifiesto que Irán se ha convertido en uno de los actores más importantes de la zona, lo que trae consigo que Israel siga vigilando de cerca sus actividades, y no solo las nucleares, sino también la de los diversos grupos armados que se encuentran bajo su patrocinio económico, militar y político.
\end{abstract}

Resumen:

Palabras Clave: Negociaciones nucleares de Viena, Irán, sanciones, Corte Internacional de Justicia, Hamás, Hezbolláh, Israel, Operación "Guardián de los Muros" en Gaza, Trump, Biden

Title in English: President Biden's Challenges in the Middle East after Former President Trump's successes (?). From Trump to Biden: Continuity or Discontinuity?

\section{Abstract:}

The Middle East has recently seen a few bright spots in Arab Israeli relations, as evidenced by the wellknown Abraham Accords, led by former President Donald Trump and former Israeli Prime Minister Benjamin Netanyahu. There remain, however, two major unresolved issues: one is that of Iran and the armed groups massively supported by Tehran, such as Hamas, Hezbollah and others that are beginning to have a certain relevance in both Iraq and Syria, as highlighted by international news; and the other, which is more defined, concerns the issue of Iran's nuclear programme, an aspect that is currently being addressed in the Vienna nuclear negotiations, following the Donald Trump withdrawal from the July 2015 nuclear deal. This highlights the fact that Iran has become one of the most important players in the region and Israel continues to keep a close eye on its activities, not only nuclear, but also those of the various armed groups under its economic, military and political patronage.

Key words: Vienna nuclear negotiations, Iran, sanctions, International Court of Justice, Hamas, Hezbollah, Israel, Operation "Guardian of the Walls" in Gaza, Trump, Biden.

Copyright @ UNISCI, 2021.

Las opiniones expresadas en estos artículos son propias de sus autores, y no reflejan necesariamente la opinión de UNISCI. The views expressed in these articles are those of the authors, and do not necessarily reflect the views of UNISCI

\footnotetext{
${ }^{1}$ Romualdo Bermejo García es Catedrático de Derecho Internacional Público de la Universidad de Leon, Profesor Visitante en la Universidad de Friburgo, Suiza E-mail: <rberg@unileon.es>

DOI: http://dx.doi.org/10.31439/UNISCI-122
} 


\section{Introducción}

Si la Presidencia de Trump ha supuesto un terremoto en la zona de Oriente Medio, para algunos con efectos positivos y no tanto para otros, queda por ver si los pasos dados por Trump ${ }^{2}$ van a ser respetados por el actual presidente Joe Biden. Dicho de otra forma: ¿Habrá continuidad, dentro de lo que cabe, o una ruptura? Esta pregunta ha estado en la boca de casi todos los analistas en seguir los acontecimientos en la zona, sin que se pueda vislumbrar en el momento actual una respuesta contundente. Como se sabe la zona puede pasar de una paz relativa a una guerra en cuestión de horas, como se ha visto en otros casos, pero también ahora en la operación denominada por Israel "Guardián de los Muros", cuyas causas y desarrollo trataremos en este estudio. Sin embargo, sí que parece que borrar todas las huellas de Trump no será fácil, por mucho que el actual presidente lo quiera, por lo que tendrá que reconocer que no todo lo hecho por el anterior inquilino de la Casa Blanca ha sido malo, aunque lo bueno "haya sido por accidente", como él mismo ha señalado ${ }^{3}$.

Pero la presidencia de Joe Biden se ha iniciado tras serios problemas en las elecciones que todo el mundo ha podido contemplar, y el subsiguiente asalto al Capitolio por los partidarios de Trump ha demostrado que la democracia americana no es tan perfecta como ellos pretenden, incluido Joe Biden. Evidentemente, estos acontecimientos han puesto sobre la mesa muchos interrogantes de cómo iba a reaccionar la primera potencia mundial, al menos hasta ahora, suscitando amplios debates a nivel interno e internacional. Sin embargo, Joe Biden ya traía bajo el brazo su programa en política exterior, habiéndolo expuesto y publicado a principios del año $2020^{4}$. No obstante, Joe Joe Biden peca ya en su programa de una cierta ingenuidad, pues más que mirar hacia el futuro con el fin de hacer ondear el blasón de los Estados Unidos, que él dice que quiere hacer, parece que lo único que quiere plasmar es demoler lo que construyó Trump. Por otro lado, Joe Biden podría haber sido un poco más hábil indicando que también hubo errores durante la presidencia de Obama de cuyo gobierno fue vicepresidente, que como se sabe fueron muchos, y que han estado minando en gran medida la política exterior estadounidense, como fue el caso en Siria. Al heredar un país muy marcado por la división, Joe Biden se erige en una especie de "arquitecto renovador"5 cuya narrativa va rápidamente a traicionar, "al firmar en una semana más órdenes ejecutivas, memorandos y proclamaciones presidenciales que ninguno de sus predecesores y, además, en todos los ámbitos externos e internos"6.

Desde esta perspectiva, y pasados ya los cien días de su presidencia, hay que reconocer que hasta ahora tiene en la zona del Medio Oriente dos temas principales: a) el asunto nuclear de Irán, de cuyo acuerdo se salió Donald Trump; y b) el problema israelo-palestino, que ha vuelto a renacer de sus cenizas, y en torno al cual lo menos que se puede decir es que no ha sido muy fino. Como colofón a este estudio, examinaremos también las razones de la operación "Guardián de los Muros", así como su desarrollo, demostrando Israel una vez más su poderío militar en la zona, así como el respeto a las normas que regulan el derecho internacional humanitario.

\footnotetext{
${ }^{2}$ Sobre la política de Trump y sus efectos no solo en el conflicto israelo-palestino, sino también en relación con los países árabes, cfr. Bermejo García, Romualdo (2021): "La política de Trump ante el conflicto israelo palestino a la luz del Derecho internacional: un balance positivo", Anuario Español de Derecho Internacional. vol. 37, pp. 970 .

${ }^{3}$ Bermejo García, Romualdo (2021): "De Trump a Biden: Ruptura o continuidad en la política exterior de los Estados Unidos”, en Fernández Liesa, Carlos y López-Jacoiste Díaz, Eugenia (Coords.): Nuevas dimensiones del Desarrollo sostenible y los derechos económicos sociales y culturales, Thomson-Reuters-Aranzadi.

4 Biden, Joseph Jr.: "Why America Must Lead Again Rescuing U.S. Foreign Policy After Trump", vol. 99, n 2 , Foreign Affairs (March/April, 2020), pp. 64-76.

${ }^{5}$ A este respecto, Seill, Isabel (2021): "How Biden Can Rebuild a Divided and Distrustful Nation. Americans Must Get to Know Another Again”, vol. 100, n 1, Foreign Affairs, 4 January 2021.

${ }^{6}$ Navarro, Beatriz: "La rutina vuelve a casa", La Vanguardia, 29 de enero de 2021.
} 


\section{La cuestión iraní: Un rompecabezas para el presidente Joe Biden}

Una de las cuestiones que va a estar siempre presente en la administración Biden va a ser Irán, tanto como potencia emergente en la zona y sus ramificaciones con las milicias que están bajo su control en Irak, Líbano y Siria, pero también Hamás, como con su programa nuclear, dado que su antecesor Trump se retiró del acuerdo nuclear de $2015^{7}$, del que Obama fue el gran impulsor. Como se sabe, Joe Biden prometió por activa y por pasiva reintegrar a los Estados Unidos en el acuerdo, y los pasos que está dando en este sentido no están exentos de problemas de diversa índole, de lo que Joe Biden se está dando perfectamente cuenta. Y es que los iraníes han demostrado en muchas ocasiones que son buenos negociadores, y tienen un país postrado a los pies de los Ayatolas, pero con unos Guardias Revolucionarios que actúan con cierta autonomía. Si a esto añadimos la nueva situación reinante en la zona tras los Acuerdos de Abraham $^{8}$, y la oposición israelí a que los Estados Unidos se reintegre en el acuerdo sin más. Así las cosas, es muy difícil en estos momentos saber qué derroteros va a seguir el nuevo presidente, pues Israel tiene las espadas en alto, y los países árabes del Golfo, que están bajo el patrocinio de Arabia Saudí, ya han mostrado también su fuerte oposición al programa nuclear iraní, pero también a que los Estados Unidos vuelvan sin más al acuerdo de 2015.

A este respecto, en un simposio organizado por el Instituto de Jerusalén para la Estrategia y Seguridad (JISS), en colaboración con el B'nai B'rith International se examinaron las eventuales alternativas, posibilidades o prioridades que el futuro presidente, Joe Biden, podría adoptar en materia de política exterior, especialmente en relación con Irán y el tema palestino9. Entre las distintas opiniones de determinados expertos que participaron en dicho simposio, conviene mencionar las siguientes. Para el antiguo embajador estadounidense en Israel, Dan Shapiro, las prioridades de Joe Biden estarían centradas sobre todo en resolver los problemas generados por la pandemia de la COVID-19, mejorar la economía, intentar encontrar soluciones a los problemas raciales y abordar la cuestión del cambio climático. Pero esto, señaló, no quiere decir que se vaya a ignorar la política exterior, y entre sus prioridades se incluirían revitalizar las tradicionales alianzas como la OTAN, sin olvidar las asiáticas. Sin embargo, sus prioridades no terminarían solo en estos temas, sino que intentaría restablecer el liderazgo estadounidense a nivel multilateral como en el ámbito de las Naciones Unidas, el Acuerdo sobre el Clima de París, así como hacer frente a la rivalidad estratégica con China y con Rusia, calificando a esta última de "agresiva".

Sin embargo, respecto al tema iraní, no estaría por lo menos de forma inmediata entre las preocupaciones de primer nivel para la administración Biden, reconociendo que este tema sería una de las grandes diferencias entre los presidentes Biden y Trump. Es más, en relación con el tema nuclear iraní el embajador estadounidense en Israel cree que si Israel piensa que Irán puede ser presionado a través de las sanciones a abandonar la carrera al arma nuclear, en este caso cabrían solo dos opciones: a) el riesgo de guerra, y b) el riesgo de una carrera nuclear. En esta tesitura, sostiene que sería incomprensible que la Administración Biden no incorporara a los

\footnotetext{
${ }^{7}$ Para un estudio pormenorizado sobre las consecuencias de la retirada del Acuerdo nuclear, cfr. Pozo Serrano, Pilar: "La retirada de los Estados Unidos del Plan de Acción Integral conjunto y la reimposición de sanciones a Irán: aspectos jurídicos y políticos”, Anuario Español de Derecho Internacional, no 35, 2019, pp. 219-259; y Calumani Quilca, Milagros: "Implicancias de la salida natural de los Estados Unidos del Acuerdo Nuclear con Irán”, Vol. XX, Anuario Mexicano de Derecho Internacional, 2020, pp. 655-685.

${ }^{8}$ Algunos autores piensan que se ha exagerado el papel de estos Acuerdos, como Sánchez Arreseigor, Juan: Dudas sobre la verdadera trascendencia y eficacia de los Acuerdos de Abraham, Documento Opinión 41/2021, IEEE, 13 de abril de 2021, 12 p. Esta no es la tesis en general más aceptada, pues es evidente que hay cambios sustanciales tras estos Acuerdos. A este respecto "Underestimating the Abraham Accords, Biden Has Lost the Middle East", en Breaking Israel, 20 May 2021:

9 "Experts Predict Israel Can Expect from Biden Administration", Israel 365 News, 26 December 2020, en https://www.israel365news.com/162964/experts-predict-what-israel-can-expect-from-biden-administration/?...
} 
actores regionales de la zona, como Israel y los Estados del Golfo, en el proceso de decisiones en esta materia y en las futuras negociaciones con Irán ${ }^{10}$. Esto no impediría, sin embargo, que, en relación con los palestinos, la administración Biden volviera al modelo tradicional de negociaciones entre israelíes y palestinos, teniendo siempre en mente la solución de dos Estados, y al mismo tiempo preparar un cambio de liderazgo palestino con el fin de abrir el callejón sin salida en el que se encuentran actualmente las negociaciones.

No todos compartieron, sin embargo, estas opiniones del precitado embajador Dan Shapiro. Tal es el caso del profesor de relaciones internacionales de la Universidad de Georgetown, Robert Lieber, quien no comparte la opinión de Dan Shapiro cuando afirma que sería "inconcebible" que la administración Biden pueda excluir a Israel y a los Estados del Golfo del proceso de negociaciones con Irán, como hizo la administración Obama, indicando que "There is a stark, almost embarrassing contrast to what the Obama Administration did... (Obama) it consciously failed to consult with Israel and others in the region. And when it did, it lied to them". El profesor Lieber señala, además, que Joe Biden necesita parar a China, Rusia e Irán, y que cuando empiece con su nueva "agenda" corre el riesgo de cometer los mismos errores que Barack Obama. Y en relación con la posibilidad de llevar a la mesa de negociaciones a los líderes palestinos con el fin de llegar a un acuerdo de paz, dudo que Joe Biden pueda llegar más lejos que los presidentes Clinton, Bush u Obama ${ }^{11}$. A esta opinión del profesor Lieber se puede poner una gran interrogación, y es que no toma mucho en consideración la nueva situación generada en la zona tras los famosos Acuerdos de Abraham, ni tampoco el nuevo marco de relaciones entre Israel y Marruecos, que deja a los líderes palestinos en una situación muy delicada, al ponerse de manifiesto los problemas que se han suscitado a causa de la intransigencia palestina, al decir no a casi todo.

Pero otros, como Yaakov Amidroor, antiguo consejero de Seguridad Nacional de Israel, se pregunta cuál es el problema entre los Estados Unidos e Israel respecto a Irán, indicando que la diferencia entre estos dos Estados hay que abordarla desde una doble perspectiva. Si para Israel Irán representa una amenaza muy cercana, tanto física como geográfica, ya que atañe ni más ni menos a la destrucción de Israel. Es decir, si para Israel "it is the threat to its existence"12, para los Estados Unidos "it is another threat. Not critical”. La segunda perspectiva puede tener riesgos tan peligrosos, aunque no se vean tan cercanos, pues si la administración Biden levanta las sanciones y se lanza a destruir el legado de Trump, esto implica volver al legado de Barack

\footnotetext{
${ }^{10}$ No hay que olvidar que el programa nuclear iraní ha sido seguido de cerca por Israel. Y es que, como se sabe, el desarrollo nuclear iraní, que se estaba llevando a cabo de forma encubierta fue descubierto y difundido al mundo por los israelíes en 2002, tras el anuncio que hizo a este respecto un grupo iraní opositor. A este respecto, véase Bermejo García, Romualdo y Gutiérrez Espada, Cesáreo. "El programa nuclear iraní en el ojo del huracán”, Revista Española de Derecho Internacional, vol. 57, no 1 (2005), pp. 105-119.

11 "Experts Predict Israel can Expect from Biden Administration", op. cit.

${ }^{12}$ Cuando se habla de una "amenaza para la existencia de Israel" no es lo mismo que una "amenaza a los intereses vitales de Israel”, como señaló el anterior Jefe de Estado Mayor de Israel, Gadi Eizenkot, en el diario Yediot Ahronot del 31 de diciembre de 2020, señalando que "The challenges are difficult but do not constitute an existential threat" para Israel. Y sitúa esta diferencia reconociendo que desde la Guerra de la independencia de 1948 hasta la Guerra de Yom Kippur, "esa amenaza a la existencia de Israel jugó un papel muy importante a la hora de evaluar la situación de la seguridad para Israel”, pero esto cambió en 1973 con la Guerra de Yom Kippur, ya que en esta guerra el presidente Anwar Sadat adoptó un cambio estratégico profundo, ya que “... He planned the war for a limited purpose only: not to threaten Israel's existence but to deal a harsh blow to its status and security concept". Desde esta perspectiva, Eizenkot no considera el conflicto con los palestinos como una amenaza existencial, sin embargo, si se considera a Irán. No obstante, Eizenkot propugna con los palestinos firmes acuerdos en materia de seguridad con el fin de garantizar la seguridad de las poblaciones judías en la zona, ya que como queda bien probado con la experiencia de Gaza, la seguridad y/o los acuerdos de desmilitarización no tienen sentido sin una substancial presencia militar israelí sobre el terreno. Para unos comentarios sobre esta visión, véase Hscohen Gershon: Not an Existential Threat - A Vital national Interest, The Begin-Sadat Centre for Strategic Studies, Besa Center Perspectives Paper nº 1898, 22 January 2021.
} 
Obama, lo que significaría un gran retroceso. Por eso, este antiguo consejero de Seguridad Nacional israelí señala que el pensamiento de Joe Biden en relación con Irán se rige más por emociones que por lógica, debido a que es consciente de que su Administración no hará nada para borrar del mapa las políticas mantenidas por Trump. Y abundando en su análisis, señala con claridad que apartarse de las políticas de Trump "this would be a big mistake not to use this leverage created by Trump only because it was created by Trump". Desde esta perspectiva, la administración Biden podría crear una gran oportunidad para convencer a Irán de aceptar la propuesta, aunque para ello es necesario hacerlo con prudencia y sabiduría, pues Amidror parte de la premisa de que "los iraníes son mejores negociadores que los americanos". Así las cosas, este consejero israelí es de la opinión que hay que mantener las sanciones y continuar presionando a Irán.

Estas ideas y advertencias relacionadas sobre todo con el arma nuclear nos parecen no solo sensatas, sino las más adecuadas para tratar el asunto iraní, que no comprende ya solo el territorio de Irán, sino que su influencia se extiende a Irak, Siria, Líbano y el Yemen, en una especie de arco que une el Mediterráneo al Golfo Pérsico. En estas circunstancias, el programa nuclear iraní se revela de una importancia trascendental para toda la zona, tesis que es generalmente aceptada, y más ahora que en julio de 2015, que fue cuando se adoptó el discutido y discutible acuerdo nuclear.

En estas circunstancias habrá que ver si la presidencia de Biden es capaz de cumplir con las expectativas que muchos demócratas esperan, sobre todo en relación con el Medio Oriente. No hay que olvidar que pocas horas después de iniciarse en el cargo, empezó a adoptar órdenes ejecutivas a una velocidad vertiginosa, sobre todo en el ámbito interno, con el fin de demoler las huellas de Trump. En el ámbito exterior, estableció un nuevo ¿marco? de relaciones con Rusia en una simple llamada de teléfono que mantuvo con el presidente Putin, y al mismo tiempo su administración empezó a establecer los nuevos marcadores con China, y otras zonas calientes en las relaciones comerciales como es América Latina, pero retuvo el status quo en todo aquello relacionado con el Medio Oriente. Este hecho tiene un gran alcance para la región, pues significa que el traslado de la embajada estadounidense a Jerusalén ${ }^{13}$, el reconocimiento de la soberanía israelí sobre los Altos del Golán y los Acuerdos de Abraham que representan unos nuevos vínculos con los países del Golfo, Sudán e incluso con Marruecos (aunque en este último caso habrá todavía que ver cómo se va desarrollando) ${ }^{14}$ se respetarán tal y como los dejó Trump ${ }^{15}$. Es más, incluso el acercamiento del que ha hecho gala en algunos momentos en

\footnotetext{
${ }^{13}$ Conviene apuntar que la República Checa acaba de abrir una Oficina diplomática en Jerusalén el 11 de marzo de 2021, hecho que ha sido considerado por la Liga Árabe y por la Autoridad Palestina como una violación flagrante del derecho internacional. El Ministerio de Asuntos Exteriores de la Autoridad Palestina lo ha considerado además como "une attaque éhontée du peuple palestinien et de ses droits, une violation flagrant du droit international”, añadiendo que esta Oficina perjudica a las perspectivas de paz. La respuesta de la República Checa no se ha hecho esperar, indicando su primer ministro, Andrej Rabis, que esta Oficina se encargará de cuestiones políticas, económicas y actividades consulares, entre otras tareas. La República Checa sigue así el camino de Hungría.Véase Berman, Lazav: "L' ouverture d'un bureau diplomatique tchèque à Jérusalem dénoncée par l'AP”, The Timesw of Israël, March 14, 2021. Ver también, "El Primer Ministro checo inaugura una oficina diplomática en Jerusalén", Aurora, 11 de marzo de 2021.

${ }^{14}$ Sobre esta cuestión, véase Dekkiche, Vanis: "Rétablissement des relations diplomatiques sur fond de reconnaissance de la souveraineté mavocaine sur le Shara Occidental", Chronique des faits internationaux, Revue générale de droit international public, $\mathrm{n}^{\circ} 1$ (2021), pp. 89-93.

${ }^{15} \mathrm{Si}$ este proceso de reconocimientos continua adelante, que es lo que parece, salvo que la guerra iniciada con Hamás en mayo tras las violentas manifestaciones en Jerusalén, hay otros cuatro países a los que se ha referido Netanyahu el 16 de marzo de 2021, diciendo que "I brought peace for peace and there are four move peace agreements on the way", sin mencionarlos. No obstante, en este mismo sentido se ha pronunciado Jared Kahner, antiguo consejero de Donald Trump, señalando en el diario The Wall Street Journal, del 14 de marzo de 2021 que varios países estaban en la cúspide de una adhesión a los Acuerdos de Abraham, entre los que se encuentran Mauritania, Omán y Catar. Respecto a Arabia Saudí, señaló que las relaciones entre Arabia Saudí e Israel son de
} 
relación con los palestinos parece que puede ser más simbólico que real, y habrá que ver si el nuevo presidente muestra realmente un gran interés por poner sobre la mesa un nuevo marco de negociaciones, o lo dice solo para apaciguar los espíritus palestinos que ven en Biden el único "Salvador" para poder salir del atolladero en el que se encuentran ${ }^{16}$. Es evidente, sin embargo, que muchos altos funcionarios de su administración, no se lo van a poner fácil.

Esto parece indicar que, en relación con esta zona, la administración Biden tan solo quiere tratar de forma primordial todo lo relacionado con el acuerdo nuclear tras la retirada de Trump, pero no de forma apresurada. Y es que, a pesar de la insistencia iraní en que se levanten las sanciones impuestas por Trump para que el petróleo iraní pueda volver a los mercados, el nuevo secretario del Departamento de Estado, Antony Blinken, no parece tener prisa en ello, al señalar lo siguiente: "We are a long ways from that point. Iran is out of compliance on a number of fronts, and it will talk some time, should it make a decision to do so, to come back into compliance, and time for us to assess whether it's meeting its obligations... so we're not there yet to say the least" ${ }^{\prime 17}$. Y es que, con elecciones en Irán, en junio de 2021, con candidatos que adoptaron una línea dura con posibilidades de ganarlas, una cierta prudencia se imponía no sea que se vuelvan a cometer los errores que Barack Obama cometió en 2015. Es más, el tema de los misiles balísticos y el apoyo a grupos terroristas por parte de Irán complican la nueva situación, sobre todo cuando Irán no quiere abordarlos como parte de las negociaciones del acuerdo. Esto no ha impedido, además, a Antony Blinken de reconocer que el periodo que necesita Irán para conseguir al arma nuclear se está reduciendo considerablemente, aludiendo a las declaraciones del propio régimen iraní según las cuales comenzaba a enriquecer uranio al $20 \%$, por lo tanto, mucho más allá del 3'5\% que permitía el acuerdo de 2015 , y a un paso técnico del $90 \%$ necesario para construir el arma nuclear ${ }^{18}$.

\subsection{Biden y el acuerdo nuclear: muchas cuestiones y pocas respuestas de Biden}

El acuerdo nuclear del 14 de julio de 2015 fue considerado en su día por un amplio espectro de analistas internacionales como un paso crucial para contener, e incluso detener, que Irán pudiera un día conseguir el arma nuclear. Sin embargo, era evidente que el acuerdo, que se negoció al final de forma apresurada, adolecía de defectos estructurales importantes, como se ha comprobado posteriormente, algo que ya pusimos de manifiesto en su día ${ }^{19}$. Y es que el acuerdo nuclear de julio de 2015 aplazaba el desarrollo del arma nuclear por un corto período de tiempo, por un lado, mientras que, por otro, el sistema de control era muy débil, por no decir muy malo, al tener una gran complejidad en la que cohabitaban una serie de aristas y elementos distorsionadores que hacían de la supervisión real algo impracticable. Este fue el regalo que hizo el presidente Obama a pesar de las muchas advertencias que hicieron muchos expertos en la materia. Así las cosas, no es extraño que pronto se descubriría en la práctica lo sinuoso del camino establecido debido a las lagunas que el acuerdo tenía, sobre todo en todo aquello relacionado con la supervisión del proceso nuclear, a pesar de que Israel, a quien Barack Obama

interés nacional y parecen ser una realidad si la Administración Biden aprovecha a esta extraordinaria oportunidad. A este respecto, véase. Wrobel, Sharon: "Netanyahu Says Israel Has Four More Peace Agreements in Region On the Way", The Algemeiner, 16 March 2021.

${ }^{16}$ Para más detalles, cfr. Schnar, Dan. “Biden’s Status Quo Middle East Policy”, Jewish Journal, 1 February 2021.

${ }^{17}$ Ibid..

${ }^{18}$ Blinken: Si l'Iran continue d'enfreindre l'accord, elle pourrait avoir la bombe", The Times of Israël, 1 février, 2021.

${ }^{19}$ Sobre el acuerdo nuclear del 25 de julio de 2015, véase Bermejo García, Romualdo y Gutiérrez Espada, Cesáreo: "Del programa nuclear iraní de la República Islámica de Irán y de su evolución (política y Derecho)", Anuario Español de Derecho Internacional, vol. 31, 2015, pp. 7-63. Ver también, Cone de los Rios, Augusto: Las implicaciones de la llegada de Biden para Irán, IEEE, Documento de Opinión 23/2021, 25 de febrero de 2021,21 p. 
apartó de las negociaciones, dispusiera de las capacidades, tanto a nivel de la inteligencia y de los servicios de información, como tecnológicos.

Todo esto demuestra que Obama no quería seguir la estela israelí, porque sus intereses eran muy difusos. Ya no era solo una cuestión personal entre él y Netanyahu. Un ejemplo que pone en evidencia lo que acabamos de señalar es que en 2010, durante la Conferencia de revisión del Tratado de no proliferación nuclear, en la que se debatía la agenda a seguir por parte de los Estados Unidos para la Conferencia de revisión que tendría lugar en 2012 sobre una zona libre de armas nucleares para Oriente Medio, se hace una llamada a Israel para que se integre en el tratado, del que no es parte y, sin embargo, mutismo absoluto en relación con el programa nuclear iraní ${ }^{20}$. Esto demuestra la ambivalencia de la administración Obama con el programa nuclear iraní, sobre todo cuando ya en ese momento los republicanos, con mayoría en el Congreso, se oponían a esas negociaciones, siguiendo así las sendas marcadas por Netanyahu. Unos años más tarde, en 2013, Obama volvió a defender a Irán cuando el Congreso empezó a examinar unas nuevas sanciones económicas a Irán si este país no cumplía con el acuerdo interino al que se había llegado en ese momento. A esta propuesta de sanciones, Obama respondió amenazando con su veto ${ }^{21}$. Dicho de otra forma, Obama no quiso conocer la verdad ni el alcance real del tema nuclear iraní al apartar a Israel del marco de negociaciones, a pesar de las advertencias hechas ${ }^{22}$.

Con esta experiencia que se tiene hoy en día sobre la mesa, la administración Biden debería adoptar por mera prudencia una serie de medidas en el marco de las negociaciones con Irán que podrían ser las siguientes: a) mantener las sanciones, pues esto puede ayudar a negociar, y eventualmente levantarlas después en el momento más oportuno; b) las negociaciones pueden ser difíciles, a la luz de la experiencia vivida hasta el momento, por lo que deben estar muy bien preparadas y con criterios claros en torno al tiempo, así como a los medios necesarios a los que se pueda recurrir; c) Israel es el país que dispone de mayor información acerca de Irán, y por lo tanto sabe muy bien prevenir y descubrir tanto el engaño como la mentira a la hora de negociar el acuerdo; d) Irán, es hoy en día, y al margen del tema nuclear, el país que dispone de más medios de destrucción en todo el Medio Oriente, como lo demuestran sus intervenciones en Yemen, Irak, Siria y el Líbano, sin olvidar Gaza, a las que Israel se está enfrentando tanto en el

\footnotetext{
20 "United States Pursues Non-proliferation Agenda at NPT Review Conference, Agrees to 2012 Conference on Nuclear-Free Middle East", (Contemporary Practice of the United States), American Journal of International Law, vol. 104, n' 3 (2010), pp. 520-524.

21 "Iran Nuclear Agreement is Implemented Notwithstanding Expressions of Distrust by Iran and the U.S. Congress" (Contemporary Practice of the United States Relating to International Law), American Journal of International Law, vol. 108, $\mathrm{n}^{\circ} 1$ (2014), pp. 343-347.

${ }^{22}$ En Israel se piensa que el acuerdo nuclear es el que es, porque Obama así lo quiso, al llevar los Estados Unidos el peso de las negociaciones. Y no faltaron las serias advertencias que un día sí y otro también le hicieron los expertos israelíes. Fue precisamente el tema nuclear iraní el principal escollo en las relaciones israeloestadounidenses en esos años, como lo pone de relieve el contundente discurso de Netanyahu ante el Congreso de los Estados Unidos el 3 de marzo de 2015, al ser invitado por el propio Congreso y sin contar con la autorización del propio presidente, lo que fue algo sin parangón en los Estados Unidos. El desplante al presidente por el Congreso fue claro, a pesar de que en ese momento hubiera mayoría republicana. Pero la oposición al acuerdo no venía ya solo de Israel, sino también de Arabia Saudí y de Egipto, es decir casi como ahora. El discurso de Netanyahu fue duro, haciendo ver su predisposición a todo. "Les puedo prometer una cosa: incluso si Israel tiene que estar de pie solo, Israel quedará de pie...”. Y continuó diciendo “... se dice que un mal acuerdo es mejor que un no acuerdo... pues bien, lo que hay aquí es un mal acuerdo... Los días en que el pueblo judío permaneció pasivo ante el Holocausto han pasado. Por primera vez en muchas generaciones podemos defendernos por nosotros mismos. Incluso si Israel está solo, plantará cara”, haciendo ver que Israel podría atacar solo Irán si lo considerara oportuno. Para el texto del discurso, publicado en varios idiomas, véase https://www.youtube.comwach?v=mF_TKWG2vak. En español, en https://www.enlacejudio.com/2015/03/discursocompleto-del-primer-ministro-de-israel-benjamin-netanyahuante-el-congreso-de-estados-unidos.
} 
Líbano como en Siria, así como en las zonas fronterizas entre Siria e Irak; y e) es necesario que los Estados Unidos establezcan determinadas líneas rojas creíbles en el Medio Oriente si quiere contrarrestar la influencia iraní y la turca, líneas rojas de las que Obama habló para Siria pero que luego no cumplió.

Desde esta perspectiva, son conocidas las advertencias de Israel a Joe Biden en relación con el acuerdo nuclear iraní, señalando que volver al acuerdo de 2015 constituirá una pesadilla para otros Estados de la zona que buscan también armas nucleares ${ }^{23}$. Pero no solamente eso. El primer ministro Netanyahu no es la primera vez que advierte sobre los peligros que encierra volver sin más al Acuerdo nuclear de 2015. Y es que son conocidas las discrepancias que en esta materia tuvieron Netanyahu y Obama. Al final, Obama ignoró las advertencias de Netanyahu, lo que trajo consigo que Israel se pusiera en pie de guerra no solo para controlar el desarrollo del programa nuclear iraní, sino incluso para lanzar un ataque. Advertido Joe Biden, un alto oficial de Israel no ha ocultado su decisión, indicando que "If Biden adopts Obama's plan, we will have nothing to talk about him" ${ }^{24}$. Esta es la situación a la que Joe Biden deberá enfrentarse si es que quiere seguir los pasos de Obama en este asunto, o no ${ }^{25}$. Si se va por las sendas de Obama sin más, el conflicto está garantizado. Y es que no es solo Israel el país de la región que esté preocupado por esta situación, sino también Arabia Saudí y otros países del Golfo, que han exigido ser consultados. Así pues, casi todo dependerá de Biden, y él lo sabe.

\section{2. ¿Cómo conseguir que Irán no se haga con el arma nuclear?}

Una de las cuestiones que se suscitan en el tema nuclear iraní es que a pesar de los ataques cibernéticos contra las centrales nucleares iraníes, los asesinatos de varios científicos que trabajaban en el desarrollo nuclear del país, incluido recientemente el número uno "Mohsen Fakrizadeh", o las explosiones misteriosas que han ocurrido en las plantas nucleares, nadie, incluidos los Estados Unidos o Israel, haya intentado llevar a cabo un ataque convencional, como ya hizo Israel con la planta de Osirak, en Irak, en 1981, o en Siria en 2007. Una de las razones que justifican esta actitud pasiva puede ser la disuasión que puede generar Irán al tener una gran capacidad de respuesta basada no en sus fuerzas convencionales, sino en su amplia red terrorista que tiene diseminada en amplias zonas del mundo, Europa y América Latina especialmente, sin olvidar todo el Medio Oriente. Y es que bastaría lanzar la orden para que sus "proxies" (Hezbolláh, Hamás, la Jihad Islámica palestina o las milicias chiitas, etc.) comenzaran a $\operatorname{actuar}^{26}$. Estos vínculos ofrecen a Irán suficiente disuasión como para que le ataquen las plantas nucleares otros Estados, salvaguardando a Israel, que es el que vigila de cerca su desarrollo nuclear, como es bien sabido. Sin embargo, no cabe duda que si Israel lanza un ataque contra esas plantas, es muy seguro que tanto Hamás como Hezbolláh desencadenarían un conflicto armado con Israel. También podría ocurrir que si fueran los Estados Unidos los que lanzaran el ataque, tanto Israel como los países aliados del Golfo Pérsico se verían arrastrados a participar también en el conflicto. Pero ¿se podría pensar lo contrario? No tanto, aunque Irak no movió un dedo cuando se destruyó la planta de Osirak.

\footnotetext{
23 Benzion, Yakir. "Netanyahu warns that U.S. reentering the Iran Nuclear Deal would lead to 'nightmare' of other states seeking nuclear weapons", United with Israel.org, 15 January 2021.

24 Marcus, Laurent. "If Biden adopts Obama's plan, there's nothing to talk about: Israel Gears up for Clash on Iran", World Israel News, January 2021, en https://worldisraelnews.com/if-biden--adopts-obamas-plan-theresnothing-to-talk-about-israel-gears-up-for-clash-on-iran/?utm_source=centent=israel+Rea... .

${ }^{25}$ Y es que, en septiembre de 2020, Biden ya señaló: "Five years ago, Iran was a bad regional actor requiring active deterrence and pushback. But it had not conducted a major attack on U.S. forces in the region in yeas... I will offer Tehran a credible path back to diplomacy. If Iran returns to strict compliance with the nuclear deal, the United States would re-join the agreement as a starting point for follow-on negotiations". Ibid.

${ }^{26}$ Esta es la opinión de Ludvik, Jan: "Closing the window of vulnerability: Nuclear Proliferation and Conventional Retaliation", Security Studies, vol. 28, no 1 (2018), pp. 87-115.
} 
Tampoco hay que olvidar que Irán contempla crear una infraestructura civil fuerte en Siria como plataforma para crear después una futura infraestructura militar que sirva para poder abrir un frente directo con el fin de atacar a Israel. El encargado de crear estas infraestructuras es "Abu Al-Fodl Al Tabataba", consejero personal de Alí Jameimi, quien fue el que visitó ya el área en 2018. Esas infraestructuras se crearían en el sur de Siria, cuya importancia estratégica es bien conocida no solo por Irán, sino también por Israel, de ahí que este último haya llevado a cabo ya varios ataques sobre la zona, como ha sido el caso últimamente el 23 de diciembre de 2020. La estrategia iraní en esta zona es trasladar el modelo libanés del sur del Líbano al sur de Siria, aunque exista entre ambas zonas una diferencia importante, ya que si en el sur libanés la mayoría de la población es chiita, al sur de Siria esa mayoría es sunita, tanto en la zona de Kuneitra como en la de Dara, sin olvidar la zona de Sweida, de mayoría drusa, que es en donde la estrategia iraní encuentra más oposición, ambas rayando con Jordania, pero cercanas también al Norte de Israel, pudiendo así abrir dos frentes: el libanés y el sirio. Es más, hay intentos para adoptar un proceso que permita convertir a los sunitas locales a la fe chiita, recurriendo a ayudas económicas y dirigiendo los proyectos económicos en la región. A esto precisamente se refiere expresamente el Informe reciente de "Alma Research and Education Center", al señalar lo siguiente: "It is known that a Lebanese Hezbollah operative named 'Abu Ali Al-Harakhi' runs Hezbollah's political office in southern Syria and serves as the executive director of economic projects in the region" 27 .

Desde esta perspectiva, los Estados Unidos tendrían varias opciones si es que decidieran actuar. Una de ellas podría ser ir por una línea dura, reforzando sus capacidades para disuadir a Irán de que pueda llevar a cabo u ordenar acciones terroristas. Otra podría ser prepararse para convivir con un Irán nuclear, aunque esto implicaría neutralizar todo lo relacionado con los misiles balísticos a los que se puede acoplar cabezas nucleares, lo que podría conseguir recurriendo a los ciberataques, aspecto sobre el que ya tienen cierta experiencia, como ocurrió con el Stuxnet en julio del $2010^{28}$. La tercera opción podría ser diplomática y consistiría en intentar atraer a Irán al ámbito occidental ofreciéndole la posibilidad de integrarlo en el sistema económico y comercial internacional ${ }^{29}$, si deja de estar bajo la influencia económica de China que, en la actualidad, es evidente. También se podría quizás conseguir que renunciara a su programa nuclear a cambio de unas ciertas medidas de control e inspección que pudiera dar ciertas garantías de cumplimiento de que abandona el programa nuclear ${ }^{30}$.

La vuelta al acuerdo nuclear por parte de Biden no será en ningún caso una cuestión pacífica ni a nivel interno ni a nivel internacional. A nivel interno va a encontrar una posición

\footnotetext{
${ }^{27}$ A este respecto, ver el Informe Beeri, Tal: The Civilian Establishment of the Iranian-Led Shiite Axis in Southern Syria, Alma Research and Education Center, Alma's Blog, Special Reports, 17 December 2020, en https://israelalma-org/2020/12/17/the-civilian-establishment-of-the-iranian-led-shiit-axis-in-southern-syria/. Sobre este Informe, ver también Lappin, Yaakov: "New report Exposes how Iran is Entrenching itself into southern Syria", en https://www.jns.org/new-eport-exposes-how-iran-is-entranching-itself-into-southern-syria.

${ }^{28}$ Sobre estos ataques cibernéticos, véase Bermejo García, Romualdo y López-Jacoiste Díaz, Eugenia. La ciberseguridad a la luz del Jus ad Bellum y del Jus in Bello, Eunsa, 2020, 224 p.

${ }^{29}$ Irán no es todavía miembro de la Organización Mundial del Comercio. El Grupo de Trabajo sobre la Adhesión de este país se estableció el 26 de mayo de 2005, y, a día de hoy, todavía no se ha reunido. Para el estado actual de las adhesiones a la OMC, cfr. Boletín de Noticias sobre adhesiones de la OMC, $\mathrm{n}^{\circ}$ 97, diciembre de 2019. Sin embargo, Irán sí que es Miembro del Fondo Monetario Internacional y del Banco Mundial y está pagando su cuota y una parte de sus reservas, aunque lleva desde 1979, es decir desde la Revolución Islámica fuera de estas instituciones. Si a esto añadimos las sanciones adoptadas contra Irán por el presidente Trump de los Estados Unidos, sanciones que, aunque no afecten a la ayuda humanitaria, causan a Irán unos daños evidentes, como lo demuestra el hecho de que le resulta muy difícil recurrir a los mercados de capitales e incluso al propio FMI. A este respecto, véase "El presidente de Irán urge al FMI a prestar 5.000 millones de dólares a su país", El País, 8 de abril de 2020.

${ }^{30}$ Para más detalles sobre esta cuestión, véase Albert, Wolf. "Why Hasn’t Anyone Attacked Iran's Nuclear Sites?" The Begin-Sadad Center for Strategic Studes, Besa Center Pespectives Paper no 1878, 11 January 2021.
} 
muy dura en el partido republicano, como ha puesto ya de manifiesto el Senador de Texas, Ted Cruz, señalando que "The Biden-Harris Administration will set as their top foreign policy objective restoring that failed agreement. The single most important national security victory of the last four years was pulling out of that disastrous deal". Y uniendo esta cuestión a la seguridad nacional, al régimen iraní y a las amenazas que esto supone para Israel, añade. "I fear we are headed into a dangerous chapter with the Biden-Harris Administration, working actively to undermine the national security gains made in the last four years, and to reinvigorate the ayatollahs in Iran, which poses an existential threat to Israel"31. Así las cosas, no es extraño que el primer ministro Netanyahu lo considerara de "error histórico", haciendo de este tema su prioridad número 1, al ver la necesidad de impedir a Irán obtener armas nucleares.

En el contexto actual en el que se plantea esta cuestión, hay que reconocer que la vuelta al acuerdo nuclear y modificarlo no va a ser fácil, conociendo a los negociadores iraníes que suelen ser contundentes. En esta tesitura, el ministro de Asuntos Exteriores iraní, Mohammad Javad Zarif, ha recalculado que lo primero que tiene que hacer Joe Biden es levantar las sanciones contra Irán, y luego volver al acuerdo nuclear de 2015 tal y como se adoptó. Esto acarreará nuevas posibilidades para la paz y la estabilidad para la región que nunca tuvo la zona. Esto choca con algunas declaraciones hechas por la Administración Biden según las cuales se señala que es Irán la que tiene que cumplir primero con el acuerdo, lo que implica que esto ya requiere primero, una especie de negociación de partida para unos y otros. El nuevo secretario de Estado Antony Blinken ya ha indicado en el Senado que “... The president elect believes that if Iran comes back into compliance, we would too...”, y además que los Estados Unidos buscan a "longer and stronger agreement". Esto confirma la posición que ya adoptó Joe Biden en septiembre de 2020, quien literalmente declaró: "If Iran returns to strict compliance with the nuclear deal, the United States would rejoin the agreement as a starting point for followon negotiations" 32 . Pero también es claro el ministro de Asuntos Exteriores iraní, quien a estas pretensiones estadounidenses recalca que el presidente Biden puede elegir un camino mejor poniendo fin a las presiones de Trump y volver al acuerdo que este abandonó, y si lo hace, Irán volverá a cumplir con el acuerdo. Pero si Washington insiste en aprovecharse para conseguir ciertas concesiones, la oportunidad de un entendimiento se perderá ${ }^{33}$.

El regreso de los Estados Unidos al acuerdo nuclear de 2015 suscita, además, no solo cuestiones, sino que da también respuestas. En este sentido, y como se supone que cuenta con toda la información de Yossi Cohen, director del Mossad, el general Amos Gilad, ex - director de la Policía y de Asuntos Políticos del Ministerio de Defensa de Israel, ha advertido que volver al acuerdo sería poner en manos de Irán docenas de bombas atómicas en 10 años. Y es que Yossi Cohen ya ha informado a las personas claves de la administración Biden, debido a la cantidad de inteligencia que posee no solo sobre el programa nuclear iraní, sino también sobre los misiles balísticos cada vez de mayor alcance. Así pues, no es extraño que, al ser un asunto de suma importancia para Israel, les haya puesto al día durante su visita en la primera semana de enero del 2021 de todo aquello relacionado no solo con el programa nuclear propiamente dicho, sino de las respuestas que pueda adoptar Israel llegado el caso, respuestas que no excluyen un eventual ataque a Irán, algo de lo que viene advirtiendo desde 2012, estando en plena Presidencia de Obama, y que fue uno de los grandes artífices del acuerdo ${ }^{34}$.

\footnotetext{
31 “Ted Cruz warns Biden's Iran Policy Could Threaten Israel's very existence”, World Israel News, 20 January 2021.

${ }^{32}$ Sobre todos estos aspectos, cfr. Plank, Josh: "Iran warns Biden: Return to Old Nuclear Deal if you want a seat at the Table", World Israel News, 25 January 2021.

${ }^{33}$ Ibid.

${ }^{34}$ Egozi, Arie, "Mossad Head Briefs Biden Admin On Iranian Nukes, Missiles", Breaking Défense, 13 January 2021, en https://breakingdefense.com/2021/01/mossad-head-briefs-biden-admin-on-iranian-nukes-missiles/. Se
} 
Ante la situación reinante en la actualidad, Israel advierte de que está preparado para lanzar el primer ataque contra Irán y es que, como se ha apuntado, parece que Joe Biden desea iniciar una nueva etapa en la que, para apaciguar China, dé a Irán lo que este le pida. La posibilidad de un ataque hoy en día no plantearía los problemas logísticos de tiempos atrás, debido a la alianza con los dos países del Golfo, Emiratos Árabes Unidos y Baréin, sobre todo gracias a la base conjunta de la que dispone Israel cerca de los Emiratos. Esto permitiría con mucha más facilidad lanzar el ataque preventivo sin necesidad de reabastecer los aviones en vuelo ni pedir autorización a los Estados Unidos para poder sobrevolar Irak ${ }^{35}$.

Todo esto es bien sabido hoy en día, pero lo que se trata es de convencer a Biden de las consecuencias que puede tener volver al acuerdo original, ya que contra esta hipótesis no se opone solo Israel, sino también los Emiratos Árabes Unidos, Baréin, Egipto y, por supuesto, Arabia Saudí, a pesar de que no forme parte por ahora de los acuerdos de Abraham ${ }^{36}$. Desde este prisma, no es de extrañar que el Embajador emiratí en Washington señalara que "I think one of the things we should seriously consider doing is look at a bigger and better JCPOH 2.0, one that addresses the short coming of JCPOA 1.0 , 37 .

El asunto nuclear iraní ha sido objeto también de alguna que otra declaración de los líderes de los países europeos que, como Alemania, Francia o el Reino Unido negociaron el acuerdo de 2015. A este respecto, una de las más claras ha sido la que ha hecho el ministro de Asuntos Exteriores francés, Jean-Yves Le Drian, quien ha indicado abiertamente que " $L$ 'Iran - je le dis clairement - est en train de se doter de la capacité nucléaire... il y a également une élection présidentielle en Iran à la mi juin. Il est donc urgent de dire aux iraniens que cela suffit et de prendre les disposicions pour que l'Iran et les Etats-Unis reviennent dans l'accord de Vienne". El ministro francés recuerda al mismo tiempo que la admistración Trump, al retirarse del acuerdo en 2018, "ha elegido la estrategia de la presión máxima contra Irán, lo que ha reforzado la amenaza. Es preciso, pues, detener esta mecánica, aunque esto no bastará, lo que acarreará difíciles debates sobre la proliferación balística y las desestabilizaciones por parte de Irán de sus vecinos en la región. Estoy obligado a mantener el secreto sobre el calendario a seguir sobre este asunto, pero hay urgencia"38. Jean-Yves Le Drian señala además que Irán ha informado el 13 de enero de 2021 al OIEA que va a avanzar en la producción de uranio metálico para aprovisionar de carburante a un reactor, aspecto este muy sensible, pues esta clase de uranio puede utilizarse como componente para las armas nucleares, algo prohibido por el acuerdo nuclear de 2015, que prevé una prohibición de 15 años a la producción o adquisición de metales de plutonio, de uranio o de sus aleaciones. Esta cuestión del uranio metálico ha sido tratada además por Alemania, Francia y el Reino Unido conjuntamente, los cuales han adoptado un comunicado en el que se pone de relieve que se sienten sumamente preocupados por ese

espera de Yossi Cohen que sirva como principal enlace de Netanyahu con la nueva Administración Biden, al conocerse personalmente, así como a muchos de su Administración, mientras desempeñaba la dirección del Consejo de Seguridad Nacional de Israel. Ver también, Lasserre, Isabelle: "Iran: la fuite en avant vers la bombe", Le Figaro, 12 février 2021.

${ }^{35}$ Para más detalles, Mark, David. "IDF Prepares First Strike Options Against Iran”, Israel Unwired, 15 January 2021, en https://www.israelunwired.com/idf-prepares-attack-iran/

${ }^{36}$ Goldberg, Richard y Dubowitz, Mark. "Why Biden's Plan to Rejoin the Iran Deal Makes No Sense", Foreign Policy, January 8, 2021.

37 Jerenberg, Batya. "Biden source: Israel Will be Consulted Before U.S. Reenters Nuclear Deal with Iran", World Israel News, January 17, 2021.

${ }^{38}$ Clemenceau, François. "Jean-Yves Le Drian: L'insurrection aux Etats-Unis nous enseigne qu'il faut rester vigilants", Journal du Dimanche, 16-17, janvier 2021. En esta entrevista se pasa revista también a los problemas suscitados con Irán y el acuerdo nuclear. Ver también Le Figaro, del 17 de enero de 2021, el artículo "Nucléaire: <il est urgent de dire à l'Iran que cela suffit>, explique Jean-Yves Le Drian". En https://www.lefigaro.fr./international/nucleaire-il-est-urgent-de-dire-a-l-iran-que-cela-suffit-explique-jean-yvesle-drian-20210117 
hecho ${ }^{39}$. Irán por su parte no parece amedrentarse demasiado, señalando su gran líder Ali Jameini, el 8 de enero de 2021, que no tiene prisa por ver a los Estados Unidos volver al acuerdo nuclear, sino que lo que tiene que hacer es levantar las sanciones que asfixian su economía. El Imán iraní, considera que el levantamiento de las sanciones "es una exigencia racional y lógica, pues es un derecho que se ha confiscado a la nación iranín" 40 .

\subsection{El debate sobre el acuerdo nuclear y las amenazas contundentes de Israel contra Irán}

Algunos analistas no comparten las tesis de aquellos que defienden y afirman que hoy Irán está más cerca de producir el arma atómica que en 2015, cuando se concluyó el acuerdo, y que solo la renovación del acuerdo "can prevent the nightmare of a nuclear Iran". En realidad, esto es una forma de reconocer que la conclusión del acuerdo fue un craso error, como algunos ya apuntamos en su momento. Sin embargo, en septiembre de 2020, Biden ya reconoció la falta de eficacia del acuerdo de 2015, al señalar que "Five years ago American-led diplomacy produced a deal that ensured it would take at least a year to produce enough fissile material for one bomb... Now-because Trump let Iran off the hook from its obligation under the nuclear deal - Tehran's 'breakout time' is down to just a few months". Y el peligro de un Irán nuclear lo remata advirtiendo que si Irán obtiene el arma nuclear, otros países de la zona, como Arabia Saudí, Turquía y Egipto seguirán ${ }^{41}$.

Toda esta confusión generada por el acuerdo nuclear, la retirada de Trump, y la vuelta de Joe Biden se puede resumir de una manera muy simple: si el acuerdo es tan bueno ¿Por qué tanto los israelíes como los árabes, que son los que están más cerca ante el peligro nuclear iraní, no piden también la vuelta de los Estados Unidos al acuerdo? ¿Por qué no tienen miedo ni pánico de que desaparezca? La respuesta es clara: "The JCPOA didn't diminish he Iranian nuclear threat; it magnified it" ${ }^{\prime 2}$. Y es que no hay que olvidar que el acuerdo de 2015 permitió a Irán conservar su fuerte infraestructura nuclear, innecesaria para un programa nuclear civil, pero un elemento esencial para un programa nuclear miliar. Sin embargo, no se cerró ninguna planta nuclear ni ninguna centrifugadora. La facilidad y la velocidad con la que Irán ha enriquecido el uranio últimamente, está ahí para demostrarlo, por lo que los fervientes seguidores del acuerdo deberían reconocer que sus presunciones fundamentales en cuento al alcance del acuerdo y su aplicación, no solo no se han cumplido por una u otra razón determinada, sino pura y simplemente porque han sido abiertamente rechazados ${ }^{43}$.

A este respecto, Aviv Kochavi, jefe del Estado Mayor del ejército israelí advirtió el 26 de enero en una conferencia en el "Institute for National Security Studies" que Irán ha desarrollado avanzadas centrifugadoras que les permitirían construir una ojiva nuclear en meses, e incluso, en semanas. Es más, también afirma que la vuelta al acuerdo nuclear de los Estados Unidos, no impedirá que Irán obtenga eventualmente armas nucleares. Y que incluso un acuerdo enmendado sería un error operativo y estratégico para todo el mundo, instando a

\footnotetext{
${ }^{39}$ Este Comunicado data del 16 de enero de 2021. Para más detalles, “Le Drian: L’Iran <est en train de se doter de la capacité nucléaire>", The Times of Israel, 17 janvier, 2021.

40 "Les États-Unis devraient compenser leur retrait du JCPOA", 14 janvier 2021, en https://french.Khamenei.ir/news/12565. Sobre el levantamiento de las sanciones, Bozorgmehr, Najmeh y Williams, Aime. "Biden will not lift Sanctions to Bring Teheran back to Talks", The Financial Times, February 7 , 2021; y Vahid, Farid: "Iran: les possible conséquences de la fin de l'embargo sur les armes", Revue Défense Nationale, vol. 2, no 837 (2021), pp. 109-114.

${ }^{41}$ A este respecto, para un análisis de lo que representa hoy el acuerdo nuclear, véase Oren, Michael y Halevi, Yossi Klein. "The Case Against the Iran Deal. Reviving the JCPOA will ensure either the emergences of a nuclear Iran or a desperate war to stop it", The Atlantic, 21 January 2021, en https://www.theatlantic.com/ideas/archive/2021/01/case-against-iran-deal/617755/

42 Ibid.

43 “Any New Nuclear Deal with Iran will Be Strategic Mistake, Says IDF Chief of Staff Kochavi”, The Algemeiner, 27 January 2021.
} 
hacer más presión sobre Irán, utilizando los argumentos siguientes: "Iran is under significant economic pressure, their trade has fallen dramatically. These pressures must continue in all directions". Pero también señala que Israel se está preparando para contrarrestar Irán adoptando medidas en varios frentes como Siria, Líbano, Gaza, Hamás, etc. Pero en relación con las plantas nucleares no guarda silencio, al indicar que ha ordenado la preparación de planes de ataque a las plantas nucleares iraníes con el fin de prevenir que pueda hacerse con el arma nuclear. Y en plan amenazante ha añadido: "Iran can decide that it wants to advance to a bomb, either covertly or in a provocative way. In light of this basic analysis, I have ordered the IDF to prepare a number of operational plans, in addition to the existing ones. We are studing these plans, and we will develop them over the next year... The government will, of course, be the one to decide if they should be used. But these plans need to be on the table, in existence and trained for" $" 44$.

Estas tesis plasmadas en el discurso que el jefe del Estado Mayor israelí pronunció el 26 de enero de 2021, iban dirigidas no solo a la administración Biden, al régimen iraní, y al público israelí, sino que también estaban en el objetivo los líderes de Hamás y de Hezbolláh, sin olvidar la opinión pública internacional, la cual no siempre comprende bien las realidades existentes en el Medio Oriente ${ }^{45}$. Sin embargo, estos diversos destinatarios pueden, llegado el caso, deducir varias interpretaciones de ciertas alusiones que ha hecho Aviv Kochavi, a pesar de que el discurso tuvo un tono muy realista y altamente profesional, al plantear los retos y riesgos que tiene Israel hoy en día en múltiples frentes, aunque el más preocupante sea en la actualidad el iraní, y quizás también el posicionamiento adoptado por la administración Biden de negociar con Teherán el tema del acuerdo nuclear. Pero no se centra solo en esto, sino que también deja claro que las organizaciones terroristas de Hamás y de Hezbolláh operan militarmente hablando dentro de la población civil, lo que no impedirá que las fuerzas del Tsahal les dé un golpe decisivo, siguiendo así la conocida doctrina "Dahiya", barrio del Sur de Beirut, de mayoría chiita, cuya población civil fue tomada como una especie de "escudo humano colectivo" por parte de Hezbolláh durante el conflicto que mantuvo con Israel en 2006, y que fue objeto de ataques aéreos por parte de Israel ${ }^{46}$.

Unos días más tarde el actual ministro de Defensa de Israel, Benny Gantz ${ }^{47}$ confirmaría inequívocamente las declaraciones de Aviv Kochavi, señalando que Israel seguía teniendo

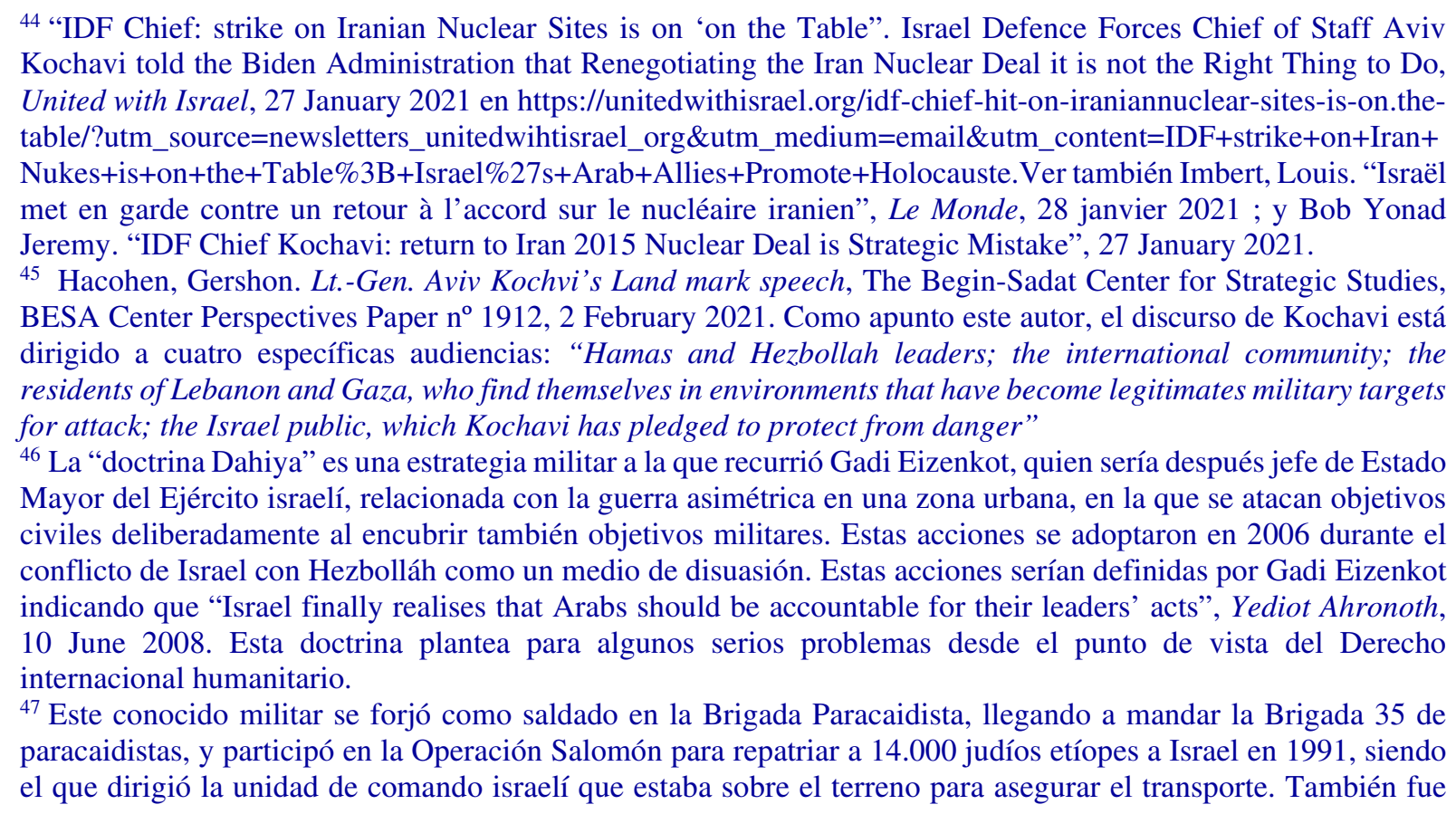


abierta la posibilidad de adoptar, si era necesario, cualquier medida contra el proyecto nuclear iraní. Y precisando su posición, dejó claro que "Israël a un objectif clair: que l'Iran ne soit pas une puissance nucléaire. Ce n'est pas seulement un intérêt israelien. C'est avant tout un interêt mondial et régional... Tsahal et la Défense israélienne gardent la possibilité de prendre des mesures contre le projet nucléaire iranien si c'est ce qui doit être fait... J'espèrere quion n'arrivera pas là" 48 .

El anuncio y la clara advertencia de que estos planes se podrían llevar a cabo si el Gobierno así lo decidiera ${ }^{49}$, constituye la amenaza más clara lanzada por Israel desde los años 2012/2013, durante los cuales el asunto nuclear iraní generó serias discordancias entre Obama y Netanyahu, al marginar el primero al segundo en todo aquello relacionado con el tema nuclear de Irán, de ahí que Obama ni le consultara siquiera. Es más Obama negoció incluso con Irán en secreto sin comunicar nada a Netanyahu. De ahí que Netanyahu reaccionara marginando a Obama viniendo a su propia casa para dar el discurso del 3 de marzo de 2015, ya mencionado, en el Congreso, sin que Obama lo autorizara. No parece que ahora con Joe Biden se esté en una situación similar a la de Obama por las dos razones siguientes: a) Joe Biden y otros líderes de su Administración insisten en que quieren reforzar el acuerdo alcanzado por Obama; b) Joe Biden se ha comprometido a consultar a Israel, a los países del Golfo que se oponen a los planes nucleaes de Irán (Arabía Saudí, Emiratos Árabes Unidos y Baréin), y a Egipto, países que ya se opusieron también al acuerdo de 2015. A esto hay que añadir que por el momento y hasta 2022, Joe Biden controla el Congreso y el Senado, lo que no ocurría con Obama, ya que el Congreso estaba dominado por los republicanos que apoyaban a Netanyahu. Todo esto traerá consigo, según fuentes israelíes, que Netanyahu evitará por ahora una confrontación directa con Joe Biden, aunque en realidad esté en contra de la modificación del acuerdo. Y es que Netanyahu "... thinks the agreement is flawed to its foundations and the Iranians will agree to compromise only if pressure continues" ${ }^{50}$. Dicho esto de Netanyahu, que compartimos, tendrá que adoptar ciertas precauciones ante la Casa Blanca, pues Joe Biden no parece que esté a gusto con las políticas de Arabia Saudí y de los Emiratos, como lo demuestra el hecho según el cual acaba de decidir la congelación con estos países de los acuerdos sobre armamento ${ }^{51}$. Y es que por mucho que justifique esta decisión diciendo que es normal para una nueva Administración

comandante de la Unidas Especial "Shaldag" en la fuerza aérea israelí. Es decir, una trayectoria militar impecable que le llevaría además a dirigir las Operaciones "Pilar Defensivo" en 2012 y "Margen Protector” 2014 sobre Gaza. ${ }^{48}$ Esta declaración se hizo durante una entrevista de la televisión egipcia difundida el domingo 31 de enero de 2021. Staff of the Times of Israël y Gross Judah Ari "Gantz: Israël mènera une action militaire contre 1'Iran nucléaire si necessaire”, The Times of Israël, 1 February 2021. En otra entrevista en la cadena Arabic Alghad TV, con sede en Londres, añadió lo siguiente: "Un Iran nucléaire conduirait à une course à l'armement nucléaire dans tout le Moyen-Orient. Le regime est fondamentaliste et radical et veut en fin de compte obtenir la capacité nucléaire non seulement pour l'avoir, mais sur tout pour le levier qu'elle lui donnerait en matière de dissuasion nucléaire". Estas declaraciones no le impidieron recalcar que él no tenía nada en contra del pueblo iraní, pero que el apoyo del régimen al terrorismo, Hezbolláh, a los hutíes, etc. exige acciones.

${ }^{49}$ Los planes de Kochavi ya se están materializando en el ámbito presupuestario, tal y como se esperaba. En efecto, el 2 de febrero de 2021, el Gabinete de seguridad israelí, en el que estuvieron presentes el primer ministro Netanyahu, el comandante en jefe Kochavi, los ministros de Defensa y de Finanzas, así como altos cargos financieros y militares, tomaron parte en un encuentro con el fin de analizar el presupuesto para, llegado el caso, lanzar un ataque sobre Irán si es que se revelara necesario. Y es que Kochavi es de la opinión de que, si el acuerdo nuclear sigue tal y como se elaboró en 2015, Irán tendrá la bomba atómica, si antes, claro está, no se hace nada. "Government, IDF Working on Budget for Potential Iran Strike Plan-Report", The Jerusalem Post, 2 February 2021, en https://www.jpost.com/Israel-news-government-idf-working-on-budget-for-potential-iran-strike-planreport-657505?

${ }^{50}$ Kerstein, Benjamin. "Netanyahu will seek to Avoid a Confrontation with Biden on Iran Nuclear Issue-Report", The Algemeiner, 27 January 2021. Es más, algunos pretenden incluso que el deseo de Joe Biden es precipitar el ataque israelí contra Irán. "Bidens Desire to Reach out to Iran, Sparks Israel's Potential Attack on Iran”, Breaking Israel, 27 January 2021.

51 “A Shock for the Saudis: Joe Biden Puts Saudi Arabia on Notice", The Economist, 5 February 2021. 
controlar esta clase de acuerdos, todo apunta a que hay otros intereses ocultos que no quiere desvelar. Y es que la rapidez con la que ha adoptado esta decisión no ha dejado de sorprender a propios y extraños.

\subsection{El debate sobre las sanciones y sus efectos ¿Habrá Break Down Nuclear?}

Otro aspecto importante en relación con este acuerdo es el de las sanciones. En efecto, la vuelta al acuerdo nuclear vuelve a plantear el tema de las sanciones a Irán que Trump decidió al retirarse del acuerdo. Y es que no conviene olvidar que cuando Obama negoció y presionó para llegar al acuerdo, su vicepresidente era Joe Biden. Pero esto, que ya es historia, tiene su influencia todavía en la actualidad, pues hay que reconocer que dicho acuerdo ha tenido sobre todo nefastas consecuencias para Irán ${ }^{52}$ y para todo el Medio Oriente. Dicho de otra forma, sin acuerdo, no hubiera habido sanciones, algo que Joe Biden parece no querer reconocer, y eso que era vicepresidente. Para Joe Biden, Donald Trump tiene que asumir su responsabilidad por sus errores, él y Barack Obama no.

Dejando al margen la cuestión de la eficacia/ineficacia de las sanciones, todo el mundo está de acuerdo en los efectos que pueden tener en la población, que puede ser en algunos casos la más afectada, de ahí que se haya pasado al concepto de "sanciones inteligentes" para paliar no solo el significado del concepto, sino también los efectos ${ }^{53}$. En torno a los efectos, parece evidente que las sanciones adoptadas por Donald Trump han tenido esos efectos nefastos para todo Irán, para el gobierno y para la población, lo que es evidente y se refleja en los indicadores económicos iraníes como son una alta inflación, depreciación constante de su moneda, etc., todo esto en unos momentos difíciles para Irán a causa también de la pandemia ${ }^{54}$, como ya hemos apuntado.

Sin embargo, lo que no se entiende muy bien es que Joe Biden quiera volver al acuerdo sin reconocer previamente que no ha funcionado, y eso que diversos informes ponen de relieve que

\footnotetext{
${ }^{52}$ A este respecto, es claro el análisis de Mousavian Seyed, Hossein al señalar en su artículo "Sanctions Make Iran's Coronavirus Crises more Deathly", Aljazeera, 8 May 2020, lo siguiente: "The Iranian leadirship indeed made some mistakes in its handling of this public health emergency, such as initially under estimating the threat posed by the virus and failing to close the country's borders in time. It is however impossible to claim that the Iranian government is solely responsible for the devastation the pandemic has caused in the country. Ever since Trump unilaterally withdrew the U.S. from de Joint Comprehensive Plan of Action... the Islamic Republic has been under strict economic sanctions that limit its ability to trade with other nations. These sanctions, which choked of Iran's oil exports, cripped its economy and practically pushed it out of the international banking system, made it impossible for the country to swiftly take the necessary medical, economic and social measures to protect its citizens from the coronavirus". El autor reconoce después, sin embargo, que el objetivo de las sanciones es presionar a Irán para que vaya a la mesa de negociación en una situación más débil o incluso desesperada. Lo que el autor no señala es que las sanciones no parecen haber impedido su apoyo a Hamás ni a Hezbolláh ni tampoco a continuar intentando establecerse en Siria, a pesar del centenar de ataques que Israel ha llevado a cabo en 2020 para impedir desarrollar sus infraestructuras, pero también en 2019.

${ }^{53}$ Para más detalles sobre esta cuestión, cfr. Bermejo García, Romualdo: “Algunos comentarios sobre las sanciones del Consejo de Seguridad de las Naciones Unidas y la protección de Derechos Humanos: luces y sombras”, Revista Electrónica Iberoamericana, vol. 7, n 2 (2013), pp. 16-40. Y sobre las sanciones del ex - presidente Trump a Irán, Razaian, Jason. “Opinión: Don’t Sanction Iran - Trade with it”, The Washington Post, November 1, 2018. Este autor critica las sanciones porque piensa que se castiga al pueblo y plasma por escrito lo que ya aseveró el ministro de Asuntos Exteriores iraní, Mohammad Javad Zarif a la "CBS News": "The U.S. has an adiction to and they believe that the sanctions are the panacea that resolve all the problems. They don't. They in fact hurt people; With Iran under pressure, Foreign Minister Tells CBS News U.S. Sanctions 'Hurt', but won't work', 29 October 2018, en https://www.cbsnews.com/news/iran-foreign-minister-mohammed-javad-zarif-cbs-news-donald-trumpsanctions-hurt/.

${ }^{54}$ Para un análisis de estas cuestiones económicas y comerciales de Irán desde el establecimiento de la República Islámica, Tavakol, Mohsen. "Iran's Economiy and the Burden of Multiple Exchang Rates", Atlantic Council, 12 May 2020, en https://www.atlanticcouncil.org/blogs/iransource/irans-economy-and-the-burden-of-multipleexhange-rates/
} 
Irán ha almacenado diez veces más de uranio enriquecido desde que Barack Obama y Joe Biden dejaron la Casa Blanca, lo que implica que el acuerdo tenía y tiene lagunas importantes. No se puede, por lo tanto, atribuir toda la responsabilidad de lo que ocurre actualmente a Trump, y no a los que elaboraron el acuerdo. Por lo tanto, no nos parece correcto afirmar, como hizo Joe Biden en la CNN el 13 de septiembre de 2020, indicando lo siguiente: "Five years ago, American led diplomacy produced a deal that ensured it would take Iran at least a year to produce enough fissile material for one bomb. Now - because Trump let Iran of the hook from its obligations under the nuclear deal-Tehran's 'breakout time' is down to just a few months... The bottom line is that Iran is closer to a nuclear bomb today than it was when Donald Trump took office. And Trump has no answer for that. Five years ago, even Russia and China stood with our European allies behind an American - led approach to Iran's nuclear program" 55 .

Claro, pero si la responsabilidad fuera de Donald Trump, y no del acuerdo, no diría después que "The United States would rejoin the agreement as a starting point for follow-on negotiations. With our allies, we will work to strengthen and extend the nuclear deal's provisions, while also addressing other issues of concern" ${ }^{56}$. No tardo mucho tiempo en responderle el ministro de Asuntos Exteriores iraní, Muhammand Javad Zarif, afirmando que la República Islámica está preparada para ello, pero que para que sea posible, el presidente Biden tiene que tomar en consideración los efectos negativos el acuerdo sobre el pueblo iraní y la estabilidad del Medio Oriente ${ }^{57}$.

Algunos analistas han sostenido también que las sanciones no han impedido que Irán haya incrementado los elementos necesarios para construir la bomba nuclear. Este es el caso de Colum Lynch quien sostiene que "Two years after Trump withdrew from the Iran nuclear deal, Tehran has cut in half the time it would need to produce enough weapons-grade fuel for a nuclear bomb" ${ }^{58}$. Y recurre para reafirmar su tesis, indicando que Richad Nephew, que participó en las negociaciones del acuerdo, ha dicho también que "Iran is manifestly closer to being able to produce a nuclear weapon tan they were two years ago"59.

Similares afirmaciones son también compartidas por Eric Brewer, quien defiende las tesis de Joe Biden de volver al acuerdo, y critica a aquellos que defienden que no es buena idea volver, dada la evolución que se ha experimentado en los últimos cuatro años o, lo que es lo mismo, desde su entrada en vigor, señalando lo siguiente: “... Returning to the deal is not only viable but also presents the best chance of preventing an Iranian bomb. It is the best path toward building on the agreement and addressing some of the short falls that critics deride. Moreover, with a bit of planning, the Biden team could address several key concerns about the U.S. return" ${ }^{\prime 60}$.

Estas afirmaciones demuestran dos cosas: a) que esto no es nuevo, pues Israel lo viene señalando casi desde que se adoptó el acuerdo en 2015, y no solo tras la retirada de Trump en 2018; b) habría además que ver si esta afirmación es válida tras el asesinato de Mohsen Fakhrizadeh el 27 de noviembre de 2020, el científico más importante del programa nuclear

55 "Joe Biden: There's a Smarter Way to Be Tough on Iran", $C N N, 13$ September 2020, en https://edition.cnn.com/2020/09/13/opinions/smatter-way-to-be-tough-on-iran-joe-biden/index.html.

${ }^{56}$ Ibid.

57 Hay que resaltar que la respuesta se da exactamente el 22 de enero de 2021, es decir, un día después de ser investido Joe Biden. A este respecto, Zarif Mohammed Javad. “Iran Wants the Nuclear Deal it Made. Don’t Ask Tehran to Meet New Demands", Foreign Affairs, 22 January 2021.

${ }^{58}$ Lynch, Colum. "Despite U.S. Sanctions, Iran Expands its Nuclear Stockpile”, Foreign Affairs, 8 May 2020, en https://foreignpolicy.com/2020/05/08/ran0advances-nuclear-program-withdra-wal-jcpoa/

${ }^{59}$ Ibid.

${ }^{60}$ Brever, Eric. "A clean return to the Iran nuclear deal should be Biden's first option", 75 years and counting, Bulletin of the Atomic Scientist, 11 January 2021, en https://thebulletin.org/2021/01/a-clean-return-to-the-irannuclear-deal-should-be-bidens-first-option/ 
iraní $^{61}$. Pero esto indica sobre todo las debilidades inherentes al propio acuerdo, en el que Obama puso todo su empeño ${ }^{62}$, lo mismo que hizo en gran medida con su discurso de El Cairo del 4 de julio de 2009, que dio alas a lo que después se denominarían las "Primaveras Árabes", que todos sabemos los efectos que han tenido hasta ahora.

Por otro lado, cuando se critican las sanciones porque perjudican el comercio internacional, que es el sector que genera riqueza y por lo tanto beneficia al pueblo, esto no ha sido el caso en Irán, ya que entre 1990 y 2017, el poder de compra iraní ajustado al producto nacional bruto se dobló, pero el pueblo iraní seguía teniendo una pobreza bastante extendida en ese período, y no hubo ningún signo de democratización en el país, ni tampoco un cierto aperturismo. Esto ha producido una gran fuga de talentos que dejan el país buscando mejores oportunidades. Aunque esto no es algo exclusivo de Irán, otros muchos países también lo han padecido, y otros lo siguen padeciendo, existen otros problemas como la corrupción o la falta de transparencia que han impedido cualquier reforma económica o política. Esto ha traído consigo que millones de iraníes dependan del Gobierno para encontrar un empleo ${ }^{63}$. Desde esta perspectiva también se señala la falta de confianza en el Gobierno tanto a nivel interno (se pone como ejemplo la mala gestión del Covid-19, aunque esto no ha sido exclusivo de Irán, sino también de otros países, como por ejemplo España) como internacional, y sobre todo en relación con el programa nuclear iraní desde que fue descubierto por un grupo opositor en $2002^{64}$. Desde entonces numerosos acuerdos que se firmaron fueron violados, y esto ha continuado con el acuerdo de 2015.

Ane esta situación, es Joe Biden el que tendría que demostrar lo que le mueve realmente a reintegrarse en el acuerdo, si es un Irán pacífico o belicoso. Lo que está claro es que hasta ahora las buenas relaciones que Irán espera tener con Joe Biden, no impide a Irán seguir amenazando a Israel ${ }^{65}$. Y es que el hecho de levantarse las sanciones no implicaría un gran beneficio para el pueblo iraní, como ya hemos señalado, pues durante cuarenta años la población iraní ha estado ausente de las preocupaciones gubernamentales. Además, no es la primera vez que se imponen sanciones, pues ya las tuvo entre junio 2012 y enero de 2016, precisamente siendo el actual presidente de los Estados Unidos, vicepresidente de Barak Hussein Obama. Es decir, desde que la Revolución Islámica llego al poder en 1979, Irán ha sido objeto de sanciones reales unos seis años. Es ahora, el presidente Biden el que debe decidir si quiere luchar por una sociedad más justa y libre en Irán o si quiere apoyar al régimen de Teherán. Y es que no todos los Ayatollahs que hay en Irán son del régimen, ni piensan igual. A este respecto, queremos destacar que el Ayatollah Masoumi-Tehrani ha insistido sobre el hecho de que los iraníes y los judíos tienen tras de sí muchos años de amistad, y tras hacer esta afirmación señala claramente lo siguiente: “... I have not met any Iranians who had a negative

\footnotetext{
${ }^{61}$ Ya sabemos también que al menos cuatro científicos relacionados con el programa nuclear iraní fueron también asesinados entre 2010-2012, y otro fue gravemente herido. Tampoco conviene olvidar los efectos del ciberataque denominado "Stuxnet" en 2010, cuyos efectos fueron bastante destructivos. Sobre el ciberataque "Stuxnet", véase Bermejo García, Romualdo y López-Jacoiste Díaz, Eugenia: La ciberseguridad a la luz del jus ad bellum y del jus in bello, op. cit., pp.58, 61,81 y 176.

${ }^{62}$ No conviene ignorar que la Administración Trump intentó además establecer un embargo de armas a Irán, proponiendo esta idea a los países europeos firmantes del acuerdo (Alemania, Francia y Gran Bretaña) que no mostraron mucho interés, arguyendo que en el Consejo de Seguridad se opondrían tanto China como Rusia. A esta iniciativa, Irán hizo saber que, si esto se llegara a adoptar, además de las sanciones, se retiraría muy probablemente del acuerdo de 2015, pero también del Tratado de no proliferación nuclear. Lynch, Colum: "Despite U.S. Sanctions...", op. cit.

${ }^{63}$ A este respecto, Khosnood, Arvin. The Dangers of Lifting Sanctions on the Islamic Region of Iran, The BeginSadat Center for Strategic Studies, BESA Center Perspectives Paper nº 1907, January 28, 2021.

${ }^{64}$ A este respecto, véase Bermejo García, Romualdo y Gutiérrez Espada, Cesáreo: "El programa nuclear iraní en el ojo del huracán”, Revista Española de Derecho Internacional, op. cit., pp. 106 y ss.

${ }^{65}$ Iran will demolish Tel Aviv and Haifa if Israel attacks, Threaten Tehran”, World Israel News, 31 January 2021.
} 
opinion of Israel. We don't have a problem - not with Israel and not with any other country in the world". Al mismo tiempo no tiene ningún problema en criticar al régimen actual iraní, que lo describe como un "dictatorship that stifles dissenting opinions and freedom of expression" (su oposición al líder Supremo Ali Khameini le valió cinco años de prisión). Y Masoumi Tehrani termina su declaración señalando que “... if I stay alive, with God's help, I would like to see the day when the illogical hostility between Iran and Israel will end...", con el fin de cumplir mi sueño de viajar a Jerusalén para rezar "at the western wall" 66.

Lo que es evidente, es que Irán no solo no ha dejado de violar el acuerdo nuclear tras la llegada de Joe Biden a la Casa Blanca, sino que el ritmo de esas violaciones se ha acelerado, poniendo a Joe Biden en una situación no solo incómoda, sino bajo una presión constante ${ }^{67}$. En buena parte, esto se debe a una actitud crítica de Joe Biden hacia Donald Trump por haberse retirado del acuerdo durante toda su campaña electoral, como si el acuerdo hubiera sido respetado por Irán, lo que ahora está obligado a reconocer que no era cierto ${ }^{68}$. Esto trae consigo que ahora, ya en el poder, se encuentre ante una presión constante de Irán. Y es que el tiempo apremia, ya que el acuerdo prevé que Irán podía enriquecer el uranio solo en la planta subterránea de Natanz, recurriendo a las centrifugadoras de primera generación, que son las IR1. Pero ya en 2020, Irán ha empezado a enriquecer uranio en cascada (clúster), utilizando las centrifugadoras IR-2m, tal y como ha reconocido la Agencia Internacional de la Energía Atómica, indicando que Irán había ya terminado la instalación de una de esas centrifugadoras en cascada, conteniendo 174 IR-2m centrifugadoras el 30 de enero de 2021, siendo alimentadas con UF6, es decir, el Hexafluoruro de uranio, que es el más pesado. La AIEA señala también que Irán ha empezado también a enriquecer uranio con la segunda cascada ${ }^{69}$. Todo esto parece que no basta para Irán, ya que este país ha informado además a la AIEA, el 1 de febrero de 2021, que dos cascadas de IR-6 centrifugadoras serían instaladas también en Fordow, para ser utilizadas con 1044 IR-1 centrifugadoras de la primera generación, es decir, que deben instalarse pero que todavía no están ${ }^{70}$.

Esta actitud desafiante de Irán pone a Joe Biden en una situación delicada, pues se levantan voces indicando una profunda preocupación ${ }^{71}$. Tal es el caso de la propia Unión

\footnotetext{
66 Berkowitz Adam, Elisyu. "Iranian Ayatollah I want Peace with Israel, to Pray with them at Western Wall", Israel365 News, 31 January 2021.

${ }^{67}$ Conviene apuntar que el 5 de noviembre de 2019, Irán ya anunció que reanudaba las actividades de enriquecimiento de uranio, y que restringiría aún más los compromisos asumidos con la comunidad internacional en el acuerdo nuclear de 2015, decisión que fue considerada por los Estados Unidos como una especie de "chantaje nuclear”. Esta declaración destaca por su claridad, pues Irán señala incluso que sus actividades de enriquecimiento de uranio se reiniciarán en la planta de Fordow, en torno a unos $180 \mathrm{~km}$ de Teherán, que permanecía inactiva desde que entrara en vigor el acuerdo nuclear de 2015. Esta declaración la hizo expresamente el presidente Hasan Rohani, el día siguiente de que expirara el plazo que dio el Gobierno iraní a los socios del acuerdo con el fin de que estos le ayudaran a esquivar las consecuencias de la retirada de los Estados Unidos al haber impuesto duras sanciones contra Irán. Los tres Estados europeos que participan en el acuerdo, sobre todo Francia y Reino Unido, instaron a Irán a revocar la decisión, mientras que Rusia dejó claro que estaría muy pendiente de la situación, al mismo tiempo que comprendía la preocupación de Irán por las sanciones. www.swissinfo.ch, 5 de noviembre de 2019. 68 "United States Fails to Secure Multilateral Snapback Sanctions Against Iran" (Contemporary Practice of the United States Relating to International Law Eichonsehr Kristen Ed.), American Journal of International Law, vol. $115, \mathrm{n}^{\circ} 1$ (2021), pp. 140-146.

${ }^{69}$ Sobre esta cuestión, cfr. "Iran Deepens Breach of Nuclear Deal at Underground Enrichment Site", The Algemeiner, 2 February 2021.

70 “ONU : L'Iran enfreint l'accord et installe de nouvelles centrifugeuses à Natanz", The Times of Israel, 3 février 2021.

${ }^{71}$ Esta preocupación es bien real, desencadenándose una serie de pronósticos en torno al tiempo necesario que debería transcurrir para que Irán pueda llegar al "break down” nuclear. Si Antony Blinken, secretario de Estado ha hablado de unos tres meses, siempre y cuando, claro está, que el proceso no se paralice, el actual ministro de Energía israelí, Yuval Steinitz, ha ido más lejos, reconociendo que las medidas de Trump "dañaron seriamente" el proyecto nuclear de Irán, por lo que el "tiempo de ruptura" sería de unos seis meses. Además, añade un elemento
} 
Europea, que ya el 11 de enero de 2021, por lo tanto, antes de la investidura de Joe Biden, apuntó que "Lamentamos profundamente las inquietantes medidas adoptadas por Irán en los dos últimos años y recordamos que la UE ha instado reiteradamente a Irán que ponga fin a todas las acciones que sean incompatibles con los compromisos adquiridos por Irán en el marco del PAIC. El inicio del enriquecimiento de uranio hasta un $20 \%$ por parte de Irán en la planta de enriquecimiento de combustible de Fordow, que fue confirmado por el OIEA el 4 de enero pasado, constituye un hecho muy grave y un motivo de profunda preocupación. La actuación de Irán es asimismo incompatible con las disposiciones inequívocas del PAIC sobre Fordow y puede tener graves consecuencias en materia de proliferación... instamos a Irán a que se abstenga de proseguir la escalada y detenga inmediatamente este proceder"72. Este comunicado fue recibido con agrado por otros países no solo partes en el acuerdo nuclear, sino también por los países árabes y sus agencias de noticias ${ }^{73}$.

Pero si la administración Biden quiere volver al Plan de Acción Conjunto, las reticencias de Irán a negarse a enriquecer uranio el $20 \%$, está suscitando en los Estados Unidos serias dudas de que Irán cumpla con las condiciones previstas en el acuerdo, y hasta que esto no sea una realidad, los Estados Unidos no levantarán las sanciones. Esta actitud del gobierno de Joe Biden se hizo pública un día después de que el ministro de Asuntos Exteriores de Irán, Mohammand Javad Zarif dijera que "[the] time is running out for the Americans" para reincorporarse al acuerdo nuclear y levantar las sanciones a Irán. Es más, preguntado directamente Biden "Will the U.S., lift sanctions first in order to get Iran back to the negotiating table?". La respuesta de Joe Biden ha sido rotundamente "No"74. Y es que la cronología de cómo deben sucederse los acontecimientos no cuadran entre los Estados Unidos e Irán. Para los diplomáticos iraníes, los americanos, que son los que se han salido del acuerdo, deben ser los primeros en abrir la puerta de una sincronización, y son ellos los primeros que deben demostrar "su buena fe". Sin embargo, no parece que esta sea la opinión del secretario de Estado, Antony Blinken, quien piensa que será necesario un cierto tiempo para que Irán vuelva al lugar que se le espera, y después un cierto tiempo para que los Estados Unidos evalúen que han respetado los compromisos ${ }^{75}$. A estas ideas de Blinken, el ministro de Asuntos Exteriores iraní, Mohammad Javad Zarif, ha respondido que la "sincronización" (o el "timing") no es el problema, pues ciertos aspectos pueden volver a respetarse en menos de un día, otros pueden llevar varios días o incluso semanas, pero que no requiere más tiempo que lo que necesitan los

muy importante que es la distinción entre "términos de enriquecimiento" y lograr el "armamento nuclear", diciendo lo siguiente: "En términos de enriquecimiento, si hacen todo lo necesario, pueden alcanzar su objetivo en aproximadamente medio año... En cuanto al armamento nuclear, el alcance es de uno o dos años". Para más detalles, cfr. "Según Israel, Irán está a seis meses de desarrollar armas nucleares”, Ynetespañol, 2 February 2021, en https:/www.ynetespanol.com/global/medio-oriente-mundo/article/B1875ALlu. Estas cifras nos parecen más apropiadas, no solo porque los servicios de información israelíes tengan una mejor información, sino también porque dados los riesgos y las constantes amenazas iraníes, dudamos que Israel espere a un tan corto espacio de tiempo antes de llevar a cabo alguna operación para impedirlo. Véase "Iran Deepens Breach of Nuclear Deal at Underground Enrichment Site", op. cit. Pero al margen de todo esto, también es cierto que Irán sigue negando tener la intención de producir armas nucleares.

${ }^{72}$ Irán: Declaración del Alto Representante, en nombre de la UE, sobre el Plan de Acción Integral Conjunto (PAIC), en respuesta a las últimas actividades de Irán, Comunicado de prensa, 11 de enero de 2021 (www.consilium.europa.eu), consultado el 3 de febrero de 2021.

${ }^{73}$ Tal fue el caso de alarabiya.news. véase https://english.alarabiya.net/News/world/20enrichment-help-nucleardiplomacy-EU, 12 January 2021

74 "Biden: No Easing of sanctions until Iran Complies with Nuclear Deal”, Israel365 News, 8 February 2021.

75 "Nucléaire : Téhéran demande aux Européens de jouer les médiateurs avec Washington", Le Temps, 2 février 2021. 
Estados Unidos "para aplicar los decretos presidenciales necesarios para levantar las sanciones ${ }^{76}$.

Por otro lado, todos sabemos que no va a ser la Unión Europea ni los países europeos Partes en el acuerdo nuclear los que van a impresionar a Irán y hacerle cambiar de posición. Es más, algunos dudan incluso de los Estados Unidos, al menos actualmente, dada la debilidad de sus reacciones. Así las cosas, ante esta situación de provocación por parte de Irán, y ante una cierta pasividad, al menos encubierta, por parte de los Estados Unidos, se han levantado voces en Israel para hacer frente al desafío iraní, y no solo por parte del jefe de Estado Mayor Aviv Kochavi o del ministro de Defensa Benny Gantz, que ya hemos comentado, sino también por parte del ministro para las Implantaciones (Asentamientos), Zahi Hanegbi, que mantiene tesis políticas próximas a Benjamin Netanyahu. En este sentido, no ha dudado en afirmar que como los Estados Unidos no atacarán jamás las instalaciones nucleares iraníes “... Israël doit décider s'il acceptera un Iran nucléaire”. Y prosiguiendo en esta misma línea, afirma que "Israël sera forcé d'agir indépendamment pour écarter a danger" y si se llega a plantear esta cuestión, "j'estere que lorsque nos dirigeants seront confrontés à ce dilemme, ils n'accepteront pas [un Iran doté de l'arme nucléaire]" 77

Esta tensa situación no ha impedido ciertos avances diplomáticos a los que han consentido los Estados Unidos en relación con Irán. Se trata de suavizar ciertas medidas relativas a las restricciones, a las que están sometidos los diplomáticos iraníes ante las Naciones Unidas en Nueva York ${ }^{78}$, medidas que no parecen que den sus frutos, pues el 18 de febrero de 2021 Irán ha previsto restringir a partir del día 21 de febrero, es decir, tres días más tarde, el acceso de los inspectores de la AIEA a las instalaciones no nucleares, incluyendo los lugares militares en los que se sospecha que tienen una actividad nuclear. Ante esta situación, Alemania, los Estados Unidos, Francia y el Reino Unido han advertido a Irán de bien evaluar "las consecuencias de una medida tan grave, precisamente en un momento en el que parece abrirse un nuevo camino de vuelta a la democracia. Y es que lo que se pretende es celebrar una reunión entre Irán más el grupo P $5+1^{79}$, iniciativa que proviene de la Unión Europea, para poder avanzar en todo aquello relacionado con el programa nuclear iraní ${ }^{80}$.

En estas circunstancias, fue cuando se hizo el 18 de febrero, por lo tanto, un día antes de que tuviera lugar en Munich la Conferencia de Seguridad, el anuncio por la administración Biden de que asistiría a tal reunión, entre otras cosas para reencontrarse con sus socios europeos en el acuerdo nuclear, indicando que "la Alianza trasatlántica ha vuelto", una buena respuesta a la invitación hecha por la Unión Europea. La asistencia a la Conferencia de Munich por parte de Biden ha sido objeto de polémica, pues según Reuters, fue notificada a Israel antes de que se hiciera pública, mientras que Mark Dubowitz, portavoz de la "Fundación para la Defensa de las Democracias", pone en duda esa información, al afirmar que "My understanding is that this is not true U.S. did not inform Israel ahead of major Iran policy announcement" $"$.

\footnotetext{
${ }^{76}$ Que Irán ha recibido con cierto regocijo la victoria de Biden, es obvio, aunque supiera que este no le iba a dar lo que Irán quiere, es decir, el levantamiento de las sanciones de forma inmediata, y después negociar el acuerdo nuclear. Vakil, Sanan. "How is a Biden Victory Perceived Across Both Sides of the Gulf?", Chatham House, Five Key Questions on Biden's Middle East Policy, en htps://www.chathamhouse.org/2020/11/five-key-questionsbidens-middleeast-policy

77 Tzahi, Hanegbi : "Washington n'attaquera jamais l'Iran ; Israël pourrait agir seul”, The Times of Israel, 3 février 2021.

${ }^{78}$ Hasta ahora no se les permitía libertad de movimientos en Nueva York, sino que debían establecerse en calles aledañas a la sede de las Naciones Unidas, y con un recorrido preciso para ir y venir del Aeropuerto Kennedy.

${ }^{79}$ El P 5+1 está constituido por los cinco miembros permanentes del Consejo de Seguridad, más Alemania.

80 “Les Etats-Unis multiplient les gestes à l'égard de l'Iran”, Le Temps, 19 février 2021.

81 "Concern in Israel Over Us Announcement Welcoming Nuclear Talks with Iran", The Algemeiner, February 19, 2021.
} 
Un día más tarde, el primer ministro israelí Benjamin Netanyahu vuele a recordar cual es la posición israelí en este aspecto, indicando dos cosas: a) "Israel believes that going back to the old agreement will pave Iran's path to a nuclear arsenal. Israel is in close contact with the United States on this matter; ...b) Israel remains to preventing Iran from getting nuclear weapons and its position on the nuclear agreement has not changed" 82 . Por su parte, el ministro sin cartera israelí, y miembro del Likud, en una entrevista concedida al "The New York Times" ha afirmado que, si se quiere realmente prevenir que Irán tenga acceso a un programa de armas nucleares, el acuerdo debe ser negociado para que sea válido para varias generaciones. Estas declaraciones del gobierno israelí siguen la tendencia de los Gobiernos precedentes, sobre todo del de Benjamin Netanyahu, desde el 2002, año en que el grupo opositor iraní denunció públicamente que Irán está desarrollando de forma secreta un programa nuclear. Dicho de otra forma, Israel, que no es parte en el acuerdo nuclear de 2015, sigue vigilante y dispuesto a impedirlo por cualquier medio, incluido el uso de la fuerza, aspecto que, aunque no sea novedoso, sigue siendo trascendente. $\mathrm{Y}$ es que todo apunta a que la carrera armamentística nuclear iraní prosigue, según algunos expertos, que lo deducen también de los últimos Informes de la AIEA $^{83}$. Es más, como ya se ha señalado supra, el 13 de enero de 2021 Irán informó a la AIEA que estaba investigando la producción de uranio metálico, una actividad prohibida por el JCPOA $^{84}$. Y el 21 de febrero de 2021 Irán anunció que había empezado a enriquecer uranio al $20 \%$.

Esta tensa situación, que parece descontrolarse y llegar a bloquear cualquier decisión razonable, parece haber encontrado un poco de oxígeno tras las negociaciones mantenidas entre la AIEA e Irán. En efecto, el director general de la AIEA, Rafael Mariano Grossi, ha anunciado el 20 de febrero haber encontrado una salida temporal al embrollo iraní que permite a este Organismo las inspecciones nucleares en Irán, aunque estas sean limitadas. No obstante, a pesar de estas limitaciones, tendremos la capacidad necesaria para poder ejercer la vigilancia y la verificación. Es una solución que nos permite salvar la situación problemática en este momento. El plazo fijado por la ley iraní para prohibir la vigilancia de los inspectores nucleares debía empezar el 21 de febrero de 2001, pero el Gobierno iraní lo retrasó hasta el 23 de febrero, salvo sí los Estados Unidos levantaban las sanciones, algo que no se espera. Así las cosas, la solución temporal negociada por la AIEA con Irán, aunque temporal, ¿puede? salvar la situación mientras que las Partes en el JCPOA negocian el tema nuclear ${ }^{85}$. Mientras Joe Biden se prepara para negociar con Irán, habrá que ver como Israel se prepara para la guerra ${ }^{86}$.

\footnotetext{
${ }^{82}$ Ibid. Ver también, "Biden Repudiates Trump on Iran, ready for Talks on Nuke Deal", World Israel News, February 19, 2021. Ver igualmente, Mars, Amanda. "Joe Biden, en su primera cumbre internacional: Estados Unidos ha vuelto", El País, 20 de febrero de 2021.

83 "Report: Iran Hiding Important Components of Its Nuclear Program from UN Inspectors", The Algemeiner, 23 mars 2021. Este encubrimiento de instalaciones nucleares demuestra que “... Iran is trying to conceal vital elements of its nuclear program from the outside world shows that Teheran has no intention of complying with its international obligations under the terms of the nuclear deal”. Es decir, una prueba más de que el régimen sigue teniendo la voluntad de adquirir armas nucleares.

${ }^{84}$ Para más detalles, véase OFEK, Raphael. Signs that Iran Might Be continuing its Nuclear Weapons Program, The Begin-Sadat Center for Strategic Studies, BESA Center Perspectives Paper nº 1937, 19 February 2011.

${ }^{85}$ Para un análisis muy desarrollado de esta situación, cfr. Alonso, Pierre. "Malgré la pression du Parlement iranien, l'Agence de l'énergie atomique pourra poursuivre ses inspections. Un mini-accord pour éviter le pire", $L a$ Liberté, 23 février 2021. Ver también MUR, Robert. "Rafael Grossi, el argentino más atómico", La Vanguardia, 27 de febrero de 2021.

${ }^{86}$ Sobre este acuerdo temporal de vigilancia de las actividades nucleares iraníes, cfr. "L'Iran et l'AIEA annoncent un accord 'temporaire' de surveillance des activités nucléaires", en https://www.france24.com/fr./moyenorient/20210221-nucleaire-I-iran-salue-des-discussions-fructueuses-avec-I-aiea. El director de la AIEA, consciente de que el acuerdo alcanzado puede también suspenderse en cualquier momento, ha sido claro al reconocer los límites del acuerdo, afirmando que : "l'acces sera réduit, ne nous voilons pas la fasse, mais nous serons en mesure de maintenir le degré nécessaire de surveillance et de vérification... Cela sauve la situation dans
} 
Desde este prisma, habrá que ver cómo evolucionan los acontecimientos, pues la actitud del primer ministro israelí, Netanyahu, en relación con el programa nuclear iraní es firme como una roca, enviando mensajes dirigidos tanto a Irán como a la Casa Blanca: "Pledging that Israel will prevent Iran from gaining nuclear weapons even if Iran concludes a deal with the US". Y continuó advirtiendo en tono amenazante directamente a Irán, señalando que “... We will not allow your extremist and aggressive regime to attain nuclear weapons... We have not made the journey of generations, o thousands of years, to return to the Land of Israel, to allow the delusional regime of the ayatollahs to end the story of the revival of the Jewish people". Es más, poniendo el ejemplo de Corea del Norte que concluyó varios acuerdos con los países occidentales, para después violarlos, recalcó: "With or without agreements, we will do everything so that you will not arm yourselves with nuclear weapons" ${ }^{87}$. Además, todo apunta a que se está ampliando las instalaciones nucleares alrededor de Dimona, ciudad conocida por albergar el sistema nuclear israelí, sin que por ahora se sepa fehacientemente con qué objetivo ${ }^{88}$.

\section{Las negociaciones de Viena sobre el programa nuclear iraní}

La complejidad del programa nuclear iraní y los deseos de Joe Biden de volver al acuerdo nuclear de 2015 tras la retirada de la administración Trump, han tenido como resultado la necesidad de convocar unas negociaciones entre las Partes que se han iniciado en Viena el 6 de abril de 2021. El primer escollo al abrir las negociaciones ha sido que podían participar todos los firmantes del acuerdo, excepto los Estados Unidos, que ya no es Parte, y por lo tanto no podía participar en las negociaciones. No obstante, aunque oficialmente ausente, los Estados Unidos no lo están tanto, ya que negocian con Irán de forma indirecta, e inmediatamente lanzan su propuesta de adoptar un programa de seguimiento para poder establecer un acuerdo de mayor duración que permita un mayor control y, al mismo tiempo, una especie de rendición de cuentas que permita informar a los países árabes y a Israel de su evolución, a lo que se ha comprometido la administración Biden ${ }^{89}$. Pero no solo esto, sino que los Estados Unidos están también muy preocupados por el programa de los misiles balísticos iraníes, que afecta a toda la región. El ambiente de las negociaciones ha sido positivo según fuentes estadounidenses e iraníes, aunque el portavoz del Gobierno iraní, Ali Rabiyee, ha puesto algunas condiciones, al señalar lo siguiente: "Today, we are at the beginning of a plan to revive the nuclear deal and the US government has no choice but to end its law-breaking beharior and ilegal sanctions... Iran will not reverse the steps it has taken in reduction of its obligations until the sanctions are completely lifted... No step-by-step plan has been announced by us and Iran has not accepted any such plan" ${ }^{\circ 0}$.

l'immédiat... un résultat raisonnable après des consultations intenses”. Así pues, el número de inspectores sobre el terreno continúa sin cambios, pudiendo además proceder a inspecciones inesperadas. Sobre esta cuestión, ver también “Iran's Zarif Says US Must Fist Lift Sanctions Before Talks to Revive 2015 Deal”, The Algemeiner, February 21, 2021.

${ }^{87}$ Kerstein, Benjamin. "Netanyahu Sends Message to White House, Iran: We Are Not Pinning Our Hopes on Any Agreement with an Extremist Regime", The Algemeiner, 23 February 2021.

88 "What the construction is for, however, remains unclear. The Israeli government did not respond to detailed questions from the AP about the work", World Israel News, 25 February 2021.

${ }^{89}$ En el aspecto nuclear, se está notando una cierta aproximación de los Estados Unidos para entablar negociaciones con Irán, aunque estas sean indirectas, al no poder estar presente a causa de la retirada del Acuerdo por parte de Trump, en las negociaciones directas que el 6 de abril de 2021 se han abierto entre los otros Estados firmantes e Irán en Viena. Evidentemente este paso está siendo examinado con cierta preocupación por Israel, pues se interpreta como que quiere volver al Acuerdo, sin reforzarlo, lo que sería otro paso más en el acercamiento estadounidense a Irán. Para más detalles, Harkov, Lahav: "Israel, in first Comment, Says Troubled by US Position ahead of Iran Talks", The Jerusalem Post, April 5, 2021. Ver también, Harkov, Lahav: "US, Iran Head to Vienna for Indirect Nuclear Deal Talks”, The Jerusalem Post, April 3, 2021.

90 Kerstein, Benjamin. “Ahead of Vienna Talks, US Envoy Says Iran's Missile Programm, Regional Activities Should Be Addressed in 'Follow-On' Deal”, The Algemeiner, 6 April 2021. Ver también “EE. UU e Irán acuerdan 
Las negociaciones sobre el programa nuclear iraní en Viena ya han tenido algún resultado, al haberse creado entre los Estados Unidos e Irán dos grupos de trabajo para que los dos países vuelvan a cumplir con lo que prevé el acuerdo nuclear de 2015: uno se ocupará del levantamiento de las sanciones impuestas por Trump a Irán; y el otro se centrará en cómo conseguir que Irán retroceda en su política de enriquecimiento de uranio. Esta situación ha hecho saltar las alarmas en el Gobierno israelí, cuyo primer ministro en funciones, Benjamin Netanyahu ha señalado lo siguiente: "The nuclear deal with Iran, wich gives it international approval to advance the development of an arsenal of atomic bombs, is once again on the table. But history has taught us that such agreements, with such extremist regimes, aren't worth the paper they're written on ... Even to our best friends, I say: We are not bound in any way to an agreement with Iran that paves the way for nuclear weapons. We are obligated to only one thing: To prevent anyone who seeks to destroy us from carrying out their plot" ${ }^{\prime 1}$. Sin embargo, para el Jefe de las negociaciones nucleares iraní, Abbas Araqchi, la creación de estos dos grupos ha sido considerada como "... a welcome step, it is a constructive step, it is a potentially useful step as we seek to determine what it is that the iranians are prepared to do to return to compliance..."92. Este proceder de paso a paso del jefe de las negociaciones iraní ha sido interpretado como que los Estados Unidos están dispuestos a levantar las sanciones a la luz de lo que ha señalado el portavoz del Departamento de Estado, Ned Price, quien no ha dudado en afirmar que "We are prepared to take the steps necessary to return to compliance with the JCPOA, including by lifting sanctions that are inconsistent with the JCPOA" ${ }^{\text {"93 }}$.

De una nueva generación de centrifugadores se han hecho eco también los negociadores en Viena entre Irán y los otros Estados parte presentes en las negociaciones, al anunciar Irán, el 10 de abril del 2021, por lo tanto en plenas negociaciones, la inauguración de una línea de 164 centrifugadoras IR-S, y otra de 30 IR-5, instaladas en la planta de Natanz, que permiten enriquecer uranio en porcentajes más altos, más rápido y en cantidades más importantes, lo que está prohibido por el acuerdo de 2015. No obstante, el presidente Hasan Rohani, al hacer este anuncio en la "Jornada Nacional de la Tecnología Nuclear" ha insistido en que el programa nuclear iraní es pura y simplemente "pacífico"94. No obstante, esto no parece detenerse ahí, pues en el "Nuclear Day" iraní, del 9 de abril, que ya es el "decimoquinto", Irán ha anunciado las centrifugadoras IR-9, que pueden producir uranio cincuenta veces más que las primeras IR1. El momento elegido para anunciarlo no puede ser más oportuno, ya que las Partes en el acuerdo están negociando en Viena la cuestión de saber cómo los Estados Unidos pueden volver a reintegrarse en el acuerdo ${ }^{95}$. Pero también anuncia otra cosa muy importante, como que acaba de reparar la planta avanzada de centrifugadoras destruida por Israel en una misteriosa

grupos para tratar de rescatar el acuerdo nuclear", en France24.com ,7 de abril de 2021; y “Estados Unidos e Irán dan el primer paso para salvar el acuerdo nuclear", El País, 6 de abril de 2021.

91 Isaac, David. "Netanyahu: We Will not be bound by an Iran Deal that Threatens to Destroy Us", World Israel News, April 7, 2021. Ver también "Netanyahu: Israel Will Defend Itself Against 'Existential Threat' Regardless of Iran Nuclear Deal”, The Algemeiner, 7 April 2021.

${ }^{92}$ Wrobel, Sharon. "Israel Keeping close Eye on Vienna Nuclear Talks Between Iran and World Powers, Experts Say", Ibid.; y Pellicer, Luis y Mars, Amanda. "Estados Unidos e Irán dan el primer paso para salvar el acuerdo nuclear", El País, 6 de abril de 2021.

${ }^{93}$ Schindman, Paul. "Biden Administration Changes Policy, says it is now Prepared to Lift Sanctions before Iran Stops its violations of the Nuclear Deal", World Israel News, 8 April 2021.

94 "Nucléaire: l'Iran se dote de centrifugueuses nouvelle génération, dont l'utilisation lui est pourtant interdite", Le Monde, 10 avril 2021. Ver también "Iran Enriching Uranian with New Advanced Machine Type at Underground Plant: IAEA”. The Algemeiner, 16 March 2021. Se trata de la avanzada centrifugadora 174 IR-4, según hizo saber la propia AIEA el 15 de marzo de 2021.

${ }^{95}$ A este respecto, cfr. "Iran celebrates 'Nuclear Day' by firing up Advance Centrifuge Iran's IR-9 Centrifuge is 50 Times Quicker than the First Iranian Centrifuge, the IR-1”, World Israel News, 10 April 2021. 
explosión en Natanz en julio del $2020^{96}$. Sin embargo, el Gobierno guarda silencio por ahora sobre el accidente ocurrido en la mañana del 11 de abril, es decir, un día más tarde, en la red eléctrica de la Planta, tal y como ha anunciado el portavoz de la AIEA, Behrouz Kamalvandi ${ }^{97}$. ¿Accidente? ¿Sabotaje ? $^{98}$. Todo apunta a que detrás de este incidente está Israel, según han apuntado fuentes anónimas de los servicios de inteligencia israelís. También se señala que los daños causados a la planta nuclear son significativos, afectando no solo a las centrifugadoras IR-9. Irán ha considerado esta acción como "ataque terrorista", anunciando al mismo tiempo que se reserva el derecho a responder ${ }^{99}$. Además, para más datos, se señala que los daños causados se deben a un masivo ciberataque que desconectó completamente los sistemas de la planta nuclear ${ }^{100}$. Pero este asunto también ha estado presente en el jefe de Estado Mayor, Aviv Kochavi, quien de una forma indirecta ha hecho alusión a la implicación de Israel en los recientes ataques contra objetivos iraníes en las últimas semanas, indicando que Teherán "reflexionaba con prudencia" en cómo reaccionar"101.

No es la primera vez que la planta nuclear de Natanz ha sufrido esta clase de ataques o sabotajes, tal y como ha anunciado el jefe del Comité de Energía del Parlamento Iraní, A Fereydaun Abbasi, quien a este respecto señaló lo siguiente: "This is not the first time something similar has happened in Natanz but the method de sabotage is new. This is not the first-time sabotage and the use of explosives have been reported. For the past 15 years, the enemy has been constantly trying to do this". Abbasi ha destacado, sin embargo, que la última misteriosa explosión ha sido la mayor llevada a cabo en la planta nuclear ${ }^{102}$.

Este ataque a la planta nuclear de Natanz no ha complacido a alguno de los altos representantes de los Estados que están llevando a cabo las negociaciones con Irán en Viena. Tal es el caso del ministro de Asuntos Exteriores alemán, Heiko Maas, quien en un tuit recogido en la Associated Press, del 12 de abril de 2021, señaló que "the attack on Iran's underground Natanz nuclear facility was not a positive contribution to ongoing nuclear talks in Vienna". Esta opinión, viniendo de donde viene, es lógico que desatara alguna reacción, pues demuestra que el ministro alemán no es muy consciente de la sensibilidad que tiene el pueblo israelí en una materia que les afecta y que es considerada como "existencial". No hay que olvidar que Irán ha amenazado en muchas ocasiones a Israel, y aunque se pueda dudar de que esto sea

\footnotetext{
${ }^{96}$ Ibid. Para más detalles sobre lo que ocurrió en la planta nuclear de Natanz, cfr. Isaac, David. "Israel behind Natanz Nuclear Mishap? IDF Cheaf of Staff says our actions are not hidden from enemy eyes", World Israel News, 11 April 2021. A este respecto, Aviv Kochavi, el jefe de Estado Mayor del Tsahal dice: "We will continue to act with might and with judgement, with determination and responsibility to ensure the security of state of Israel". Es más, señala que "las fuerzas armadas israelíes en sus acciones a través del Medio Oriente, no se esconden de los ojos de nuestros enemigos. Nos están vigilando, viendo nuestras capacidades y examinando cuidadosamente los próximos pagos". Ibid.

${ }^{97}$ A este respecto, véase. Marcus, Laurent. "Mysterious 'accident' reported at Iranian Nuclear Facility", World Israel News, 11 April, 2021. Sobre este accidente, ver también Berkowitz, Adam Eliahu. "Iran's main nuclear site mysteriously suffers power outrage right after advanced centrifuges go online”, Israel 365 News, 11 April 2021.

${ }^{98}$ Sobre esta cuestión la prensa internacional recoge el accidente con diferentes títulos, sin embargo, otros apuntan a que haya podido ser incluso un "sabotaje", tal y como ha anunciado un diputado iraní, véase "Un 'apagón' sospechoso en una instalación nuclear de Irán”, en: https://www.swissinfo.ch/spa/afp/un--apagón--sospechoso-enuna-instalación-nuclear-de-irán/46522156.

${ }^{99}$ Isaac, David. "No Accident: Israel Behind Iran Nuclear Incident, Intel Sources Say", World Israel News, 11 April 2021. Ver también Kerstein, Benjamin. "Iran's top Nuclear Official Calls Major Malfunction at Natanz Facility, Attributed to Israel, an Act of Nuclear Terrorism", The Algemeiner, 11 April 2021.

${ }^{100}$ Ver también Gross, Judah Ari. "Le complexe nucléaire de Natanz touché par un acte de 'terrorisme' dit Teheran", The Times of Israel, 11 avril 2021.

${ }^{101}$ Gross, Judah Ari. "Le chef de Tsahal fait allusion aux attaques présumées d'Israël contre l'Iran", The Times of Israel, 11 avril 2021.

${ }^{102}$ Shindman, Paul. "Iran Admits Top-secret Nuclear Facility was attaqed 5 Times", World Israel News, 2 May 2021.
} 
posible a día de hoy, esto no impide que Israel adopte todas las medidas que estén en sus manos para que esto no ocurra. Pero es que, además, la declaración del ministro alemán parece que no es consciente de que una declaración de este tipo suscite una gran sensibilidad en Israel, pura y simplemente porque es alemán, y en un país como Israel, en donde todavía tienen unos doscientos mil supervivientes de la "Shoah", que tal declaración venga de un "alemán", levanta muchos recelos e incluso angustia. Por lo tanto, en nuestra opinión solo puede ser considerada como "desafortunada", y aunque no haya sido hecha con malas intenciones, no es oportuna ${ }^{103}$.

Desde esta perspectiva, no es extraño que haya tenido rápidamente una respuesta contundente, que es ni más ni menos de Abraham Cooper, Decano Asociado del Centro Simon Wisenthal, que ha criticado al ministro alemán y a las negociaciones que se están celebrando en Viena, señalando que: “Foreign Minister Maas in $100 \%$ correct. The sabotage won't help talks whose main agenda is to get rid of tough sanctions on Iran. This is a regime that has violated the nuclear agreement time and time again threatens genocide against Israel, poses an existential threat to the Gulf States, and blatantly puts in place a spy/terror network across Europe... The sabotage at the nuclear facility was only necessary because European powers have blinked every time Tehran advances its nuclear weapons development... Germany has made it abundantly clear that its deep economic ties with Iran override all other concerns" 104. Pero el margen de esta cuestión en torno a la desafortunada declaración del ministro alemán, hay que reconocer que el ataque en la planta de Natanz tiene que ser interpretado como una especie de seria advertencia al nuevo presidente Biden de lo que es capaz de hacer Israel, y algo más también. Y es que Israel ya lo ha advertido en numerosas ocasiones, y esto puede ser también interpretado como que le puede esperar al nuevo inquilino de la Casa Blanca algo más grave si no toma en consideración los intereses israelíes. Las dudas y tergiversaciones de Biden en su política medio oriental, quizás no sean evaluadas correctamente por la Casa Blanca en cuanto a los efectos que pueden tener, y esto sería un grave error, sobre todo teniendo ya los antecedentes de Obama ${ }^{105}$.

Según fuentes israelíes, la explosión fue causada por una bomba de control remoto que fue clandestinamente introducida en el lugar ${ }^{106}$. Aunque originalmente las fuentes iraníes hablaron de un "accidente", ahora estas mismas fuentes reconocen con un cierto humor que "The enemy's plot was very beautiful”, según ha apuntado Feredy oun Abbassi, un reconocido científico nuclear iraní. Tanto le ha gustado cómo se ha llevado a cabo que ha señalado lo siguiente: "I'm looking at it from a scientific point of view. They thought about this and used their experts and planned the explosion so both the central power and the emergency power cable would be damage" ${ }^{107}$. El Gobierno estadounidense ha guardado un absoluto silencio. No obstante, el portavoz de la Casa Blanca, Jen Psaki, ha dicho que los Estados Unidos no han participado en nada en esta operación, sin especificar si habían sido advertidos previamente o

\footnotetext{
${ }^{103}$ Un ejemplo de la sensibilidad israelí en esta materia, lo vemos en la seria advertencia hecha por Benjamin Netanyahu al secretario de Estado de Defensa estadounidense durante su visita a Israel, advirtiéndole seriamente de que Israel no permitirá a Irán llevar a cabo su objetivo de un genocidio nuclear. "Netanyahu to Austin: Israel Won't Allow Iran to Carry Our Goal of Nuclear Genocide”, Jewish Journal, 13 April 2021.

104 "German Foreign Minister Rebuked After Saying Sabotage of Iranian Nuclear Facility Not a Positive Contributions", The Algemeiner, 12 April 2021.

${ }^{105}$ Para más detalles, véase Jaccottet, Aline. "Au coeur de Natanz, la mise en garde israélienne”, Le Temps, 13 avril 2021.

${ }^{106}$ Algunos medios han atribuido al Mossad israelí la autoría del ataque. Bob Yonah, Jeremy, Lahar, Harkov y Joffre, Tzivi. “Mossad Behind Attack on Iran's Natanz Nuclear Facility”, The Jerusalem Post, 13 April 2021.

${ }^{107}$ A este respecto, cfr. Marcus, Lauren. "Iran Admits Nuclear Sabotage Was 'Beautiful': Remoted-controlled Bomb Caused Explosion”, World Israel News, April 13, 2021. Este texto se encuentra también, en https://www.nytimes.com/2021/04/11/world/middleeast/iran-nuclear-natanz.htm.
} 
no ${ }^{108}$. Este ataque supone, según los expertos, que la planta de Natanz tardará unos nueve meses en restablecer la producción. La explosión ha tenido lugar recurriendo a una bomba activada por control remoto, localizada a 40-50 metros bajo tierra, dañando miles de centrifugadoras ${ }^{109}$.

Pero el relato sobre este ataque puede que no se quede solo en las fechas actuales, pues Ehud Olmert, antiguo primer ministro entre 2006 y 2009, y actualmente en prisión, dice que "probablemente la bomba en cuestión podía haber sido colocada ya hace más de 10 años, esperando el momento adecuado para activarla. Señalando previamente que no tiene directamente ninguna información directa de la Operación, ha criticado no obstante al primer ministro actual, Netanyahu, al hacerle responsable de las filtraciones a los medios israelíes y extranjeros que han atribuido el ataque al Mossad. Hay que recalcar también que, durante su mandato, se llevó a cabo el ataque a la planta (instalación) nuclear en Siria durante la noche del 6 al 7 de septiembre de 2007, que fue supervisado por él, y el ataque cibernético Stuxnet de 2010 imputado a Israel y a los Estados Unidos, fue organizado y puesto a punto también durante su mandato ${ }^{110}$.

Pero Irán no se amilana ante estos ataques, y la escalada nuclear iraní se prosigue, al menos de palabra. Tanto es así que el principal negociador nuclear de Irán, Abbas Aragchi, ha anunciado el 13 de abril que la República Islámica quiere enriquecer uranio al $60 \%$. Si esto se hace realidad, el peligro es bien real, porque el siguiente paso sería enriquecer uranio al $90 \%$, que es el umbral requerido para poder usarlo para armas nucleares. No todos se creen, sin embargo, que esto vaya a ser así, y piensan que puede ser más un brindis al sol que una realidad, sobre todo en la planta de Natanz, seriamente afectada por el ataque. Lo mismo se puede decir del anuncio hecho por Aragchi de introducir en Natanz 1000 centrifugadoras más. Todas estas dudas sobrevuelan los cielos iraníes, sin que se pueda distinguir muy bien la retórica, de la realidad, que ellos conocen, pero que todo apunta a que esa realidad es también conocida por los servicios de inteligencia israelíes. De todas formas, no hay que olvidar que Irán también tiene otras plantas nucleares importantes, como la de Fordow, dejada un poco de lado por los acontecimientos que aquí comentamos ${ }^{111}$.

Pero el reciente ataque a la planta nuclear de Natanz suscita otras muchas cuestiones, ya que algunos autores piensan ${ }^{112}$ que el ataque es una seria advertencia a Irán y a Joe Biden: al primero, porque demuestra que Israel no va a tolerar que progrese en el desarrollo nuclear; al segundo, porque Israel le demuestra que continuará con sus operaciones en Irán poco importa el acuerdo o las clases de acuerdos que firme con Irán. Al margen de esto que apuntan, es evidente que Israel está ejerciendo una fuerte presión sobre todos los negociadores en Viena, y no solo frente a Irán. Y es que se piensa que los negociadores en Viena ya han llegado a un acuerdo para levantar las sanciones a cambio de que los Estados Unidos se reincorpore al acuerdo de 2015, aunque esto también puede suscitar ciertas dudas y esto es en realidad lo que quiere Irán. Y en cuanto a la venganza por el ataque, que ha dicho que lo hará, habrá que ver de qué calibre, aunque se piensa que no irá muy lejos, sobre todo hasta que no se levanten las sanciones y Estados Unidos no se haya reincorporado al acuerdo. Dicho esto, es evidente que

\footnotetext{
${ }^{108}$ Para una descripción del ataque y sus consecuencias, cfr. Bergman, Ronen, Gladstone, Rick y Fassihi, Farnaz. "Blackout Hits Iran Nuclear site in What Appears to Be Israeli Sabotage", The New York Times, 11 April 2021.

${ }^{109}$ Para más detalles sobre el ataque, cfr. Joffre, Tzivi y Bob Yonah, Jeremy. "Natanz Attack it is 50 Meters Underground Destroyed Most of the Facility", The Jerusalem Post, 13 April 2021.

${ }^{110}$ A este respecto, "Olmert : La bombe de Natanz en Iran pourrait avoir été placée il y a 10 ou 15 ans", The Times of Israël, 14 avril 2021.

${ }^{111}$ Sobre esta nueva situación creada, véase "L'Iran annonce qu'il <<va commencer à enrichir l'uranium à 60 \%>>”, The Times of Israël, 13 avril 2021. Conviene recalcar que el acuerdo nuclear de 2015 pone el límite en 3'67 $\%$.

${ }^{112}$ A este respecto, véase el interesante estudio de Khoshnood, Ardavan. The Attack on Natanz and the JCPOA, The Begin-Sadat Center for Strategic Studies, BESA Center Perspectives Paper n 1997,14 April 2021.
} 
el ataque pone de relieve las lagunas que tienen los iraníes en materia de inteligencia y de contrainteligencia.

Esta desconfianza en la administración Biden está presente en algunos analistas que piensan ${ }^{113}$ que el presidente Biden hará lo que estime oportuno con el fin de volver al acuerdo, poco importa si es bueno o no para el resto de países, entre ellos Israel. Esta actitud se refleja en la declaración que ha hecho Neid Price, portavoz de la Casa Blanca, al señalar que "We are prepared to take the steps necessary to return to compliance with the JCPOA, including by lifting sanctions that are inconsistent with the JCPOA. I am not in position here to give you chapter and verse on what those might be "114. Es más, Biden ha ofrecido mil millones de euros si Irán congelaba su producción de uranio enriquecido al $20 \%$, pero los líderes iraníes le han pedido 30.000 millones. Pero es que, además, es conocida su mala situación económica y financiera, que se ha incrementado mucho tras las sanciones.

Pese a todo esto, con las tensiones comentadas a flor de piel, Rusia ha señalado el 16 de abril de 2021, que las negociaciones en torno al acuerdo nuclear se desarrollan de una manera positiva $^{115}$. Sin embargo, no es esto lo que parece que está ocurriendo entre Rusia y los Estados Unidos. Y es que la Organización de una cumbre entre Joe Biden y Vladimir Putin, propuesta por Joe Biden, podría estar en peligro, a pesar de que en la llamada telefónica que ha hecho Joe Biden a Putin, haya expresado su anhelo de normalizar las relaciones ruso-americanas. Sin embargo, las acciones de la administración Biden indican lo contrario, según la portavoz de la diplomacia rusa María Zakharova. Y es que, como ha señalado Dmitri Peskov, el portavoz del Kremlin, las sanciones financieras contra Moscú, y la expulsión de diez diplomáticos rusos, a causa de los presuntos ciberataques y las injerencias en las pasadas elecciones presidenciales de los Estados Unidos de 2020, no favorecen en absoluto la organización de la cumbre. Parece que después de que Biden llamara "asesino" a Putin, hecho que consternó al mundo entero, se está arrepintiendo de ese "exabrupto", estimando ahora que es crucial para las relaciones entre ambas potencias detener la escalada antes de que degenere aún más. Siempre se ha dicho que por "la boca muere el pez", pero lo que no se sabe es si a un "western" le ocurre lo mismo, aunque parece que sí $1^{116}$. La cumbre que ya ha tenido lugar el 16 de junio en Ginebra parece haber apaciguado un poco al "western" americano, consciente de su exabrupto.

En este marco de tensiones ha salido a colación el tema ucraniano, sobre todo el Donbás. A este respecto, y en relación con las maniobras del ejército ruso en territorio ruso, la portavoz María Zajárova, ha advertido que no hay que interpretar el entrenamiento del ejército ruso como una forma de "agresión". Por segunda semana consecutiva, ha dicho, nuestros diplomáticos instan a no distorsionar la realidad, y a no interpretar el entrenamiento militar ruso, que se lleva a cabo en territorio ruso, como una clara manifestación de intenciones agresivas ${ }^{117}$. Las agencias de noticias se hacen eco de esta situación que tiene su origen más cercano en la palabra

\footnotetext{
113 Rafizadeh, Majid. “On Iran, Biden Administration Ready to Undo Former Administration's Work, whether it is Good for the World or Not?”, Gatestone Institute, 14 April 2021.

114 Ibid.

115 "Iran Accord sur le nucléaire: des négociations <<positives〉>”, Centre-Presse, en https://www.centrepresse.fr/article-787417-iran-accord-sur-le-nucleaire-des-negociations-positives.html. Ver también "Nucléaire iranien : Des négociations 'positives' après des tensions en série”, The Times of Israël, 15 avril 2021.

116 Sobre estas sanciones y las malas relaciones con Rusia, cfr. "Moscou promet des contre-sanctions visant EtatsUnis et convoque l'ambassadeur", L'Orient-le Jour, 15 avril 2021. Ver también Sánchez Vallejo, Mª Antonia. "Biden impone duras sanciones a Moscú por los ciberataques y la injerencia en las relaciones", El País, 15 de abril de 2021. Para más detalles sobre la crisis ruso-americana, véase. "Samuel Greene: Pour Joe Biden, la Russie ne détient aucune solution aux problèmes du monde", Le Temps, 15 avril 2021; y Sahuquillo, María R.:"Moscú amenaza con una respuesta contundente al castigo de Estados Unidos", El País, 16 de abril de 2021.

117 "Rusia/EEUU. Rusia convoca al embajador de EEUU tras el anuncio de sanciones y promete una respuesta contundente", Agencia DPA,15 de abril de 2021, en https://www.clarin.com/agencias/dpa-rusia-ecunrusia.convoca-embajador-eeuu-anuncio-sanciones-promete-respuesta-contundente-_O_evbFKHLqf.html.
} 
"killer" lanzada por Biden contra Putin, exabrupto cuyas consecuencias ha intentado subsanar en la medida de lo posible, pero que ahora agrava la situación al adoptar nuevas sanciones contra Rusia, quizás también por el desaire que ha padecido al no tener su propuesta de celebración de una cumbre entre los dos países, una buena acogida en el Gobierno ruso. Por eso, lo de invadir Ucrania por el ejército ruso, es un brindis al sol. "La intención del Kremlin no es invadir Ucrania, sino poner a prueba a la administración Biden, tomar la temperatura a Washington y recordarle que mantiene la superioridad militar en fuerzas convencionales en su frontera con Ucrania, lo que, por ahora, facilita el control de Donetsk y Lugansk e impide el acercamiento de Ucrania a la OTAN y a la UE"118.

Sobre el tema nuclear iraní y las tensiones con Israel, mucho se ha especulado sobre la cuestión de saber si Israel tenía la capacidad militar suficiente como para destruir el programa nuclear iraní o no, tomando en consideración las peculiaridades geográficas de Irán, con una superficie de $1.648 .145 \mathrm{~km}^{2}$, y su potencialidad y su fuerte población, que supera los 83 millones de habitantes en la actualidad. Sin embargo, no parece que esto presente muchas dificultades para que Israel pueda cumplir con sus promesas, como ya lo ha demostrado en Irak en 1981 y en Siria en septiembre de 2007. Esta es al menos la opinión de algunos expertos militares quienes afirman que nada impedirá esa posibilidad si es que se decidiera así ${ }^{119}$. Y es que para el general Tal Kalman, que ha participado en debates sobre este tema con altos funcionarios de la administración Biden, lo primero que habría que hacer es alinearse con los Estados Unidos para establecer el marco requerido de Inteligencia como primer paso ${ }^{120}$.

Este general, jefe del Directorio de las fuerzas armadas israelíes que estudia los desafíos que presenta Irán a Israel, y antiguo piloto de combate, señala que una operación de esta índole es compleja y delicada, pero que Israel dispone de capacidad más que suficiente para llevarla a cabo. Es más, el general Kalman, tras dar esta afirmación lanza una seria advertencia al decir que "... to avoid dealing with these problems could pose a strategic threat for Israel”, y para hacer frente al reto iraní es necesario tomar en consideración cuatro elementos: “... The first is the extreme regime, that as long as it rules Iran, Israel will have a major challenge. The second is the nuclear issue. The third is the military strengthening which is close to that of a regional

\footnotetext{
118“Pretende Rusia invadir Ucrania?”, Fundación FAES, 7 de abril de 2021, en https://fundacionfaes.org/es/contenido/47405/a-pretende-rusia-invadirucrania?et=t0\&mc_eid=2e37ba5/5d\&mc_eid=28a8e=bd18.

119 Sobre esta cuestión, véase Kerstein, Benjamin: “IDF's Point Man on Iran Says Israel 'Definitely’ Has Capacity to Destroy Nuclear Program, Biden Administration Keeping Its Promises So Far", The Algemeiner, 30 March 2021.

${ }^{120}$ Para más detalles, véase Limor, Yoav: "Israel has the Ability to completely Destroy Iran's Nuclear Program”, Israel Hayom, 29 March 2021. Para más detalles sobre el papel de los servicios de inteligencia, Fard, Erfan: Biden's CIA Director and Iran, The Begin-Sadad Center for Strategic Studies, BESA Center Perspectives Paper $\mathrm{n}^{\circ}$ 1965, 14 March 2021. Para este analista, el nombramiento de William J. Burns como director de la CIA revela que ha sido un gran acierto de Joe Biden, ya que tiene una gran experiencia profesional y un real conocimiento del funcionamiento del régimen de los Ayatolas. Y es que la CIA, señala, ha tenido grandes errores de apreciación, y uno de ellos ha sido el no detectar la revolución islámica de 1979, por oposición al Mossad israelí y a la SAVAK del Sha, que habían detectado 11 grupos terroristas fomentando la crisis en Irán. Así, entre William J. Burns y David S. Cohen como director adjunto, podrán trabajar para intentar cercenar el programa de misiles balísticos, detener el programa de armas nucleares, terminar con el apoyo iraní a las milicias "proxies" que Irán tiene en la región, y eliminar el sostén del régimen al terrorismo en zonas del Medio Oriente, Europa y América Latina. Sin embargo, el apoyo y la ayuda del resto de los servicios de inteligencia de la región serán cruciales, como bien se ha puesto de manifiesto con ciertas acciones espectaculares llevadas a cabo por Israel. Y es que la experiencia de William J. Burns le ha demostrado que no se puede confiar en los líderes del régimen iraní. Todo esto no es sin embargo suficiente para parar a Irán, ya que las vacilaciones frente al régimen iraní son aprovechadas por Irán. Por eso, Arabia Saudí propuso una alianza de potencias regionales semejante a la OTAN. Sobre estos aspectos, ver igualmente "Moyen-Orient Tant que Joe biden tergiverse, l'Iran s'en donne à coeur joie", Courrier international, 14 March 2021.
} 
power. And the fourth is the Iranian attempt to grow its regional influence that in the long run uses areas with lack of governance and establishes capabilities there" 121.

Desde esta perspectiva, es evidente que el reto iraní al que tiene que hacer frente Israel es quizás el mayor que ha tenido en muchas décadas, y es existencial, mientras que otros conflictos a los que ha tenido que hacer frente Israel no lo han sido, incluyendo la famosa guerra de Yom Kippur, pues en esta ocasión los elementos de disuasión o de defensa no tienen el mismo papel que en conflictos anteriores, dada la superficie del país y su población, sin olvidar su distancia, acarreando así unos componentes complejos que no son solo de índole militar, sino también diplomáticos, económicos, políticos, etc. Por eso, el reto que presenta Irán no es de hoy para mañana, sino a largo plazo, de ahí la combinación de todos estos elementos para poder elaborar una doctrina que sincronice todos estos esfuerzos que implican no solo ver el presente, sino también el futuro. Y es que el programa nuclear iraní no es solo un asunto que interesa o preocupa solo a Israel sino a otros países de la zona como Arabia Saudí, los Emiratos y también a Egipto y Turquía. Esto quiere decir que el tema nuclear iraní de hoy en día ya no es el mismo que existía en 2015, año en el que se adopta el famoso acuerdo nuclear con Obama, lo que requiere una cierta cooperación, si es posible, no solo con los Estados Unidos, que también sostienen que no permitirán un Irán nuclear, sino también con los países precitados, tres de los cuales (Arabia Saudí, Egipto y los Emiratos) comparten abiertamente las preocupaciones israelíes, mientras que Turquía vigila de cerca los movimientos. Todo esto, que es comprensible y que requiere si es posible, encontrar un instrumento de cooperación en esta materia, no impide afirmar que en caso de que sea necesario recurrir a medios militares, Israel dispone de la habilidad de frustrar el programa nuclear iraní como ya lo hizo en Irak y en Siria.

Hechas estas consideraciones no conviene olvidar que las relaciones irano-israelíes fueron muy buenas con el Sha de Irán, algo que se cultivó desde los años 1950, a iniciativa del primer ministro Ben Gurión, bajo la conocida doctrina de la "periferia", es decir cultivar las relaciones con los Estados no árabes de la zona y ciertas minorías étnicas. Es más, el 23 de julio de 1960 el Sha garantizó a Israel un reconocimiento de facto, debido a que ambos países tenían buenas relaciones con los Estados Unidos, oponiéndose a los esfuerzos de la Unión Soviética, deseosa de impulsar su influencia en la región, como luego se vería más tarde. Tanto eran de buenas esas relaciones, que el Mossad y la CIA mantenían un contacto muy regular con los servicios secretos del Sha, la denomina SAVAK, para supervisar a ciertos grupos islamistas y marxistas existentes en la zona que mantenían ciertos vínculos con el KGB de la URSS. Pero todo esto dio un grio de 180 grados en 1979 con la deposición del Sha y la toma del poder con el ahora ya muy conocido Ruollah Jomeini, señalando no solo su oposición al Estado de Israel desde una perspectiva pura y simplemente política, sino también claramente antisemita, sosteniendo que "I once again remind everyone of the danger of the prevalent, festering and cancerous Zionist tumor in the body of Islamic countries", instalándose así en todas las mezquitas un discurso antisemita y antiisraelí ${ }^{122}$, que trajo consigo de forma inmediata que desde entonces, ambos países hayan sido antagonistas en la zona, practicando a todas luces una manifiesta enemistad ${ }^{123}$.

Desde entonces, varios retos se han interpuesto en el camino entre estos dos países, algunos de ellos por intermedio de los grupos o "proxies" afines a Irán y financiados generosamente por el gobierno iraní, como ha sido el caso de Hezbolláh, en Líbano, como lo

\footnotetext{
${ }^{121}$ Ibid.

${ }^{122}$ Ambas conductas suelen ser en general antisemitas, sobre todo cuando se niega el derecho al pueblo judío de tener un Estado, o, lo que es lo mismo, niegan su existencia. Esto no implica, sin embargo, que no se pueda ser crítico con ciertas medidas o políticas que adopte el Gobierno israelí, como con cualquier otro Gobierno o Estado. ${ }^{123}$ Sobre estos aspectos, véase Fard, Erfan. Antisemitisme Is Inseparable from Khomeinism, The Begin-Sadat Center for Strategic Studies, BESA Center Perspectives Paper n 1999, 16 April 2021.
} 
demuestra la guerra abierta que mantuvo con Israel en 2006, pero también Hamás y la Jihad islámica ${ }^{124}$. Pero hoy en día ya se sabe que entre los dos países hay un tema de mayor calado, como es el nuclear, que Israel considera un peligro real para su existencia, aunque Irán siga insistiendo en que el programa nuclear que desarrolla es exclusivamente pacífico.

Sin embargo, no parece que la diplomacia de Joe Biden se haga mucho de rogar en el asunto nuclear iraní, pues por lo que se apunta en algunos medios, los Estados Unidos ya estarían dispuestos a levantar si no todas las sanciones, sí algunas de las más importantes, como las sanciones contra el Banco Central iraní vinculadas con el terrorismo, así como aquellas relacionadas con las compañías petrolíferas y otras que afectan a sectores claves desde un punto de vista económico como el acero, el aluminio, etc. Sin embargo, esta maniobra ha sido obstaculizada ante el rechazo de los negociadores iraníes a sentarse a negociar con los norteamericanos en la misma mesa en donde se llevan a cabo las negociaciones sobre temas nucleares. Otro problema es que los Estados Unidos no están de acuerdo en la demanda iraní que pretende retirar a la Guardia Revolucionaria Islámica (IRGG) como "organización terrorista extranjera", calificada así por los Estados Unidos. No obstante, Joe Biden no lo tendrá fácil, ya que un grupo de 34 senadores republicanos han depositado un proyecto de ley el 20 de abril de 2021 para dar al Congreso el poder de oponerse a que la Administración pueda llevar a cabo el levantamiento de cualquiera de las sanciones ${ }^{125}$. Por otro lado, tampoco parece que Joe Biden siga las consignas israelíes que le aconsejan abandonar el acuerdo de 2015 por mucho que haya dicho que consultaría con los expertos israelíes y que tomaría en cuenta sus intereses $^{126}$.

Pero en relación con Israel, las buenas palabras no coinciden con los hechos, como lo demuestra la respuesta que ha dado el portavoz de la Casa Blanca, Jen Psaki, el 23 de abril, cuando fue preguntado en una conferencia de prensa si la visita de una importante delegación israelí, dirigida por el director del Mossad, Yossi Cohen, podía dar como resultado un cambio de la política de Joe Biden en relación con el acuerdo, la respuesta fue inequívoca, respondiendo con un "no" rotundo ${ }^{127}$. Esta respuesta ha suscitado algunos comentarios en algunas personalidades israelíes, como la del Michael Oren, antiguo embajador en Washington, quien no ha dudado en señalar que "... this is kind of humiliating after Israel's important ally in the Middle East said it will not listen. I would be very hesitant in sending this delegation... If we are going back to the JCPOA, which is flawed, there could be a very dangerous outcome... There is a lot of visual appearance in this in that shows that there were consultations with Israelis. We should be very careful to legitimize the agreement" ${ }^{\prime 28}$. Y es que Israel deduce que los acontecimientos que se están desarrollando en la zona demuestran claramente que han sido

\footnotetext{
${ }^{124}$ Sobre las redes de apoyo que tiene Irán esparcidas por todo el Medio oriente, cfr. Wrobel, Sharon. "Report: Tens of Thousands of Allied Fighters Serve as Iran's Four-Pronged Network of Proxy Forces", The Algemeiner, April 16, 2021. En este estudio se señala que el denominado "Iran Threat Network" (ITN), que cuenta con decenas de combatientes aliados en todo el Medio Oriente (Siria, Líbano, Yemen, Irak y los territorios palestinos) se ha convertido en el "much larger and more mobile net work, and will continue to threaten US interests". Coordinado por los IRGG (los guardianes de la revolución islámica), el ITN cuenta con alrededor de 200.000 miembros, entre los que se encuentran grupos de diferentes ideologías e identidades, entre los que se encuentran miembros no chiitas, e incluso en cierta medida adversarios, como Al-Qaeda o los taliban. Numerosos miembros del ITN interactúan también con la famosa milicia libanesa Herzolláh, la cual cuenta con la plena confianza iraní.

125 Schindman, Paul: "Biden Administration Willing to Lift Terror Sanctions on Iran", World Israeli News, 22 April 2021.

126 Véase a este respecto "White House: Israeli Delegation Will Not Sway Biden Into Abandoning Iran Nuclear Deal”, The Algemeiner, 25 April 2021.

127 The White House. Press Briefing by Press Secretary Jen Psaki and Secretary of the Interior Deb Haaland, 23 April 2021, en https://www.whitehouse.fov/briefing-room/speeches-remarks/2021/04/23/press-briefing-by-presssecretary-jen-psaki-and-secretary-of-the-interior-deb-haaland-april-23-2021/.

128 Wrobel, Sharon. "Israeli Security Officials Head to Washington to Share Iran Threat Intel as White House Says It Can't Be Swayed on Nuclear Deal", The Algemeiner, 26 April 2021.
} 
abandonados por los Estados Unidos en relación con Irán ${ }^{129}$. Es más, se sabe que John Kerry aconsejo al ministro de Asuntos Exteriores iraní, Yavad Zarif, en 2018, es decir cuando Trump abandona el acuerdo e impone sanciones, de esperar a las elecciones de 2020, ya que se esperaba que los Demócratas ganaran las elecciones ${ }^{130}$.

Para el presidente iraní, Hassan Rohani, la filtración del audio del ministro iraní de Asuntos Exteriores tenía como objetivo sembrar la discordia en Teherán en plenas discusiones para relanzar las negociaciones sobre el programa nuclear iraní1 ${ }^{131}$. Y lo mismo ha sucedido unos días después con el líder supremo iraní, Alí Khameini, para quien los comentarios de Yavav Zariv constituyen un gran error que no se puede hacer por un oficial de la República Islámica, indicando además que "Nowhere in the world the foreign ministry determines foreign policy. There are higher-ranking officials that make the decisions and policies. Of course, the foreign ministry is also involved" ${ }^{\prime 32}$.

Pero si el presidente iraní, Hassan Rohani, y el líder supremo iraní, Ali Khameini, han hablado, Joe Biden calla, al menos hasta ahora. Sin embargo, esta situación generada por esta información es muy preocupante, ya que podría constituir un grave peligro no solo para los Estados Unidos, sino también para Israel. Por eso choca el mutismo oficial que mantiene la administración Biden. Y esto a pesar de las advertencias de Israel y de las amenazas que el programa nuclear iraní acarrea, amenazas que reconoce el propio Biden al señalar en su primera comparecencia ante el Congreso que "el programa nuclear iraní y Corea del Norte son serias amenazas para América y para la seguridad mundial ${ }^{133}$.

Así ha sucedido, pero es que, además, los encargados hoy en día de la política exterior de los Estados Unidos son todos antiguos veteranos de la Administración de Obama, incluido, por supuesto, a Joe Biden. Esto trae consigo que los Estados Unidos están intentando que Israel dé marcha atrás en sus esfuerzos y preparación para detener a Irán en su carrera nuclear, y confiar en el equipo de Joe Biden para que resuelva el problema buscando una solución diplomática. Esto supone un riesgo que Israel no está dispuesto a asumir, pues no hay confianza ni en Joe Biden ni en los principales actores estadounidenses encargados del tema, como pueden ser Antony Blinken, Portavoz de la Casa Blanca, y Robert Malley, enviado especial de Biden para Irán. Este último, no es solo uno de los principales artífices del Tratado nuclear de 2015, sino que además es un veterano apaciguador y, sobre todo, muy crítico con Israel. Desde esta perspectiva, el lema de "Trust US" que propone la administración Biden no podrá ser aceptado por ningún gobierno israelí que sea mínimamente responsable, sobre todo cuando Robert

\footnotetext{
${ }^{129}$ Ver Tobin Jonathan S. "Opinion: Israel has no choice but to Act on Its Own to Stop Iran", World Israel News, 27 April 2021.

130 Véase a este respecto, “John Kerry Accused of Sharing Israel's Vital Security Information with Iran”, Breaking Israel, 27 April 2021, en

https://mail.google.com/mail/u/O/\#imbox/FMfcgxwLtkSCegKpWgRBfRJVVTQxTJvb. Esta revelación en torno a John Kerry suscitó una rápida y viva reacción de Nikki Haley, antigua Embajadora de los Estados Unidos en las Naciones Unidas, indicando en un twitter lo siguiente: "This is disgusting on many levels. Biden and Kerry have to answer for why Kerry would be tipping of Iran, the number one sponsor of terror, while stabbing one of our greatest partners, Israel, in the back". No obstante, John Kerry, niega estas acusaciones, señalando que "nunca ocurrieron". Isaac, David. "Haley reacts to Kerry's Iran Leak: Disgusting on Many Levels", World Israeli News, 27 April 2021.

131 "Iran : la fuite-d'un audio vise à crér la <<discorde〉> pendant les négociations", The Times of Israël, 28 avril 2021. Con este título ha sido recogido este incidente en muchas agencias de prensa y otros medios internacionales. 132 The Algemeiner Staff, "Khameini Criticizes Iran's Foreign Minister Over Leake Remarks", The Algemeiner, 2 May 2021.

133 "Biden Admits Iranian Nukes a 'Serious Threat', but Supports JCPOA Talks", World Israel News, 2 May 2021. Véase a este respecto, "Biden Admin Silent about Alleged Massive National Security Breach by Kerry", Breaking Israel Video, en https://mail.google.com/mail/u/O/\#inbox/FMfcgxwLtVTzgcSDThKgQXdmFXcDvZ.
} 
Malley nunca ha tenido interés en reforzar el pacto nuclear de 2015 con el fin de prevenir que Irán se haga con el arma nuclear, y tampoco detener que el régimen apoye el terrorismo ${ }^{134}$.

En estas circunstancias, todas estas informaciones que están saliendo en relación con la administración Biden en torno al Pacto nuclear, y en general con Israel, están suscitando no solo ya una enorme desconfianza, sino incluso una ruptura ${ }^{135}$. Los mensajes que están saliendo de los negociadores son confusos, y a veces incluso contradictorios, aunque no pierden la esperanza de que se llegue a buen puerto. Esto es también lo que sostienen tanto China como Rusia, que pueden ser en este caso quizás los más objetivos. Desde esta perspectiva, será difícil para Israel detener las negociaciones e impedir que los Estados Unidos vuelvan al Tratado. Y esto es lo que se vislumbra al menos por ahora, sobre todo a la luz del comportamiento que la administración Biden está teniendo con Israel, que no parece que sea amistoso, y menos todavía con Netanyahu ${ }^{136}$. Esto no impide, sin embargo, que sean Rusia y China las que parecen más optimistas, mientras que los Estados Unidos y los tres países europeos son más circunspectos, aunque estos últimos quizás utilicen esta estrategia de prudencia para luego dar el asalto final. Por su parte, Irán, a pesar de la necesidad que tiene de que se levanten las sanciones, resiste dignamente, aunque esto no quiere decir que no padezcan sufrimientos a causa de las sanciones $^{137}$.

Pero puede ocurrir alguna sorpresa, ya que, según algunas fuentes, Rusia podría sabotear las negociaciones sobre el acuerdo con el fin de impedir la normalización de relaciones entre los Estados Unidos e Irán. Esta información ha salido a la luz a raíz de una entrevista que el ministro iraní dio el año pasado, pero que ha sido publicado tras la filtración en el New York Times del 25 de abril de 2021. En esta entrevista, Mohammad Javad Zarif reconoce que el general Soleimani le ha desautorizado en muchas ocasiones, trabajando conjuntamente con Rusia para sabotear el pacto nuclear de 2015, y adoptando políticas en relación con Siria que dañan los intereses iraníes. El ministro ha recalcado lo siguiente: "In the Islamic Republic, the military field rules... I have sacrified diplomacy for the military field rather than the field servicing diplomacy" ${ }^{138}$.

Estas informaciones, que han sido filtradas por el ministro de Asuntos Exteriores iraní, y de las que se ha hecho eco el New York Times, no solo critican el papel que ha desempeñado

\footnotetext{
${ }^{134}$ Tobin, Jonathan S. "Opinion: Israel has no Choice but to Act on Its Own to Stop Iran”, op. cit. Ver también Plank, Josh. "Kerry's Reported Leaks to Iran about Israel Lead to Calls for his Dismissal", World Israel News, April 27, 2021. Sobre este tema el Senador (R-Alaska) declare en el Senado estadounidense que "Today I've heard such disturbing news that if true, it should absolutely result in the call of John Kerry either being fired or resigning. Enough is enough". En este artículo sale también a colación el consejo que John Kerry dio al ministro de Asuntos Exteriores iraní, Zariv, que ya hemos apuntado.

${ }^{135}$ Que Irán sigue con su política nuclear, ocultando, si puede su programa, es una evidencia. Véase, a este respecto, "Intelligence Website Releases 3D Reconstructed Images of Iran's Fordow Nuclear Facility", The Algemeiner, 30 May 2021.

136 Berman, Lazar. "Si Teherán et Washington s'accordent, Israël a besoin d'une nouvelle approche", The Times of Israël, 27 avril 2021. Ver también Wilkenfeld, Yon. "Israel Says US 'Very Considerate' of Its Concerns on Iran Threat After Week of High-Level Talks”, The Algemeiner, 30 April 2021. Sobre estas conversaciones nucleares de Viena, el ministro israelí de Inteligencia, Eli Cohen, ya señaló el jueves 29 de abril que Israel no se consideraría vinculado por un mal Tratado que enviaría a la región a la guerra. Pero además señaló que "Israel will not allow Iran to attain nuclear arms. Iran has no immunity anywhere. Our planes can reach everywhere in the Middle East and certainly Iran”. Ver también "Our Warplanes Can reach Iran, Israel Minister Warms Amid Nuclear Talks", Idem, 29 April 2021.

${ }^{137}$ A este respecto, se ha señalado que "Nous ne devrions pas être surpris que les iraniens ne se présentent pas, en suppliant pour cet allégement. Ils sont très habiles dans ce genre de négociations, et savent très bien jouer même avec une mauvaise main. Cela aide à expliquer pourquoi ils ne se montrent pas particulièrement nécessiteux à ce stade, même si la situation économique pourrait suggérer le contraire", Ibid.

138 "Iran's Foreign Minister in Leaked Tape, Says Revolutionary Guards Set Policies", The New York Times, 25 April 2021, en https://nytimes.com/2021/04/25/world/middleast/Iram-suleimani-zarif.html.
} 
el general Soleimani en la política exterior de Irán, sino que han traído consigo que el presidente iraní, Hassan Rohani, haya ordenado identificar a los agentes de esta "conspiración" añadiendo que el dossier de la entrevista había sido robado por razones evidentes. Pero esto va más allá de una simple filtración, pues revela que, en Irán, los Guardianes de la Revolución, y a la cabeza de estos la "Fuerza Qods", que es la encargada de las operaciones exteriores, no siempre van por el mismo camino que el gobierno de la República Islámica ${ }^{139}$. Conviene apuntar que estas declaraciones del ministro iraní Mohammad Javad Zarif no tenían como destino su publicación, como lo señala el propio ministro. Esto revela que Irán no es tan raro como se apunta, y estas declaraciones revelan lo que ocurre también en otros muchos países, en donde suceden cosas similares, sobre todo en relación con la política exterior, en donde suelen suscitarse diferencias importantes a la hora de trazar sus principales directrices.

También se ha señalado una información según el cual John Kerry informaba a los iraníes de los objetivos iraníes que Israel iba a atacar en Siria. Esta información en torno a John Kerry, que la niega rotundamente, aunque no ha insistido mucho en ello suscita muchas cuestiones en el ámbito de las relaciones entre los Estados Unidos e Israel, sobre todo a la luz de la desconfianza que se está generando en torno a la conducta de la administración Biden con Israel, al tener en su seno personalidades como Kamala Harris y Nancy Pelosi, que se han mostrado en muchas ocasiones haciendo declaraciones y contrarias, por lo tanto al espíritu que debe reinar entre dos Estados que comparten los mismos valores, y que han sido, por lo menos hasta ahora, dos pilares unidos en la política medio oriental . Por eso no es extraño, que el editor jefe de "Algemeiner", David Efane, no haya dudado en afirmar que "The desclosure of this Kind of information... if this esfound to be true, is devastating to the ability of US allies to trust the Unites States on national occurity issues-specially in that very, very delicate region in the Middle Ease" ${ }^{140}$ y es que al margen de la cuestión de saber si esa información es verdadera o no ${ }^{141}$, lo cierto es que no deja de ser muy preocupante y sorprendente la actitud reinante den algunos altos miembros de la actual administración Biden y antes en la de Obama ${ }^{142}$. Por eso precisamente es muy importante para los Estados Unidos hacer ver que actuará de una manera responsable con sus aliados en la zona, entre los que sin duda está Israel, aunque a veces haya acciones que pueden poner en duda esta afirmación, algo que ocurre oyendo ciertas declaraciones de Nancy Pelosi o de Kamama Harris, entre otras. Y es que la actual Administración debe comprender que Irán no es cualquier Estado, sino el mayor enemigo hoy por hoy de Israel en la zona. Por eso no es extraño que el Republicano Andy Barr haya señalado que a la luz de los comportamientos de John Kerry y Joe Biden que han demostrado ya ser proiraníes, algo se tiene que hacer, pues “... this type of betrayal of a staunch ally is simply unconscionable. We need the inspector general to launch an immediate, impartial investigation to determine the validity of these claims" ${ }^{\prime 43}$.

\footnotetext{
${ }^{139}$ Para más detalles, véase "Rohani ordonne une enquête après des propos du chef de la diplomatie ayant fuité", The Times of Israël, 27 avril 2029.

140 "Reports of Kerry Disclosure to Zarif on israelí Strikes 'Disturbing' Says Algemeiner Editor-in-Chief”, The Algemeiner, 29 April 2021.

${ }^{141}$ Por de pronto, según fuentes judiciales iraníes, 15 personas vinculadas con esa famosa entrevista han sido ya notificadas de la prohibición de salir de Irán, según la Agencia Reuters, de la que se hacen eco otros medios, véase "Iran Bans 15 People From Travelling Over Zarif Leak, Official Resigns", en https://www.reuters.com>middleast, 29 April 2021. Ver también https://www.swissinfo.ch>on>ira...

${ }^{142}$ En estas circunstancias, miembros Republicanos del Congreso han solicitado a la propia administración Biden que se investigue a John Kerry sobre las filtraciones a Irán en relación con los ataques aéreos llevados a cabo por Israel en Siria. Véase, Watch: "Investigate Kerry over Leaks to Iran about Israeli Airstrikes, Demand Republicans", World Israel News, 8 May 2021.

143 JNS. "Former Israeli Ambassadors Say Kerry's History of Conflict with Israel Lends Weight to Iranian Accusation”, Israel365 News, 30 April 2021. Al republicano Barr, se unieron también los republicanos Ann
} 
En estas negociaciones también habría que tomar en consideración el pacto de cooperación estratégico de 25 años que Irán ha firmado con China el 27 de marzo de 2021. Aunque este pacto tiene bastantes aspectos algo misteriosos, lo cierto es que se inscribe dentro del proyecto de construcción de la nueva Ruta de la Seda que proyecta el gigante asiático, pero que permite a Irán abrir más su comercio con su principal socio comercial que es China ${ }^{144}$. No obstante, el volumen de los intercambios comerciales entre ambos países ha pasado de 51.800 millones de dólares, en 2014, a 16.000 millones en 2020, precisamente a causa de las sanciones. Tampoco hay que ignorar el contexto político existente en esos momentos, ya que se está en un período de fuertes tensiones entre Rusia, China e Irán de un lado, y los Estados Unidos del otro, tras la llegada al poder de Joe Biden, quien ya ha mostrado los dientes tanto a China como a Rusia, aunque con muy poco éxito, como ya hemos apuntado, al menos por el momento. $\mathrm{Su}$ agresividad hacia estos dos países ya se ha puesto de manifiesto, y aunque ha intentado recomponer lo que descompuso tras llamar a Vladimir Putín "killer", la situación está lejos de calmarse.

No obstante, las negociaciones nucleares de Viena siguen su curso, pero no todos los mensajes van por el mismo camino. El sábado 1 de mayo se aplazaron las negociaciones, y mientras los negociadores rusos expresaron "prudencia y un creciente optimismo", señalando que en un período de tres semanas esperan llegar a resultados concretos, el propio Joe Biden, sin embargo, comunicó al director del Mossad, Yossi Cohen, que los Estados Unidos están lejos de volver al pacto nuclear de 2015, demostrando así que los negociadores estadounidenses son más pesimistas que los rusos. Pero, aunque Yossi Cohen intenta convencer a Joe Biden de que volver al pacto es un error para los Estados Unidos, Joe Biden sigue insistiendo en las negociaciones ${ }^{145}$. Para algunos, el progreso en las negociaciones nucleares parece depender de unas pocas cosas, aunque, sin embargo, se quiere imponer a Irán que acepte ciertos compromisos, tal y como se ha señalado el 6 de mayo. El quid del acuerdo "was that Iran committed to take steps to rein in its nuclear program to make it harder to obtain the fissile material for a nuclear weapon in return for relief from US, EU and UN sanctions". A esto Irán responde que no tiene ambiciones de armas nucleares y, por lo tanto, lo que se le ofrece carece de sentido ${ }^{146}$. De todas formas, habrá que reconocer que los iraníes son buenos negociadores, y no se amilanan ni ante los Estados Unidos ni ante el resto de Estados partes en el Tratado. Ya lo demostraron en las negociaciones que propiciaron el Pacto, y ahí siguen.

En las últimas semanas, y a raíz de las discusiones suscitadas por el nuevo grupo de coalición que se enfrenta a Benjamin Netanyahu, hay profundos debates no solo a nivel interno, sino también en relación con el acuerdo nuclear, ya que tanto Naftali Bennet como Yair Lapid apoyan en general las actuaciones de Joe Biden. Habrá que ver todavía cómo se desarrollan los acontecimientos tanto a nivel israelí como en las negociaciones de Viena ${ }^{147}$. Y es que, en el mes de junio, se ha abierto un cierto pesimismo y falta de confianza en relación con Irán, al darse cuenta el secretario de Estado, Antony Blinken, que la voluntad de Irán para cumplir con los límites que impone el acuerdo nuclear es más que dudosa. Esto implica que los Estados Unidos

Wagner y Lee Zeldin, cuestionando que Kerry pueda seguir teniendo su posición actual en la administración Biden. Otros republicanos senadores como Ted Cruz pidieron claramente también la dimisión.

${ }^{144}$ Irán y China firmaron un "pacto de cooperación estratégico de 25 años", en swissinfo.ch. Ver también, de una manera más detallada, "Iran et Chine signent un pacte de coopération stratégique de 25 ans", The Times of Israël, 28 mars 2021.

145 Para más detalles, véase "Biden Informs Mossad Chief That US Is Far from Returning to Iran Deal: Report", The Algemeiner, 3 May 2021. Ver también Sonnenfeld, Daniel: "Israeli Officials Likely on Damage Control Mission as Iran Nuclear Deal Revival Nears. Biden, Blinken and Sullivan Have All Met in Washington with Israeli Security Officials in the Last Week", Jewish Journal, 4 May 2021.

146 “Nuclear Deal Possible Soon if Iran Takes 'Political Decision’ Says US Official”, The Algemeiner, 6 May 2021. ${ }^{147}$ Para un interesante estudio sobre estos aspectos, véase GLIC Caroline. "The Price of Friendship with Biden's Washington: Analysis", World Israel News, 7 June 2021. 
se estén planteando reintegrarse en el acuerdo, tal y como ha anunciado el precitado Antony Blinken, quien señala lo siguiente: "We're not even at the stage of returning to compliance for compliance... We don't know if that's actually going to happen. We've been engaged in indirect conversations, as you know, for the last couple of months, and it remains unclear whether Iran is willing and prepared to do what it needs to do to come back into compliance. So we're still that proposition". Y reconociendo que el tiempo se va acortando, afirma que "the longer this goes on, the more their breakout time gets down"

Que las negociaciones de Viena están pasando por ciertas dificultades lo reconoce también Irán, aunque el portavoz del gobierno iraní, Ali Rabici, haya dicho que no es que estén en un callejón sin salida, sino que "the negotiations have reached a stage where a few key issues need to be decided, and these issues required the proper attention, perfectionism and tine". Por eso, no es extraño que haya dejado caer sus dudas en torno al resultado de las actuales negociaciones, dejando así la puerta abierta a otra ronda de negociaciones. Y es que todo parece indicar que Joe Biden esperaba que Irán le abriera las puertas y le pusiera la alfombra roja sin contrapartidas previas, olvidando así lo que es evidente: primero, que no está en las negociaciones directas, y, segundo, que no es el único que esté interesado en este tema ${ }^{149}$. Por otro lado, tras las elecciones del 18 de junio en Irán de 2021, ganadas por Ebrahim Raisi, elegido como Presidente de la República, y considerado como duro dentro del régimen iraní, ha levantado las alarmas en Israel, suscitando una vez más los programas de ataque para hacer frente a los planes nucleares iraníes, retomando lo que ya hemos apuntado en relación con la necesidad de disponer ya de los presupuestos adecuados, aspecto que implica la necesidad de nuevos recursos dedicados a este menester ${ }^{150}$. Es más, el 21 de junio, Raisi ya ha anunciado su rechazo a reunirse con Biden para tratar el tema de los misiles balísticos, que tanto preocupan a los Estados Unidos ${ }^{151}$.

Pero la llegada a la Presidencia de Raisi en Irán no es el único elemento novedoso en el tema nuclear iraní, sino que también lo es el cambio de gobierno en Israel con el dúo Bennet/Lapid, pasando Netanyahu a la oposición, quien había mantenido una constante oposición al Acuerdo nuclear de 2015, amenazando desde 2012, por lo tanto, ya antes del

\footnotetext{
${ }^{148}$ Kerstein Benjamin. "Blinken to US House Committee: 'It Remains Unclear' whether Iran Prepared to Comply with Nuclear Deal Limits", The Algemeiner, 7 June 2021.

149 "Iran Says Nuclear Talks Not at Impasse, but Difficult 'Issues' Remains", The Algemeiner, 1 June 2021. La prueba de que Israel ha ido en serio a la hora de tratar los problemas con Irán, lo pone de relieve el anterior jefe del Mossad, Yossi Cohen, quien en una amplia entrevista ha relatado algunas de sus actividades en Irán, reconociendo que el Mossad había hecho saltar por los aires la instalación subterránea de centrifugadoras de la planta nuclear de Natanz, de la que tanto se ha hablado. Pero sus actividades no han terminado ahí, pues ha dado además una descripción precisa de la operación de 2018 durante la cual el Mossad robó los archivos de Irán en los cofres de un depósito de Teherán, archivos que expuso públicamente con sumo detalle Netanyahu. Al mismo tiempo ha confirmado que Mohsen Fakhrizadeh, el principal científico nuclear iraní asesinado el 27 de noviembre de 2020 en una emboscada cerca de Teherán, estaba en el punto de mira de su Agencia desde hacía años. Y, por último, ha insistido sobre una cuestión que en este estudio hemos comentado ampliamente, al señalar que el régimen iraní debe comprender que Israel es sincero cuando promete abiertamente que impedirá a Irán dotarse del arma nuclear. Tras estas declaraciones, y habiendo sido preguntado si las instalaciones de la planta de Natanz ya no funcionaban como antes, ha respondido: "En effet...Ça ne tourne plus comme avant" Véase. "En interview TV, l'ancien chef du Mossad met en garde l'Iran et défend Netanyahu", The Times of Israël, 11 juin 2021, en https://fr.timesofisrael.com/en-interview-tv-lancien-chef-du-mossad-met-en-garde-liran-et-defendnetanyahu/?utm_source=A+La+Une\&utm_campaign=a-la-une-2021-06-11\&utm_medium=email.

${ }^{150}$ Marcus, Laurent: "'Prepare for Iran Nuclear Facility Strike', Says Israeli Official after Election of 'Butcher of Tehran”, World Israel News, 20 June 2021.

151 "Iran's President-Elect Refuses to Meet Biden, Digs in on Ballistic Missiles”, World Israel News, June 21, 2021. Para un estudio sobre lo que se puede esperar de la llegada del presidente Raisi en Irán, véase Suissa, David: "What Does Iran's New Leader Mean for the Iran Deal? Jewish Journal Round Table, 22 June 2021; y Schnur, Dan: “A Symbolic Impact", Idem, en https://mail.google.com/mail/a/0/\#inbox/FMfcgzGkXwDNqDFKmKMBDflTrrfVsbbc,.
} 
Acuerdo, con intervenir militarmente en Irán para impedir, si esto fuera necesario, que este último pudiera hacerse con el arma nueclear. El nuevo gobierno israelí también se ha mostrado contrario a que Irán pueda hacerse con el arma nuclear y, a este respecto, se ha mostrado también vigilante. Tanto es así que, tras un Informe de la AIEA sumamente crítico con Irán, en donde se ponía de manifiesto la falta de colaboración por parte de Irán, Israel ha levantado el tono. Esto trajo consigo que el propio director de este Organismo, Rafael Grossi, tomara cartas en el asunto tras la destrucción de las cámaras de vigilancia en emplazamientos nucleares iraníes. La sospecha inicial iba dirigida hacia Irán, no obstante, algunas fuentes han insinuado que los autores podrían haber sido agentes del Mossad israelíi ${ }^{152}$. Así las cosas, el director de la AIEA se volcó en la tarea de conseguir que Irán aceptara que inspectores de la AIEA controlaran las cámaras de vigilancia, con el fin de poder probar al mundo que todo está bajo control $^{153}$. Todo esto parece demostrar que la AIEA ha estado, y lo sigue estando en estos momentos, vigilante en torno al comportamiento iraní. Y es que, ya en febrero de 2021, la AIEA ordenó retirar la mayoría de los precintos y cámaras de vigilancia que Irán había implantado en sus instalaciones nucleares, amenazando con llevar el asunto al Consejo de Seguridad de la ONU si esto no se llevaba a cabo ${ }^{154}$. Sin embrgo, no parece que el comportamiento iraní este por encima de toda sospecha, ya que también se ha apuntado en The Wall Street Journal del 14 de septiembre de $2021^{155}$, que los guardias de seguridad iraníes acosaron a varias mujeres inspectoras de la AIEA en la planta nueclar de Natanz. Y todo apunta a que ha habido entre otros cinco y siete incidentes de este tipo.

Por último, al margen de estas consideraciones relativas a la vigilancia de las instalaciones nucleares iraníes, ciertas declaraciones recientes hechas por el actual ministro de Defensa israelí, Benny Gantz, anunciando que él estaría dispuesto a aceptar un escenario en el que los Estados Unidos podrían renegociar un nuevo acuerdo nuclear iraní, sin especificar que clase de acuerdo podría aceptar ${ }^{156}$. Esta declaración no solo ha causado sorpresa, sino también una profunda indignación en el actual líder de la oposición, Netanyahu, indicando que "el primer ministro Naftali Bennet, el ministro de Asuntos Exteriores Yair Lapid y Gantz se dirigen hacia un acuerdo peligroso en materia nuclear, que permitirá a Irán dotarse de un arsenal nuclear..." 157 . Y esto es lo que Netanyahu considera un gran error, al estimar que Irán constituye una amenaza existencial. Por su parte, el actual Primer Ministro israelí, Bennet, ha adoptado también un comportamiento más acorde con la Casa Blanca tras su reciente visita a Washington del pasado mes de agosto, señalando que no haría una campaña pública contra las iniciativas adoptadas por Biden tendentes a reintegrar Irán en el Acuerdo, aunque se supone que se está refiriendo a un Acuerdo renegociado, ya que en varias ocasiones ha dicho públicamente que una resurrección pura y simplemente del Acuerdo de 2015 era algo con lo

\footnotetext{
152“Irán. - El Mossad israelí podría haber destruido cámaras de la AIEA en instalaciones nucleares iraníes", Notimérica, 13 de septiembre de 2021, en: https://www.notimérica.com/politica/noticia-iran-mossadisraelipodria-haberdestruido-camaras-aieainstalaciones-nucleares-iraníes-20210913185454.html.

${ }^{153}$ A este respect, cfr. "Irán permitirá que inspectores de la OIEA controlen cámaras de vigilancia en emplazamientos nucleares", Euronews, 13 de septiembre de 2021, en

https://euronews.com/2021/09/12/iran-permitira-que-inspectores-de-la.oiea-controlen-camarasdevigilancia-enemplazamiento.

${ }^{154}$ Euronews/Internacional, 11 de febrero de 2021, en https://www.europapers.es/internacional/noticiarian-aiearetira-mayoria-precintos-camaras-vigilancia-centrales-nucleares-iranies-20060211225310.html.

${ }^{155}$ Norman, Laurence. "Iranian Guards Physically Harassed Female U.N. Nuclear Inspectors, Diplomats Says", The Wall Street Journal, 14 September 2021, en https:/www.wsj.com/articles/iranien-guards-physicallyharassed-ferrale-u-n-nuclear-inspectors-diplomats-say-11631626649.

${ }^{156}$ Estas declaraciones han sido hechas el 14 de septiembre de 2021, en una entrevista dirigida por Neri Zilber para la revista Foreign Policy, con el título "Israel Can Live with a New Iran Nuclear, Defense Minister Says", en https/foreignpolicy.com. Para más detalles, véase "Gantz prêt à un autre accord sur le nucleáire iranien: Netanyahu s'indigne”. The Times of Israël, 15 septembre 2021.
}

157 Ibid. 
que Israel no podía acomodarse. Es esto precisamente lo que parece que desa Gantz, es decir un plan nuclear B renegociado y dirigido por los Estados Unidos, llevando a cabo una presión política, diplomática y económica importante contra Irán, impuesta conjuntamente por los Estados Unidos, la Unión Europea, Rusia y China, en el caso de que las negociaciones de Viena tendentes a reincorporar los Estados Unidos al Acuerdo no den sus frutos. Y es que Gantz piensa que Israel no tiene capacidad para llevar a cabo una presión de esta índole, incluidas las sanciones económicas, pero sí los Estados Unidos. Dicho esto, Gantz no parece que tenga una excesiva confianza en lo que él mismo indica en sus declaraciones hechas a la revista "Foreign Policy", ya que Israel sigue teniendo su "plan C", que implica, llegado el caso, una acción militar. Y es que recuerda que "aunque Israel no es los Estados Unidos, tiene sin embargo sus capacidades" ${ }^{\prime 158}$.

Así las cosas, es difícil a día de hoy prever por donde pueden ir estas negociaciones nucleares, aunque lo único que parece claro es que Israel hará, llegado el caso, todo lo que este en sus manos, incluido el uso de la fuerza, para impedir que Irán pueda hacerse con el arma nuclear. Esto es lo que parece que defiencde el nuevo gobierno israelí, aunque no lo diga de forma tan clara como lo ha hecho siempre Netanyahu. También conviene apuntar que los Estados Unidos no fueron muy finos en la época de Obama a la hora de negociar el Acuerdo de 2015, algo de lo que todos están ahora de acuerdo. El tema es que los errores se pagan, y Biden se está dando cuenta un poco tarde. Cuestión distinta es que lo quiera reconocer o no, que no lo hará, a pesar de que tenga que comulgar con ruedas de molino. Esta posición contrasta con el planteamiento isrealí, de antes y de ahora, ya que dejan claro que los responsables de la defensa de Israel son los propios israelíes, sin que esto signifique que no requieran ayuda o que no la necesiten. Dicho de otro modo, los muertos los pone Israel...

La importancia del tema nuclear iraní no solo lo demuestran las negociaciones nucleares que se desarrollan en Viena, sino que ha llegado a la Asamblea General de las Naciones Unidas, en cuyo foro Biden ha intervenido en la $76^{\mathrm{a}}$ sesión el 21 de septiembre, en donde ha puesto de manifiesto la necesidad de que se retomen lo más pronto posible las negociaciones, tesis que ha sido también apoyada por los países occidentales. A esta tesis se ha sumado también el nuevo presidente iraní Ebrahim Raisi, aunque señalando en un video registrado, que "el objetivo final es el levantamiento de todas las sanciones opresoras" que los Estados Unidos han reintroducido al retirarse en el $2018^{159}$. Por otro lado, y aprovechando esta ocasión, el Portavoz de la diplomacia iraní, Said Khatibzadeh, ha declarado que las negociaciones, suspendidas desde junio pasado se retomarían en las próximas semanas.

Desde esta perspectiva, no parece que las negociaciones vayan a ser fáciles, pues Joe Biden ha señañado expresamente en su discurso en la Asamblea General de las Naciones Unidas "que los Estados Unidos están determinados a impedir que Irán pueda obtener el arma nuclear", siguiendo así a las tesis israelíes y que trabajará conjuntamenta con los otros Miembros permanentes del Consejo de Seguridad, más Alemania, para que Irán regrese al acuerdo, ya que tras la retirada de los Estados Unidos del acuerdo en 2018, Irán ha abandonado o ignorado la mayoría de sus compromisos. El tiempo pasa, han señalado los ministros de Asuntos Exteriores de Alemania y Francia, Heiko Maas y Jean-Yves Le Drian respectivamente, por lo que Irán "debe retomar las negociaciones lo más pronto posible". Esta tesis es también defendida por la ministra británica de Asuntos Exteriores, Liz Truss, así como por el Alto Representante de la

\footnotetext{
${ }^{158}$ A este respect, literalmente señaló lo siguiente : “(a) viable U.S. - led plan B that ineludes broad economic pressure on Iran in case the talks fail. And he gestured at Israel's own 'plan C', wich would involve military action”. Israel Can Live with a New Iran Nuclear, Defense Minister Says, op. cit.

${ }^{159}$ A este respecto véase "Les occidentaux pressent Téhéran de revenir aux négociations", The Times of Israël, 22 septembre 2021.
} 
diplomacia europea, Josep Borrell ${ }^{160}$. Así están las cosas en estos días finales de septiembre, por lo que no se pueden hacer grandes pronósticos de lo que puede ocurrir, y el fiasco de Afganistán no parece que ayude mucho a los Estados Unidos a la hora de ejercer una determinada presión ni sobre China, ni sobre Rusia ni, en teoría, sobre los países europeos.

\section{4. ¿Cómo actuará la administración Biden por el asunto de sanciones, llevado por Irán ante la Corte Internacional de Justicia?}

El tema de las sanciones impuestas por la Administración Trump a Irán, fue llevado a la Corte Internacional de Justicia por Irán, el 16 de julio de 2018, invocando la violación del Tratado de Amistad, Relaciones Económicas y de los Derechos Consulares del 15 de agosto de 1955, que entró en vigor el 16 de junio de $1957^{161}$. Irán sostiene la competencia de la Corte a la luz del artículo 36 del Estatuto de la Corte, y del artículo XXI, párrafo 2 del precitado Tratado de 1955. Irán también ha solicitado en su demanda la adopción de medidas cautelares tal y como está previsto en el artículo 41 del Estatuto de la Corte. Habiendo sido comunicada esta solicitud al Secretario de Estado de los Estados Unidos por la vía de urgencia, el 3 de octubre de 2018, la Corte, oídas las Partes, ha indicado las medidas cautelares siguientes: 1) Los Estados Unidos deben suprimir cualquier obstáculo que las medidas sancionatorias aprobadas el 8 de mayo de 2018 afecten a la exportación hacia Irán de i) de medicamentos y material medical; ii) productos alimenticios y productos agrícolas; iii) piezas de recambio, equipos y servicios conexos (como el servicio postventa, el mantenimiento, las reparaciones y las inspecciones) que sean necesarios para la seguridad de la aviación civil. Además, los Estados Unidos deben velar a que los permisos y autorizaciones necesarios sean acordados, y a que los pagos y otras transferencias de fondos no sean sujetas a ninguna restricción siempre que se trate de los precitados servicios. Y como suele ser normal en estos casos, las Partes deben abstenerse de adoptar cualquier acto que pueda agravar o ampliar la controversia tal y como se ha presentado a la Corte para dirimirla.

Dado este paso de la adopción de medidas cautelares, la Corte pasa a examinar en el procedimiento sobre el fondo las conclusiones presentadas por Irán en su demanda, centradas en eventuales violaciones de varias disposiciones del precitado Tratado de Amistad, Comercio y de Servicios Consulares de $1955^{162}$, instando a que los Estados Unidos pongan fin inmediatamente a las sanciones adoptadas de conformidad con el memorándum presidencial del 8 de mayo de 2018, o relacionadas con él, así como de amenazar con imponer nuevas sanciones, y de renunciar a las ya anunciadas. Pero Irán no se olvida de algo muy importante, que es el tema de la indemnización integral por los daños causados a causa de las violaciones de sus obligaciones internacionales, cuyo montante será determinado por la propia Corte, reservándose Irán el derecho de presentar en el momento oportuno una evaluación precisa del montante debido por los Estados Unidos ${ }^{163}$.

Frente a estas peticiones, los Estados Unidos instan a la Corte a rechazar íntegramente las demandas iraníes, porque no caen bajo la competencia de la Corte. Pide además que sean desestimadas las demandas al estar excluidas por el artículo XX.1 del Tratado, ya citado, de 1955, y niega además la competencia de la Corte para juzgar cualquier demanda basada en dicho Tratado, cuyo objeto sea las medidas relativas a terceros Estados. Es decir, los Estados

\footnotetext{
${ }^{160}$ Ibid.

${ }^{161}$ Alleged violations of the 1955 Treaty of Amity, Economic Relations and Consular Rights (Islamic Republic of Iran v. United States of America), 3 February 2021, en https://www.icj.org/public/files/case-related/175/17520210203-JUD-01-00-FR.pdf. Para el texto de este Tratado, Treaty of Amity, Economic Relations, and Consular Rights between the United States of America and Iran, August 15, 1955, en https://www.state.gov/treaty-of-amityeconomic-relations-and-consular-rights-between-the-united-states-of-america-and-iran-aug-15-1955/

162 Se trata de los artículos IV, 1-2, V.1, VII.1, VIII.1-2 y X.1.

163 Párrafos 19-20, de la decisión precitada del 3 de febrero de 2021.
} 
Unidos han pretendido zafarse del asunto invocando a todas luces la incompetencia de la Corte con unos argumentos que, dicho sea de paso, no parece que sean muy convincentes, al situar el contencioso en el ámbito del acuerdo nuclear de 2015, rechazando así el Tratado de Amistad de 1955, que es precisamente donde Irán sitúa el contencioso, invocando el artículo XXI, párrafo 2, que reza así: "Any dispute between the High Contracting Parties as to the interpretation or application of the present Treaty, not satisfactorily adjusted by diplomacy, shall be submitted to The International Court of Justice, unless the High Contracting Parties agree to settlement by some other pacific means".

Para dirimir el asunto, la Corte hace un exhaustivo análisis de los hechos tal y como se han venido sucediendo, comenzando por la cuestión de saber si el Tratado de 1955 estaba en vigor en el momento de la introducción de la demanda por Irán, es decir, el 16 de julio de 2018, a lo que responde afirmativamente. Y es que el artículo XX, párrafo 3 del Tratado prevé que cada una de las Partes Contratantes puede poner fin al Tratado al final del período inicial de diez años o en cualquier momento después de la expiración de este período, dando a la otra Parte Contratante un preaviso de un año. Desde esta perspectiva, el 3 de octubre de 2018, el Departamento de Estado de los Estados Unidos dirige una nota diplomática al ministro de Asuntos Exteriores iraní en la que le notifica que "ponían fin al Tratado", de conformidad con el artículo XXIII, párrafo 3 del Tratado. Así las cosas, no hay ninguna duda de que, en el momento de la presentación de la demanda por parte de Irán, el Tratado estaba en vigor.

Resuelta esta cuestión, que es sumamente importante, la Corte va a plasmar un desarrollo pormenorizado en torno a Irán y su adhesión al Tratado de no proliferación nuclear del 1 de julio de 1968, así como de las obligaciones que impone a las Partes, señalando las violaciones, por cierto, numerosas de Irán, hoy en día muy conocidas, tras la publicación del Informe de la AIEA del 6 de junio de 2003. Todo esto, y sus consecuencias, es expuesto con claridad por la Corte ${ }^{164}$, hasta que el Consejo de Seguridad decide en su Resolución 1737 (2006) sanciones a Irán por no suspender el enriquecimiento de uranio. Tras esta Resolución, el Consejo de Seguridad se ocuparía de Irán en varias resoluciones más ${ }^{165}$, pero la Unión Europea y los Estados Unidos adoptarían también sanciones hasta que el 14 de julio de 2015 se concluye el famoso acuerdo nuclear, avalado el 20 de julio de 2015 por la Resolución 2231 (2015) del Consejo de Seguridad, que decide además levantar, siempre en ciertas condiciones, las medidas sancionatorias adoptadas anteriormente ${ }^{166}$, tanto por las Naciones Unidas, como por la Unión Europea y los Estados Unidos. Esto permite al todavía entonces presidente Obama adoptar el 16 de enero de $2016^{167}$ el decreto 13716 por el que se derogan o modifican las sanciones vinculadas al tema nuclear.

Analizados y expuestos los hechos de forma clara, la Corte pasa a centrarse sobre "las excepciones de incompetencia" invocadas por los Estados Unidos, que es en sí el verdadero objeto del litigio, sosteniendo que la controversia no cae bajo el ámbito de aplicación del artículo XXI, párrafo 2 del acuerdo de Amistad de 1955 precitado, sino que "el objeto verdadero de la controversia cae bajo el ámbito del acuerdo nuclear de 2015, es decir del denominado "Plan de Acción Conjunto". Y, en segundo lugar, los Estados Unidos consideran que la mayoría de las medidas impugnadas por Irán se refieren principalmente al comercio y las transacciones

\footnotetext{
164 Párrafos 26 y ss.

165 Párrafo 8.

${ }^{166}$ Para un análisis de esta Resolución, cfr. Bermejo García, Romualdo y Gutiérrez Espada, Cesáreo: "El programa nuclear de la República Islámica de Irán y de su evolución (política y derecho)”, op. cit., pp. 56 y ss. Un estudio más reciente, Pozo Serrano, Pilar. "La retirada de los Estados Unidos del Plan de Acción Integral Conjunto y la reimposición de sanciones a Irán: aspectos jurídicos y políticos”, op. cit., pp. 219-259 y Calumani Quilla, Milagros. "Implicaciones de la salida natural de los Estados Unidos del Acuerdo Nuclear con Irán”, op. cit., pp. 660-685.

${ }^{167}$ Por o tanto cuatro días antes de la investidura de Trump, que tuvo lugar el 20 de enero de 2016.
} 
de Irán con terceros Estados, sus ciudadanos o sociedades, y no entre los Estados Unidos e Irán ${ }^{168}$. El trasfondo de la controversia, según los Estados Unidos, es su retirada del acuerdo nuclear el 8 de mayo de 2018, y la subsiguiente imposición de sanciones que habían sido levantadas en virtud de dicho acuerdo, por lo que el asunto que se dirime en la Corte esta "inextricablemente" vinculado a este, sin tener, pues, ninguna relación con el Tratado de Amistad de 1955.

Para justificar estos argumentos, señalan como "prueba" la propia nota diplomática del 11 de junio de 2018, por la que Irán pretende haber notificado a los Estados Unidos la existencia de la controversia en la que se queja expresamente "de la decisión ilícita" de los Estados Unidos del 8 de mayo de 2018, de "reestablecer las sanciones" que habían sido levantadas o dejadas de aplicarse en virtud del acuerdo nuclear. Lo mismo ocurre con la segunda nota de Irán del 19 de junio de 2018. Es más, los Estados Unidos insisten además en el hecho de que Irán nunca había denunciado la presunta ilicitud basándose en el Tratado de Amistad hasta que las nuevas medidas sancionatorias se han impuesto a causa de la retirada del acuerdo, a pesar de que dichas medidas estaban ya en vigor antes del acuerdo durante algunas décadas, sin que Irán las pusiera en duda en virtud del Acuerdo de Amistad. Otra prueba según los Estados Unidos sería el hecho de que Irán solo pone en duda ante la Corte el restablecimiento de las sanciones que habían sido levantadas en virtud del acuerdo nuclear ${ }^{169}$.

Los argumentos estadounidenses son rechazados de plano por Irán, apoyándose en la primera excepción preliminar de incompetencia, sosteniendo que la controversia sometida a la Corte cae plenamente en el campo de aplicación de la cláusula compromisaria del Tratado de Amistad, y que su demanda se refiere exclusivamente a las violaciones del Tratado de Amistad, poco importa que estén asociadas o no al Plan de Acción Conjunto, adoptadas con él o después. Desde este prisma, que el Plan de Acción Conjunto no haga referencia al Tratado de Amistad en lo que al arreglo de controversias se refiere, esto no tiene ninguna relevancia, a pesar de que el acuerdo nuclear disponga de su propio mecanismo de arreglo de controversias, pues esto no significa que este mecanismo tenga el efecto de sustraer a la competencia de la Corte cualquier controversia relativa a medidas que, formando parte del ámbito de aplicación de la cláusula que atribuye competencia a la Corte, puedan ser susceptibles también de ser vinculadas al Plan de Acción ${ }^{170}$.

Por último, Irán también rechaza el argumento estadounidense según el cual Irán no se había opuesto a las medidas objeto de la controversia antes de que se adoptara el JCPOA, ni tampoco durante su negociación, a lo que responde que sí que había protestado contra las medidas en cuestión que considera contrarias al derecho internacional, pero que corresponde a cada Estado “... to determine at what point the circumstances warrant pursuing its rights through judicial means rather than continuing only to seek a diplomatic settlement, which is what the Applicant has done in this instance by deciding the present dispute before the Court" ${ }^{\prime 171}$.

\footnotetext{
168 Alleged Violations of the 1955 Treaty..., op. cit., Párrafo 40.

169 Ibid, Párrafos 42-46.

${ }^{170} \mathrm{Ibid}$, Párrafo 49. Este fino análisis jurídico nos parece crucial para que la Cote se declare después competente. El tenor literal del párrafo 49 de la decisión de la Corte es el siguiente: "Iran adds that the fact that the JCPOA makes no reference to the settlement of disputes by the Court is irrelevant, given that the subject-matter of the dispute now before the Court is compliance with the Treaty of Amity, not the JCPOA. Although the JCPOA does in fact contain a specific dispute settlement mechanism might have the effect o removing from the jurisdiction of the Court any dispute relating to measures which, while falling within the scope of a clause conferring jurisdiction on the court, might also be relevant to the JCPOA".

${ }^{171}$ Ibid, Párrafo 50.
} 
Tras estas consideraciones, defendidas tanto por el demandante, Irán, como por el demandado, los Estados Unidos, la Corte pasa a examinar los fundamentos de las excepciones preliminares invocadas por este último y los argumentos iraníes en su contra, partiendo de la premisa de que las Partes aceptan la existencia de la controversia, pero que mantienen divergencias a la hora de saber si tal controversia debe ser resuelta interpretando y aplicando el Tratado de Amistad, como invocó Irán, o exclusivamente sobre el JCPOA, como pretenden los Estados Unidos. A este respecto, la Corte reconoce que la controversia se ha originado en un contexto político particular, como ha sido la retirada por parte de los Estados Unidos del acuerdo nuclear. Pero esto no impide en sí mismo que la controversia no esté relacionada con la interpretación y la aplicación del Tratado de Amistad, ya que ciertos actos pueden caer en el campo de aplicación de varios tratados u otros instrumentos jurídicos internacionales. Así pues, cualquier acto que pueda constituir incumplimiento de ciertas obligaciones que se puedan deducir del Tratado de Amistad, llevado a cabo por los Estados Unidos tras su decisión de retirarse del acuerdo nuclear, se pueden relacionar con la interpretación o la aplicación de dicho Tratado. Es más, incluso si fuera exacto, como lo señalan los Estados Unidos, que una decisión de la Corte que reconociera los derechos presentados en la demanda iraní, implicara restablecer la situación existente en la época en que los Estados Unidos participaban en el JCPOA, esto no significaría que la controversia tuviera que se analizada según el Plan de Acción y no al amparo del Tratado de Amistad $^{172}$. Este análisis demuestra ya el camino que va adoptando la Cote para declararse competente, rechazando así la primera excepción preliminar invocada por los Estados Unidos $^{173}$.

Rechazada la primera excepción preliminar, sin lugar a dudas la más importante, la Corte pasa a examinar la segunda excepción preliminar relativa a las medidas que conciernen sobre todo el comercio o las transacciones entre Irán y los países terceros o sus ciudadanos o sociedades, medidas que según los Estados Unidos no están relacionadas con el comercio entre el demandado e Irán, invocando que no entran en el campo de aplicación del Tratado de Amistad. Así pues, de las cuatro medidas recogidas en el párrafo 63 de la Decisión de la Corte, los Estados Unidos precisan que su segunda excepción preliminar no comprende las demandas de Irán relativas a la cuarta categoría, es decir “... The revocation of certain licensing actions related to carpets, foodstuffs, commercial passenger aircraft parts, and activities of foreign entities owned or controlled by United States natural or legal personness "174. Es decir, tan solo las tres primeras, precitadas supra, no caerían bajo el ámbito de acción del Tratado de Amistad de 1955. Y es que, según los Estados Unidos, las únicas sanciones que fueron levantadas durante el período de aplicación del acuerdo nuclear ${ }^{175}$, fueron aquellas relacionadas con los Estados terceros, sus sociedades y sus ciudadanos y, por lo tanto, han sido solo estas medidas relativas a los países terceros las que han sido restablecidas a partir del 8 de mayo de 2018 . Y lo mismo ocurre con las sanciones reestablecidas por el Decreto 13846, adoptado por Trump, que apuntan a personas que no están sometidas a la jurisdicción de los Estados Unidos. Así las cosas, para los Estados Unidos tales medidas no caen en el ámbito de aplicación de ninguna de las disposiciones del Tratado de Amistad alegadas por Irán ${ }^{176}$.

\footnotetext{
172 Ibid, Párrafo 57.

${ }^{173}$ Ibid, Párrafo 60. Antes, sin embargo, la Corte señala que como el argumento de los Estados Unidos es que las demandas de Irán en este caso, caen exclusivamente en el Acuerdo nuclear y no en el Tratado de Amistad, no ve cómo puede adherirse a esta pretensión sin desnaturalizar las demandas de Irán, tal y como han sido formuladas. 174 Ibid., Párrafo 63 in fine.

${ }^{175}$ Abstracción hecha de la cuarta categoría, es decir, "la revocación de ciertas medidas relativas a las alfombras, productos alimenticios, las aeronaves de transporte comercial de pasajeros o de piezas de repuesto, así como las actividades de entidades extranjeras pertenecientes o controladas por una persona física o moral americana".

${ }^{176}$ Se trata de los artículos IV. 1-2, V.1, VII. 1-2, VIII. 1-2, IX. 2-3 Y X.1. véanse Párrafos 64-69.
} 
Estas alegaciones de los Estados Unidos son rechazadas de pleno por Irán que señala que son "not only an invention on the part of the Respondent, but above all a concept that is misleading, since in reality all the United States' measures at issue in this case are specifically targeted at Iran an Iranian nationals and companies not at third States or their nationals and companies. Iran cites as evidence of this, in particular, the words of the Unites States Department of the Treasury of 5 November 2018, which described the measures at issue as the toughest U.S. sanctions ever imposed on Iran [which] will target critical sectors of Iran's economy" ${ }^{177}$. Es más, Irán sostiene igualmente que su demanda se basa en ciertas disposiciones del Tratado de Amistad que debe interpretarse a la luz de las reglas codificadas en la Convención de Viena sobre el Derecho de los Tratados y que, en este caso, el sentido ordinario del texto reviste una importancia primordial. Partiendo de esta premisa invita a la Corte a que se pronuncie al efecto, ya que las medidas americanas, incluidas aquellas relativas con los países terceros, tienen por objeto y por efecto "privar a las sociedades y ciudadanos iraníes de sus bienes", afectándoles en gran escala destruyendo la economía y la moneda iraní, lo que ha traído consigo que millones de personas se hayan visto arrastradas a la pobreza. Irán afirma, pues, que la Corte es competente para conocer del caso ratione materiae según el artículo XXI párrafo 2 del Tratado de Amistad, retomando así los términos utilizados por la propia Corte en el asunto de las plataformas petrolíferas ${ }^{178}$.

Desde esta perspectiva, y habiendo estudiado los argumentos de las Partes, la Corte se declara competente, no sin especificar previamente que "solo un examen detallado de cada medida en cuestión en torno a su alcance y a sus efectos podrá permitir a la Corte si afecta o no a la ejecución de las obligaciones de los Estados Unidos procedentes de las disposiciones del Tratado de Amistad invocadas por Irán, tomando en consideración el sentido y al alcance de las diversas disposiciones". Todo esto trae consigo, según la Corte, que la segunda excepción preliminar de los Estados Unidos suscita cuestiones tanto de derecho como de hecho que, si el caso se prosigue para dirimirlo sobre el fondo, es en este estadio que tales cuestiones deberán decidirse, tomando en consideración los argumentos avanzados por las Partes ${ }^{179}$. Así pues, todas las excepciones preliminares presentadas por los Estados Unidos son rechazadas por la Corte.

El asunto ante la Corte Internacional de Justicia que acabamos de comentar muestra la complejidad de las difíciles relaciones de los Estados Unidos con Irán, que como se sabe no datan de ayer. No es extraño, pues, que ciertas declaraciones hechas por Joe Biden ya en su campaña, y su política de acercamiento hacia Irán, no solo no sea vista con buenos ojos por muchos políticos estadounidenses, sino que también muchos analistas la ven como peligrosa, pues representa un cambio de rumbo importante que puede afectar a la confianza que muchos Estados tienen en la continuidad de unas políticas de Estado. Esto no quiere decir que no se puedan hacer cambios o adecuar ciertas políticas a las nuevas realidades, pero adentrarse en una dirección del todo o nada no parece que sea la mejor fórmula. A este respecto, una personalidad tan clara como la antigua embajadora de los Estados Unidos en las Naciones Unidas, Nikky Haley, ha hecho una declaración tan contundente como ésta dirigida precisamente al actual Presidente: "You'are actually hurting our friends, Israel and the Arab countries that worked with us on getting these sanctions passed on Iran that worked with us on

\footnotetext{
177 Párrafo 70.

178 Párrafo 73-74.

${ }^{179}$ Párrafos 81-84. La Corte rechaza también la excepción preliminar de los Estados Unidos según la cual las demandas presentadas por Irán constituirían un abuso de procedimiento (es decir mal fundado, frívolo o con intenciones dilatorias) así como de oportunismo judicial (Párrafos 85 y ss.), así como la excepción de inadmisibilidad de la demanda y cualquier otra excepción sobre la cual la Parte defensora puede invocar antes de que el procedimiento prosiga su curso para una decisión sobre el fondo. Estas excepciones suscitan serias críticas por parte de la Corte (párrafo 104), al sostener que los Estados Unidos sostienen una "posición contradictoria".
} 
trying to hold back terrorism... this is truly dangerous", calificándolo el plan de Biden como si fuera "litterally Obama 2.0" ", al proponer volver al acuerdo nuclear sin que Irán deje Siria, sin que renuncie al programa nuclear y de misiles, y sin detener su apoyo al terrorismo. Considera, además que levantar las sanciones a Irán implica dar oxígeno al país tras haber sido debilitado por las sanciones, impidiendo así el financiamiento de grupos terroristas. Pero no solo esto, sino que, además, las sanciones han servido para debilitar la economía iraní. También reprocha a Joe Biden el hecho de no haber llamado en las dos semanas posteriores, tras su investidura, a Netanyahu, uno de nuestros aliados más próximos. Es decir, unas críticas acerbas al nuevo presidente, aunque, como se sabe, no es la única. El hecho de no haberse puesto en contacto con Netanyahu en este período todavía se está interpretando como una falta de consideración hacia todo el Gobierno israelí, dadas las relaciones de amistad tan intensas que desde 1970, sobre todo, comparten ambos países.

\section{5. ¿Cuál será la política de Joe Biden ante el conflicto Israelo-Palestino tras los pasos dados por Trump?}

Recientemente se ha especulado considerablemente sobre qué medidas puede adoptar la administración Biden en el tema israelo-palestino, sobre todo tras los importantes pasos que ha dado Trump, como ya hemos puesto de manifiesto. Evidentemente, los hechos consumados que deja Trump, como el denominado "Acuerdo del Siglo" para sellar la paz con los palestinos, a pesar de que se esperaba que levantara tempestades en el mundo árabe y musulmán, no ha sido así, por mucho que fuera considerado por la Liga Árabe ${ }^{181}$, y también por la Unión Africana, como que ignoraba los derechos legítimos del pueblo palestino en su territorio. Además, como ya es conocido, también la Unión Europea hizo lo mismo, expresando el alto representante en materia de Política Exterior, Josep Borrell, su convicción de que el plan de paz propuesto por el entonces presidente de los Estados Unidos violaba el derecho internacional y, además, va en contra de la solución de dos Estados, instando a buscar soluciones el conflicto mediante acuerdo entre las partes ${ }^{182}$. Es decir, nada nuevo bajo el sol en boca de un Alto Representante que tiene serias dificultades para desempeñar su puesto, y que solo hace repetir una frase que es la que dicen todos, incluso los líderes israelíes, lo que demuestra que el disco duro de la narrativa europea no ha cambiado, y si en algo cambia, es a peor. Por lo tanto, la realidad sobre el terreno es la que es, con una fuerte aproximación de algunos países árabes hacia Israel, y un "enemigo" común, Irán, país que tiene unos intereses geoestratégicos y geopolíticos en la zona a los que Joe Biden tendrá que hacer frente con cierto pragmatismo y realismo, si es que quiere desempeñar el papel que le corresponde en la zona desde hace ya más de medio siglo ${ }^{183}$. Y este pragmatismo lo llevará Joe Biden, incluso con más facilidad, al caso de Marruecos, un gran aliado de los Estados Unidos, tras el reconocimiento de su soberanía por Trump sobre el territorio del Sahara Occidental, cuestión que ha sido también del agrado de Francia ${ }^{184}$, otro

\footnotetext{
${ }^{180}$ Isaac, David: "Nikky Haley: Biden 'snubbing Israel' While crying up to enemies by Iran”, World Israel News, 7 February 2021.

181 Declaración hecha por Ahmen Aboul Gheit, secretario general de la Liga Árabe, en https://www.dw.com/es/plan-de-trump-desperdicio-de-los-derechos-de-palestinos/a-52184526.

${ }^{182}$ A este respecto, véase Prieto Arellano, Fernando: "El desafío de Biden en Oriente Medio. Del Acuerdo del Siglo a los Acuerdos de Abraham y el pragmatismo de la nueva geopolítica regional", IEEE, Documento de Opinión 1\%72021, 9 de febrero de 2021. Este autor hace unas reflexiones muy interesantes sobre la situación actual en la zona, así como sobre su futuro.

${ }^{183}$ Mekelberg, Yossi: "The Role of the Arab States in Israeli-Palestinian Peace making", Chatham House, 20 February 2019, https://www.chathamhouse.org/events/all/research-event/role-arab-states-israeli-palestinianpeacemaking. De este mismo autor, "Is the Biden Presidency an Opportunity or a Threat to Israel?", Chatham House, 18 November 2020, en https://www.chathamhouse.org/2020/11/five-key-questions-bidens-middlecastpolicy.

${ }^{184}$ El Gobierno francés se felicitó rápidamente por este acuerdo, diciendo claramente que "La France se félicite de l'annonce de la reprise des relations diplomatiques entre le Maroc et Israël qui sont pour elle deux partenaires
} 
gran valedor de Marruecos, pero que rompe directamente con los principios que han mantenido las Naciones Unidas hasta ahora en relación con este territorio. En este caso, habrá que tomar en consideración la posición de Argelia, siempre vinculada a las tesis de la autodeterminación del pueblo saharaui, y su principal valedor material ${ }^{185}$.

Otras cuestiones, heredadas de la administración de Trump, también han suscitado ciertas inquietudes en torno a lo que puede hacer ahora Joe Biden. Desde esta perspectiva lo que ya está claro es que Joe Biden no va a cambiar de Jerusalén a Tel Aviv la embajada de los Estados Unidos que Trump mudó de Tel Aviv a Jerusalén. Y es que el 5 de febrero de 2021, el Senado votó por 97 votos a $3^{186}$, voto promovido por el senador Bill Hagerty, que la embajada de los Estados Unidos se quedaría en Jerusalén. A este respecto, el copatrocinador de esta enmienda, el senador Jim Infofe, declaró que "I'm proud to introduce legislation to protect the U.S. Embassy from relocation or being downgraded... It was an honour to see the U.S. Embassy to its rightful location in Jerusalem in 2018 after 20 years of bipartisan effort and Sen. Hagerty and I are clear in our efforts to ensure it stays there. Israel is a true friend to the United States and I look forward to many more years of friendship... The Trump Administration kept its promise to move the U.S. Embassy to Jerusalem, the eternal and indivisible capital of the Jews State of Israel, and it should remain there" ${ }^{187}$.

Pero si en el tema del traslado de la Embajada de Tel Aviv a Jerusalén la respuesta del gobierno de Joe Biden ha sido clara y contundente, no ha ocurrido lo mismo con el tema de la soberanía israelí sobre los Altos del Golán a la luz de ciertas declaraciones un poco ambiguas realizadas por el secretario de Estado Antony Blinken, según las cuales reconoce que son muy importantes para la seguridad de Israel, dejando al margen las cuestiones legales que plantea esta cuestión ${ }^{188}$. Esta ambigua respuesta de Antony Blinken ha tenido una respuesta clara de parte de Netanyahu, para quien "Israel's position is clear. In any future possible scenario the Golan will remain Israeli" 189 . Esta actitud tan confusa de Antony Blinken no es buena para la administración Biden, pues demuestra no solo que no sabe muy bien qué hacer con algunos temas sensibles de la zona, sino que no tiene un programa de acción claro, como tampoco lo

essentiels. Elle salue dans ce cadre, le rappel par les autorités marocaines de leur soutien à la solution des deux Etats vivant côte-à-côte dans la paix et la sécurité... Le conflit du Sahara occidental n'a que trop duré et fait rester un risque permanent de tensions, comme nous avons vu récemment à Guerguerate. La France est attachée a la recherche d'une solution politique dans le cadre de la légalité internationale. Elle est, sur cette base, favorable à une solution politique juste durable et mutuellement acceptable, conformément aux résolutions du Conseil de Sécurité des Nations unies. Dans cette perspective, elle considère le plan d'autonomie marocain comme une base de la discussion sérieuse et crédible”, en https://diplomatie.gour.fr.fr/dossiers-pays/israel-territoirespalestiniens/processus-de-paix/evenements/article/maroc-israel-q-r-extrai-du-point-de-presse-11-12-20.

${ }_{185}$ Para un estudio pormenorizado sobre el estado en el que se encuentra el tema saharaui, véase Ruíz Miguel, Carlos: "Colapso del proceso de paz en el Sahara Occidental y vuelta a la guerra", Razón Española, enero-febrero 2021, pp. 71-81. Como se sabe, Marruecos no está muy de acuerdo con la posición alemana en torno al tema saharaui reconocido por Trump, habiendo cortado cualquier contacto con Alemania, abriéndose así una crisis diplomática grave entre Marruecos y Alemania.

${ }^{186}$ Estos eran Bernie Sanders, Elizabeth Warren y Tom Carper.

187 “Landslide, Vatory:" Senate Votes 97-3 to Make US Embassy Move to Jerusalem Permanent”, United with Israel, 5 February 2021.

${ }^{188}$ Literalmente dijo: "Look, leaving aside the legalities of that question, as a practical matter the Golan is very important to Israel's security". Shindman, Paul: "Golan Will Always Remain Israeli: Netanyahu Responds Forcefully to Biden Team's Wishy-Washy Answer on Heights Sovereignty Secretary of State Dodges Question When Asked if Biden Administration Recognizes Israeli Sovereignty, Calling it a <<Legal Question >>, World Israel News, 9 February 2021. No obstante, reconoce que por ahora no está en su agenda, Antony Blinken dixit.

${ }^{189}$ Ibid. Las razones de seguridad que invoca Antony Blinken lo hace, entre otras razones, a causa del régimen de Al-Assad en Siria, a que Irán está presente en Siria, a las milicias de la zona que están apoyadas por Irán, etc., dejando caer "que, si la situación en Siria cambia, lo examinaremos en ese momento", "but we are nowhere near as that". 
tuvo Obama. Ciertas reminiscencias de este están todavía presentes en el que fuera su vicepresidente, es decir Joe Biden.

\subsection{El conflicto israelo-palestino ante la Corte Penal Internacional por :crímenes de guerra?}

El pragmatismo de Joe Biden tendrá que hacer frente también a un elemento novedoso, y que no depende de Trump, pero que podría complicar las cosas en el ámbito de las relaciones israelo-palestinas, en un contexto completamente diferente en la zona de la que heredó Trump. Se trata ni más ni menos de la decisión de la Sala de la Corte Penal Internacional del 5 de febrero de $2021^{190}$, la cual ha suscitado una fuerte oposición de países como Alemania, Australia, Austria, Brasil, Canadá, Hungría y Uganda, al no considerar que Palestina sea un Estado. A este respecto, muy clara es la declaración del ministro de Asuntos Exteriores alemán, Heiko Maas, al señalar lo siguiente: "Our legal viw won jurisdiction of the ICC regarding alleged crimes committed in the Palestine territories remains inchanged. The Court has no jurisdiction, because of the absence of the element of Palestinian statehood required by international law"191.

Esta decisión de la Corte Penal Internacional, y la decisión previamente comentada de la Corte Internacional de Justicia en torno a las sanciones contra Irán, ponen a la administración Biden en el ojo del huracán, suscitado por ciertas decisiones del anterior presidente Trump en el Medio Oriente ${ }^{192}$. Sin embargo, no parece que haya cambios significativos en el planteamiento de las cuestiones, así como en torno a sus efectos, pues los Estados Unidos han defendido firmemente, y lo siguen haciendo con Joe Biden, que Palestina no es un Estado, y que por lo tanto la Corte Penal Internacional no es competente. Pero es que, además, Israel no es Parte en el Estatuto de la Corte Penal Internacional, y sus tribunales se ocupan de las eventuales violaciones cometidas por las fuerzas del Tsahal como todo el mundo sabe, por lo que no se entiende muy bien dónde quiere ir la Corte. Desde este prisma, no le ha faltado tiempo a Netanyahu para reprochar a la Corte Penal que se trataba clara y abiertamente de una decisión antisemita, y que "we will fight this perversion of justice with all our might... When the ICC investigates Israel for fake war crimes-this is pure antisemitism”.

Esta decisión de la Sala de la Corte Penal Internacional está teniendo una cadena de serias reacciones por considerarla contraria a casi todo, tanto como un paso obstruccionista hacia los senderos de una paz duradera israelo-palestina, como un serio peligro para el mismo Derecho internacional, como lo han hecho saber públicamente varios países precitados, y no solo los Estados Unidos, así como otras entidades no estatales, como ha sido el caso de la Conferencia de Presidentes de las Mayores Organizaciones Judías Americanas que no han dudado en afirmar que "Our view is that this inflammatory action by the ICC needlessly obstructs the path to peace between Israel and the Palestinians"193. Respecto a los Estados

\footnotetext{
190 "Situation in the State of Palestine", $\mathrm{n}^{\mathrm{o}}$ ICC-01/18, 5 February 2021, en https://icc-cpicpi.int/CourtRecords/CR2021_01165.PDF.

${ }^{191}$ Harkov, Lahav: "Germany, Hungary Join States Opposing ICC Probe of Israel”, The Jerusalem Post, 9 February 2021.

${ }^{192}$ A este respecto, cabe mencionar también la controversia suscitada por el traslado de la Embajada de los Estados Unidos de Tel Aviv a Jerusalén presentada por el "Estado de Palestina contra los Estados Unidos, el 28 de septiembre de 2018, ante la Corte Internacional de Justicia. Véase Requête introductive d'instance, État de Palestine c. États-Unis d'Amérique, 28 septembre 2018, 19 p. Ver también Relocation of the United States Embassy to Jerusalem (Palestine v. U.S.). Application Instituting Proceedings 2018 ICJ (Sep. 28) en https://www.icj.org/files/case-related/176/176-2018098-APP-o1-00-EN.pdf. Para un comentario sobre esta demanda palestina, véase Bermejo García, Romualdo. "La política de Trump ante el conflicto israelo-palestino a la luz del Derecho internacional: un balance positivo”, op. cit., pp. 58-68.

${ }^{193}$ Wilkenfeld, Yoni: "ICC Decision on Israel 'Obstructs the Path to Peace' Say Top US Jewish Leaders", The Algemeiner, 12 February 2021.
} 
Unidos, el portavoz del secretario de Estado, Ned Price, ha indicado por su parte lo que siempre han defendido los Estados Unidos, es decir que “... The Court's jurisdiction should be reserved for countries that consent to it, or that are referred by the UN Security Council" 194 . Y es que estas acciones hostiles no solo quiebran los principios del Derecho internacional, sino que también perjudican considerablemente la legitimidad de la propia Corte, al ir mucho más allá del mandato que se le ha otorgado. Pero esto demuestra también una obsesión por el conflicto israelo-palestino.

Es más, esta Corte Penal deberá adoptar muchas precauciones, porque no es que tenga un buen "curriculum", sobre todo por actuar por motivos ideológicos y políticos, acusación que está en el orden del día por ciertas actuaciones de su todavía Fiscal, la gambiana Fatou Bensouda $^{195}$, cuyo mandato ha dejado sobre todo "sombras", a pesar de que se tuvo interés en poner en ese puesto a una persona africana, dadas las acusaciones que se hacían continuamente a la Corte de que actuaba sobre todo en el continente africano.

\section{2 ¿Pero es Palestina un Estado? Las tergiversaciones de la Sala en torno a este concepto}

Hechas estas consideraciones, hay un punto en la decisión de la Sala en el que nos queremos detener, que es en la "calidad de Estado", concepto al que recurre el Estatuto de la Corte sin distinguirlo del concepto de Estado tal y como se reconoce en el Derecho internacional, observación importante, que como ya hemos señalado, varios Estados no están de acuerdo, insistiendo en que Palestina no es un Estado, y que por lo tanto no puede ser Parte demandante. Pero la Sala que se ha ocupado del caso ha decidido por dos votos contra uno ${ }^{196}$, recurriendo a elementos heterodoxos para dirimir el caso, que algunas veces los tribunales penales nacionales tienen que determinar la extensión del territorio de los Estados con el fin de identificar la extensión de su jurisdicción territorial, sin que esa acción constituya realmente una determinación del ámbito de aplicación de esos Estados, basándose en el Asunto del Lotus (Francia contra Turquía), y señalando que esa jurisprudencia había sido recogida en una decisión de la Sala del 6 de septiembre de 2018, según la cual "[the] territoriality of criminal low [...] is not an absolute principle of international law and by no means coincides with territorial sovereignty... Therefore, any territorial determination by the Chamber for the purpose of defining its territorial jurisdiction for criminal purposes has no bearing on the scope of Palestine's territory"197.

Los desarrollos que se llevan a cabo posteriormente, sobre todo en torno a los artículos 19, 12 y 13 del Estatuto no responden a la cuestión de saber, tal y como se ha invocado, si “... the term 'State' should be defined in the Rome Statute in accordance with its ordinary meaning and general rules of international law governing statehood" ${ }^{198}$. A esta cuestión, la Corte señala que le corresponde saber si Palestina “... can be considered the State on the territory of which

\footnotetext{
${ }^{194}$ Ibid.

195 Decimos “todavía” porque dejará su puesto el 1 de junio de 2021, tras la victoria del británico Karin Khan, del 12 de febrero de 2021, en la que ha sido elegido para sustituirla por 72 votos de los 122 emitidos. De él se espera que redoble el blasón de esta Institución, de la que ningún Miembro permanente del Consejo de Seguridad forma parte, y "curriculum" no le falta, al ser un reconocido letrado con sobrada experiencia en causas juzgadas por Tribunales penales internacionales, como el de la ex - Yugoslavia, Rwanda, las Salas Especiales de los Tribunales de Camboya, el Tribunal Especial para Sierra Leona o el del Líbano, sin olvidar su participación en asuntos de la misma Corte Penal Internacional. Como se sabe, Fatou Bensouda, fue objeto de sanciones por el ex-presidente Donald Trump, por una investigación sobre presuntos crímenes de guerra por tropas estadounidenses en Afganistán.

${ }^{196}$ Los jueces Marc Perrin de Brichambaut y Reine Adélaide Sophie Alapini-Gansou han votado a favor, mientras que el presidente, Péter Kovács, ha votado en contra. Este último ha adoptado una opinión disidente, y el Juez Marc Perrin de Brichambaut una opinión individual.

197 Situation in the State of Palestine, ${ }^{\circ}$ ICC-01/18..., op. cit., párrafo 62.

198 Ibid, Párrafo 89.
} 
the conduct in question occurred withing the meaning of article 12 (2) (a) of the Statute"199, pero en el párrafo siguiente nos dice que ni en el Estatuto, ni en las reglas de procedimiento ni en las reglamentaciones de la Corte existe una definición del "Estado".

No obstante, en vez de acudir al Derecho internacional para tomar el concepto de "Estado", se lanza a hacer unas afirmaciones engorrosas en torno a la interpretación del artículo 12 que no tienen ningún sentido, salvo si es para apartarse del Derecho internacional, cosa que es lo que se trasluce del comportamiento de la Sala, pues el término de "Estado" figura en muchas ocasiones en el Estatuto y si se hubiera querido cambiar el concepto de Estado, tal y como se conoce en el Derecho internacional, se hubiera hecho en ese momento, y no veinte años después. Otra solución hubiera sido mencionar a los "Estados" y a otras "entidades" con unas características determinadas y precisas, pero tampoco se hizo, porque si se hubiera plasmado esta alternativa, no estaríamos hablando ahora de esta Corte, pura y simplemente porque no existiría. Y es que, si el artículo 125 del Estatuto menciona a los Estados en sus tres apartados, el artículo 126 (2) lo mismo, el artículo 12 (1) igual ¿qué clase de Estado tienen en mente los Jueces de esta Corte? De poco sirve invocar la Resolución 67/14 del 4 de diciembre de 2012 que reafirma "el derecho de autodeterminación y a la independencia del pueblo palestino", pura y simplemente porque si fuera un Estado, esas dos afirmaciones sobraban ya en su momento. Lo mismo cabe decir del reconocimiento por parte de las Naciones Unidas a Palestina como "Estado observador no Miembro", ni de la adhesión al Estatuto de la Corte Penal Internacional. Lo mismo ocurre si participa en diversos organismos onusianos, como lo han demostrado los siete Estados que como amisi curiae han defendido la tesis de que Palestina no es un Estado para los propósitos del artículo $12(2)^{200}$. De esto, la Sala se defiende señalando que sería una contradicción que se haya aceptado a Palestina acceder al Estatuto, y al mismo tiempo limitar los efectos del mismo sobre, en este caso, Palestina ${ }^{201}$.

La contradicción, difícil de entender, es aquella en la que cae la Sala cuando señala ${ }^{202}$ que "the reference 'to the State on the territory of which the conduct in question occurred' in article 12 (2) (a) of the Statute cannot be taken to mean a Sate fulfilling the criteria for statehood under general international law. Such a construction would exceed the object and purpose of the Statute and, more specifically of the persons before it. Moreover, this interpretation would also have the effect of rendering most of the provisions of the Statute, including article 12 (1), inoperative for Palestine”. Es decir, la Sala está reconociendo que Palestina no es un Estado. Es más, parece que tampoco le interesa mucho cuando dice que “... The Court is not constitutionally competent to determine matters o statehood that would bind the international community"203.

Este galimatías de argumentos contradictorios hace un flaco favor a esta Corte que está ya bastante tocada, y si el Estatuto es un Tratado, basta con recurrir al artículo 31 de la Convención de Viena sobre los Tratados, para saber que les está enviando al concepto Estado en el derecho internacional, artículo que mencionan, pero que sin embargo no van al Derecho internacional que es lo que les está señalando esa disposición en su apartado 1. Por eso su Conclusión ${ }^{204}$ no solo puede generar todavía más desprestigio a esta Institución, sino también que algunos Estados se retiren o que no recurran a ella, sin olvidar los efectos que puede tener

\footnotetext{
199 Párrafo 91.

200 Párrafo 101.

${ }^{201}$ Párrafo 102.

202 Párrafo 106.

${ }^{203}$ Párrafo 108.

${ }^{204}$ La conclusión que la Sala adopta reza así: "In light of the foregoing, the Chamber finds that, in accordance with the ordinary meaning given to its terms in their context and in the light of the object and purpose of the Statute, the reference to [t] he State on the territory of which the conduct in question occurred in article 12 (2) (a) of the Statute must be interpreted as a reference to a State Party to the Statute”. Párrafo 109.
} 
para los que estén pensando adherirse a ella. Dicho esto, y a pesar del terreno pantanoso en el que se adentra la Sala, una de sus Consideraciones finales parece demostrar que este asunto llegue al "Puerto" de Palestina, al indicar que sus conclusiones "... are limited to defining the territorial parameters of the Prosecutor's investigation in accordance with the Statute. The court's ruling is... without prejudice to any matters of international law arising from the events in the Situation in Palestine that not fall withing the Court's jurisdiction... The Court is neither adjudicating a border dispute under international law now prejudging the question of any future borders" ${ }^{205}$.

De todo esto se deduce que la Corte Penal Internacional parece que no aplica el Derecho internacional, sino el suyo propio, pero que no corresponde con el propio Estatuto, ya que cuando se habla de un "Estado" en un Tratado internacional, como es el Estatuto de la Corte, el concepto de Estado o se define qué se entiende por tal para el propio Tratado, o hay que aplicar el Derecho internacional. Pero si Palestina no es un Estado con plenos efectos, tal y como parece reconocer la Sala, dándole sin embargo ciertas prerrogativas de éste, como el de reconocerle ciertas competencias esenciales del Estado, tal aproximación viola el propio Estatuto, pues no existe ninguna disposición en el Estatuto que le permita reconocer nuevos Estados, ni otorgarles competencias típicas de los Estados. Y es que como apunta el Juez discrepante, Péter Kóvacs, esta decisión sobre Palestina no tiene base legal alguna, cuando tras analizar el camino adoptado por la Fiscal y la Sala, en donde encuentra muchas contradicciones y elementos políticos, dice: "... It follows that the lack of prospect for any successful prosecution, together with the relatively low gravity of the alleged crimes makes it clear that the initiation of an investigation in the present situation is unwarranted" ${ }^{\prime 206}$.

Conviene recalcar que el juez Kovács lleva a cabo un análisis exhaustivo del caso en sus 160 páginas de su Opinión, oponiéndose con argumentos de peso a la decisión de la mayoría, que contiene solo 60 páginas (de las cuales solo 20 están dedicadas al tema central de la Decisión). Y es que la decisión de la mayoría no aborda las cuestiones de peso que hubieran debido ser analizadas, como la cuestión de saber si Palestina es un Estado según el Derecho internacional o no. Todo esto trae consigo que, como este análisis les perjudicaba para llegar a la solución a la que se quería llegar, excluyéndola, no daban pie a reconocer la debilidad de sus argumentos. En estas circunstancias, el Juez Kovács no duda incluso en indicar al principio de su opinión que: “I find neither the Majority's approach now its reasoning appropriate ins answering the question before this Chamber, and in my view, they have no legal basis in the Rome Statute, and even less so, in public law"207.

\footnotetext{
205 Párrafo 130.

${ }^{206}$ Partly Dissenting Opinion of Judge Péter Kovács, en

https://www.icc-cpi.int/RelatedRecods/CR2015_13140.PDF, párrafo 42 in fine, el subrayado es nuestro.

${ }^{207}$ Para un exhaustivo comentario sobre esta decisión de la CPI, véase Special Report: The ICC Opens War Crimes Investigations into Israel and the IDF, Shurat Hadin Israel Law Center, en htps://mcusercontent.com/3e7e2c5a9ce/7856/f4b1195a01/files/2ab4be3a-9446-4916-9464-

$6102 \mathrm{f} 867069 \mathrm{c} / \mathrm{The}$ ICC_brief_paper_Last_draft_3.pdf. Entre los comentarios que aquí se recogen, y que compartimos plenamente, están los siguientes: “Kovac' makes several very important observations: First, Palestine's state hood was not at all (and is still not) a settled issue within the United Nations: Most of UN resolutions still note the need to settle the issue of Palestinian statehood and territory. Moreover, the majority's referral to UN resolutions selective-sometimes ignoring parts of the same resolution. Second, for Kovac, the focal point of the discussion is not the validity of the accession to the Rome Statute, but rather the legal character of the territory falling (potentially) under the jurisdiction of the ICC. Third, responding to the argument of the issue of neither state contesting the Palestine accession, Kovacs writes that this does no preclude considerations of particularities or special circumstances in situations following accession if such consideration is required to resolve an actual problem. The principle of 'effectiveness' cannot preclude the prosecutor's arguments as to the Palestinian statehood are based on assumptions, not legal analysis... Fundermore Kovacs rejects the Majority's
} 
El autor de estas líneas ya se pronunció en su día sobre la cuestión de saber si Palestina era o no un Estado, respondiendo de forma contundente por la negativa ${ }^{208}$. Y es que, en toda esta Opinión disidente, el Juez Kovács va desgranando los peligrosos senderos que va recorriendo la Sala considerando que ciertos hechos son graves, según el artículo 8.2 del Estatuto al no interpretarlos, como debe hacerse, en el marco del Derecho internacional y del Derecho internacional de los conflictos armados, incluyendo, como es lo propio, el Derecho internacional de los conflictos armados en el mar, tal y como lo establece el Segundo Convenio de Ginebra de $1949^{209}$. Dicho de otra forma, la Sala se alejó de las normas jurídicas para introducir elementos políticos, siguiendo así los pasos de la Fiscal. Se intenta así hacer de la expresión de "Estado de Palestina" algo popular, aunque sea una "fake news" 210 . Es evidente que esta decisión parece también una "Fake News" desde el punto de vista jurídico, en la que se aplica además un doble rasero evidente, que es lo que ha hecho la Fiscal Fatou Bensouda y dos Jueces de esta Sala, pero que no nos extraña viendo la trayectoria política de la Fiscal. Desde esta perspectiva, solo nos cabe esperar que llegue cuanto antes el mes de junio, y que el nuevo Fiscal que ha sido elegido sea mejor que el actual, lo que no será tan difícil.

\subsection{Reacciones a la decisión de la Sala de la Corte Penal Internacional}

La decisión de la Sala de la Corte Penal Internacional no solo causa extrañeza, sino que ha sido interpretada como guiada por motivos políticos en un amplio espectro de la sociedad israelí, pero también de otros países, sobre todo los Estados Unidos. Y es que, con decisiones como esta, la Corte Penal Internacional no solo genera más desconfianza en ella, y eso que ya hay mucha, sino que además amenaza a la paz en todo el Medio Oriente ${ }^{211}$.

Ante esta situación, dos corrientes se han alumbrado como respuesta a seguir ante la decisión de la Corte, decisión que todos consideran nefasta y peligrosa. Para los primeros, la mejor forma de hacer frente al Tribunal es cooperar para defenderse así mejor de las acusaciones. Tal es el caso de Yossi Beilin, un conocido político israelí, con responsabilidades ministeriales en algunos Gobiernos israelíes, quien es partidario de que Israel coopere con la Corte. Y reprocha al primer ministro Benjamin Netanyahu la frase según la cual la decisión de la Sala es "the expression of pure anti-Semitism but rather a war on anti-Semitism... Instead of seeing every judicial decision as an existential threat, Israel must present a united front with the US. If an investigation is opened, cooperate with the court, and explain everything there is to explain...”. Y Beilin señala además que el hecho de que los Jueces de la Sala hayan decidido, dos contra

opinion, according to which the Court is not 'constitutionally' qualified to assess the issue of Palestinian statehood. In his opinion, the court is entitled and even required to revie the specific situation".

${ }^{208}$ Véase Bermejo García, Romualdo: “¿Es Palestina un Estado? Reflexiones a la luz del Derecho internacional y de la práctica europea sobre los acontecimientos recientes en torno al reconocimiento de un Estado palestino", Revista de Estudios Europeos, no 65 (2014), pp. 9-40; y "El futuro de Israel y Palestina tras el reconocimiento de esta como 'Estado Observador' no miembro en las Naciones Unidas”, Revista Española de Derecho Internacional, vol. 65, n⿳ 1 (2013), pp. 262-369 (en colaboración con Carlos R. Fernández Liesa). Idem, "Cuestiones claves del Próximo y Medio Oriente”, en: Gutiérrez Espada, Cesáreo y Cervell Hortal, Ma José (dir.) (2016): La Unión Europea como actor global de las relaciones internacionales: retos y problemas seleccionados, Valencia, Tirant lo Blanch, pp. 9-122.

209 Ibid. Párrafo 41.

210 Véase a este respecto, Frisch, Hillel: Is the Phrase "State of Palestine" Catching on? The Begin-Sadat Center for Strategic Studies, BESA Center Perspectives Paper n ${ }^{\circ}$ 1931, 15 February 2021. Para este profesor de estudios políticos en la Universidad de Bar-Ilan, "Mah Abba's efforts to create an dura of statehood through name changer have been successful, especially among Palestinian and the wider Arabic-speaking public. But it takes more than a name to achieve statehood".

${ }^{211}$ Kemp, Richard: “The International Criminal Court Threatens Middle East Peace", Gatestone Institute, 11 February 2021, en https://www.gatestoneinstitute.org/17051/international-criminal-court-threatens-peace. Este autor señala que "The International Criminal Court (ICC) has long had its sights on what it not doubts considers an unholy trinity: Israel the US and Britain... These are the three western democracies most active in using legitimate military force to defend their interests". 
uno, que tienen jurisdicción para abrir una investigación contra Israel, no significa en sí mismo que sean criminales de guerra, pura y simplemente porque el fiscal tiene la autoridad y el derecho de abrir la investigación. Sin embargo, contra esto un "Israel democrático es lo suficientemente fuerte para hacer frente a las acusaciones ${ }^{212}$.

Otros, sin embargo, piensan que es mejor que Israel luche contra la Corte Penal Internacional, pues el Estado judío no debe permitir que el Tribunal socave su seguridad en sí mismo respecto a la justicia fundamental que sustenta su causa. Tal es el caso de Dore Gold, antiguo Embajador de Israel ante las Naciones Unidas, quien justifica esta actitud al contemplar que los movimientos de la Corte son en relación con Israel, y sobre todo con la fiscal Fatou Benseuda, políticos ${ }^{213}$. Y es que este autor se sorprende de que la fiscal Fatou Bansouda emitiera un comunicado diciendo que no podía hacer nada con el denominado Estado Islámico a pesar de los numerosos informes que señalaban las ejecuciones masivas, torturas de todo tipo y condición y destrucción de propiedades religiosas, sin olvidar las acusaciones de genocidio que se hicieron contra los Yazidíes. Esto, sin contar con el hecho de que hubo muchos voluntarios de Estados europeos, todos ellos Estados parte en el Estatuto de Roma, que caían claramente bajo el ámbito competencial de la Corte. Evidentemente, si hubiera habido voluntad de castigar los crímenes de lesa humanidad y de guerra, podía haber actuado con facilidad contra él, pero guardó silencio y no actuó. Y es que, su voluntad política estaba ausente en este caso, pero ya estaba pensando en el otro, es decir, Israel. Lo mismo cabe decir de la declaración que hizo en relación con el grupo Boko Haram, según la cual creía que había cometido crímenes de lesa humanidad en Nigeria, Estado que es Parte desde el 27 de septiembre de 2001, fecha en la que ratificó el Estatuto de Roma.

A esta actitud de rechazo a la Corte se suma también Abraham Cooper, del Centro Simon Wiesenthal, quien considera que la decisión de la Sala va más allá de una simple decisión judicial, al señalar lo siguiente: "Now the ICC's illegal decision to recognize the non-existent state of Palestine and to investigate Israel for possible 'war crimes' means the opening of a new front in the war against the world's largest Jewish community. It also guarantees a tsunami of colloquia at law schools and articles in legal journals attacking Israel"214.

En estas circunstancias, no es extraño que Netanyahu se considere ultrajado por la decisión de un Tribunal que considera antisemita y lleno de hipocresía, al señalar lo siguiente: "The decision of he International Court to open an investigation against Israel today for war crimes is absurd. It's undiluted antisemitism and the height of hypocrisy... without any jurisdiction, it decided that our brave soldiers, who take every precaution to avoid civilian casualties against de worst terrorists in the world who deliberately target civilians, it's our soldiers who are war criminals... We will never stop fighting this injustice. We will speak the

\footnotetext{
212 Beilin, Yossi: "Israel Should cooperate with the ICC", Israel Hayom, 2 December 2021, en https://www.israelhayom.com/opinions/cooperating-with-the-icc-to-fight-for-justice/.

213 Gold, Dore: "Israel Should Fight Back", Jews New Syndicate, 14 February 2021, en https://www.jns.org/opinion/israel-must-fight-back-against-the.icc/.

214 Cooper, Abraham: "The ICC Opens a New Front in the War Against Israel. Why We Must Fight", Jewish Journal, 9 February 2021, en https://jewishjournal.com/commentary/332735/the-icc-opens-a-new-front-in-thewar-against-israel-why-we-must-fight/. Es más, este autor, asociado del Centro Wiesenthal, reprocha a la Corte en general de ser culpable “... of a whopping double standard; its goal is to Demonize Israelis by hanging the sign 'war criminals' around their necks (read Nazis) for defending themselves from mass murderers; and to Delegitimize Israel's political leadership by isolating the Jewish state in the International Community and the facto keeping key leaders from traveling around the world... Exaggerating, you say? I feel like we have been to this rodeo before".
} 
truth in every forum, in every country, on every stage until this outrageous decision is reversed and become null and void"215.

Pero al margen de estas cuestiones en torno a la competencia de la Corte, el camino que ha elegido suscita una serie de cuestiones que no aborda en el fondo de su análisis, lo que revela su escaso interés en aclarar ciertos temas, lo que es un síntoma de arbitrariedad. Desde esta perspectiva, puede haber asuntos escabrosos, como que la Corte Penal Internacional considere ahora que el Kibbutz Kfar Etaion y la comunidad judía residente en el barrio judío de Jerusalén, Sheik Jarrah, que fueron desplazados violentamente en la Guerra de la Independencia de 1948, tras haber sido expulsados de sus viviendas volviendo a esas mismas tierras tras la Guerra de los Seis días, estén ahora en peligro de que puedan ser considerados como criminales por vivir en donde siempre vivieron. El tema de estas viviendas está en el punto de mira de la comunidad internacional, al ser una de las razones utilizadas por los árabes en los disturbios en el Monte del Templo y en Jerusalén, a pesar de que son viviendas cuyos títulos de propiedad revelan que las familias judías son las propietarias. Es más, los árabes que han vivido en ellas desde 1948, nunca han pagado un alquiler por su uso una vez que los israelíes retoman la zona en 1967 tras la toma de Jerusalén en la Guerra de los Seis Días. A esta cuestión se han referido precisamente diferentes personalidades de la administración Biden, pidiendo que no se los desaloje a pesar de las decisiones judiciales adoptadas al respecto por los tribunales israelíes.

Sin embargo, todavía está pendiente el tema de la población turca transferida desde Turquía a la zona Norte de Chipre ocupada en 1974, a pesar de que Fatou Bensouda se haya comprometido a adoptar una decisión sobre esta cuestión antes del 16 de junio, es decir, antes de que deje su puesto en la Corte Penal Internacional. Conviene tener presente que la demanda palestina para que interviniera la CPI data de enero de 2015, mientras quela primera reclamación presentada por un oficial chipriota data de julio de 2014. Desde esta perspectiva, no está nada claro lo que motivó a Fatou Bensouda a examinar primero la situación israelopalestina. Decimos no está claro, porque hasta el 16 de febrero de 2021, no se sabía si es que iba a plantear el tema chipriota o no. Y es que, durante siete años, la actual Fiscal ignoró completamente las demandas y advertencias que se le hicieron llegar sobre esta cuestión, cosa que es extraña, aunque conociendo su curriculum, no es tan chocante ${ }^{216}$.

Los problemas que se suscitan con esta decisión son de tal calado que levantará bastante polvareda, tanto dentro como fuera de la Corte, y dependiendo de la solución que se dé al caso, "somuera le glas" para esta Institución o no. La Corte se ha adentrado en un terreno pantanoso del que será difícil que salga bien parada, pues el sinuoso recorrido que ha tenido, ha traído consigo accidentes graves que solo se pueden evitar, enderezándolo o pura y simplemente cambiar de ruta.

El Gobierno israelí ha rechazado de plano que haya cometido "crímenes de guerra", indicando lo siguiente: "In addition to totally rejecting the claim that Israel commits war crimes, Israel reiterates its in equivocal position that the Hague Tribunal has no authority to open an investigation against it”. Declaración hecha el 8 de abril de $2021^{217}$. Es más, para el

\footnotetext{
${ }^{215}$ Isaac, David: "Undiluted anti-Semitism: Netanyahu Outraged at ICC for Investigating Israel”, World Israel News, 3 March 2021.

${ }^{216}$ A este respecto, véase Bob, Vomah Jeremy: "ICC Prosecutor to Decide Cyprus File Before Exist", The Jerusalem Post, 18 February 2021. Respecto a Turquía en relación con el traslado de población a Chipre, véase. BOB, Vomah Jeremy. "ICC Prosecutor to Decide Cyprus File before Exit. Case Could Have Implications for Israeli Settlement", The Jerusalem Post, 18 February 2021.

${ }^{217}$ Para más detalles, véase "Israel Reject, ICC Probe into IDF 'War Crimes', Saying it Lacks Jurisdiction”, World Israel News, 8 April 2021. Ver también, Krauss Joseph: "Israel Rejects ICC Probe, Saying it Lacks Jurisdiction”, The Washington Post, 8 April 2021. Para unos comentarios sobre esta cuestión y la posición francesa al respecto, un país que no se ha unido a otros Estados que se han opuesto a la investigación de la CPI, véase Hershco, Tsilla. Israel-France Relations in Light of the ICC Decision, 8 April 2021.
} 
primer ministro israelí, Netanyahu, que está en funciones tras las elecciones del 23 de marzo de 2021, “... L’ingérence du Tribunal est dépourvue de toute base légale et contrevient aux objectifs pour lesquels elle a été établie. L'Etat d'Israël est attachée à l'état de droit et continuera d'enquêter sur toute accusation portée contre lui, quelle qu'en soit la source, et espère que la cour s'abstiendra de violer son autorité souveraine... Les soldats de Tsahal se battent avec une moralité suprême contre les terroristes qui commettent de nouveaux crimes de guerre tous les deux jours, c'est Israël que le Tribunal de La Haye a décidé de condamner. Il n'y a pas d'autre mot pour décrire cela que l'hypocrisie" 218.

Tan categórico como Netanyahu ha sido Benny Ganz, ministro de Defensa en la actualidad y comandante en jefe de las fuerzas armadas del Tsahal durante la Operación "Margen Protector" de 2014 contra Hamás en Gaza, quien no solo ha considerado que la decisión de la CPI de investigar los supuestos crímenes israelíes es "Blind and in just", sino que piensa que “... the truth will come to light”. Es más, piensa que la decisión de la Corte dañará las relaciones con los palestinos, y empeorará la situación en la zona. Y es que para Benny Ganz, no se trata pura y simplemente de un asunto "... of the court's 'technical-legal' lack of jurisdiction, but a matter of justice and morality, of a strict military ethical code, of truth and falsehood, of a democratic state with strong legal institutions, clear values rules and lawsagainst a blind and in just decision" 219 .

La decisión de la CPI ha tenido también una fuerte reacción del Primer Ministro británico Boris Johnson, quien después de reconocer abiertamente su fuerte apoyo en general a esta Institución, ha señalado que "We oppose the the ICC's investigation into war crimes in Palestine... we do not accept that the ICC has jurisdiction in this instance, given that Israel is not a party to the Statute of Rome and Palestine is not a sovereign state... this investigation gives the impression of being a partial and prejudicial attack on a friend and ally of the $U K '{ }^{\prime \prime 220}$.

Por otro lado, la decisión de la Corte Penal Internacional ya ha tenido ciertos efectos en las relaciones israelo-palestinas, como lo demuestra el hecho de que Israel ha retirado el estatus VIP al ministro de Asuntos Exteriores palestino, Riyad al-Maliki, por su apoyo a la investigación de la Corte en relación con los alegados crímenes de guerra de Israel. El ministro fue detenido en el paso fronterizo entre Jordania y Cisjordania, al haber revocado el "Shin Bet" el estatus VIP que poseía. Y es que Al-Maliki volvía de La Haya en donde había mantenido un encuentro con la Fiscal Fatou Bensouda, con la que ha mantenido una plena cooperación. Este hecho constituye la primera sanción que Israel adopta contra un Oficial de la Autoridad Palestina a causa de la investigación ordenada por Fatou Bensouda de investigar los alegados crímenes de guerra israelíes ${ }^{221}$. Esta sanción ha sido aprobada por el primer ministro Netanyahu, y el director del Shin Bet, Nadar Argaman, se ha entrevistado con el presidente palestino Mahmoud Abbas para explicarle estas medidas, como medidas de retorsión contra los intentos palestinos de explotar a toda costa la Corte Penal Internacional contra Israel ${ }^{222}$.

\footnotetext{
218 "Netanyahu: Israël ne vas pas <<coopérer〉> avec la CPI". The Times of Israël, 9 avril 2021.

219 “Gantz: ICC's Probe Into Israel's Alleged War Crimes Blind and Unjust”, The Algemeiner, 9 April 2021. Estas declaraciones fueron hechas en i24 News.

220 Keyser, Zachary: "UK Notes Opposition to ICC probe Into Alleged Israeli War Crimes", The Jerusalem Post, 14 April 2021.

221 The Algemeiner, 21 March 2021. Ver también "Israelis Retaliate Against Palestinian Minister for ICC Move", en https://www.axios.com/israelis-retaliate-against-palestinian-minister-for-icc-move-12219f08-Oe46-47eq93od-9fd7da22ef96-html.

${ }^{222}$ Ver también “Aviv Kochavi comdamne l'enquéte de la Cour pénale internationale”, The Times of Israël, 22 mars 2021.
} 
Sin embargo, los Estados Unidos, a pesar de que se oponen a que la Corte investigue sus acciones militares en Afganistán, invocando como Israel que no es Parte en el Estatuto, han dado con la administración Biden pasos significativos que difuminan su oposición a la Corte en relación con Israel al haber retirado las sanciones adoptadas por Donald Trump contra altos funcionarios de este Tribunal, incluida la Fiscal Fatou Bensouda ${ }^{223}$. No obstante, los Estados Unidos continúan objetando los esfuerzos que la Corte está llevando a cabo para abrir una investigación contra el personal de los Estados Unidos en Afganistán ${ }^{224}$. Si a esto añadimos que la administración Biden quiere dar una serie de ayudas económicas, y lo que ellos denominan de asistencia humanitaria ${ }^{225}$, sin olvidar la reapertura de la misión diplomática palestina en Washington para reactivar la solución de dos Estados, y también para deshacer lo que hizo Trump, nos encontramos con que la administración Biden está haciendo un doble juego muy similar a lo que hizo Barak Hussein Obama, con el que fue vicepresidente. Inútil de señalar que esta actitud de doble juego de Joe Biden está minando la confianza que tradicionalmente ha existido entre ambos Estados, descontando, por supuesto, la época del presidente de Obama, como ya hemos comentado. No parece, sin embargo, que le va a resultar fácil a Joe Biden, pues para algunas decisiones de esta índole se requiere una mayoría de dos tercios en el Senado de la que no dispone. Es más, cuenta con una oposición dura republicana muy activa al ser consciente de que lo que quiere es deshacer lo que hizo Trump, ni más ni menos ${ }^{226}$.

Esta situación y otras similares están planteando problemas a Joe Biden, ya que, si se reprochaba a Donald Trump sus malas formas en algunos aspectos, no parece que él sea un buen ejemplo, como se le está notando, al calificar a Putin de "asesino", lo que ha suscitado ira, y al mismo tiempo chistes y mucha mofa, en Rusia. Como se sabe este insulto dio la vuelta al mundo $^{227}$. Y es que, si esta actitud poco amigable y chabacana de Joe Biden es la que va a adoptar durante su mandato, es muy posible que los Estados Unidos se arrepentirán un día de la agresividad de su presidente, en la que nunca cayó Trump. Algo similar, aunque sin llegar a eso, ha sido la entrevista que han mantenido en Anchorage (Alaska), el 18 de marzo de 2021, el secretario de Estado, Antony Blinken, y el consejero de Seguridad Nacional, Jack Sullivan, con el ministro de Asuntos Exteriores chino, Wang Yi, y el más alto responsable del partido comunista chino, Yang Jiechi. Los reproches han sido mutuos, y mientras que Antony Blinken ha acusado a China "de amenazar la estabilidad mundial", las dos personalidades chinas le han reprochado la amenaza de sanciones por parte de los Estados Unidos tras la intervención de China en Hong Kong, así como sus injerencias en los asuntos internos chinos ${ }^{228}$. Todo parece indicar que la administración Biden se rodea de "buenos amigos" al mostrarles los músculos

\footnotetext{
223 "United States Imposes Economic Sanctions and Visa Restrictions on International Criminal Court Officials" (Contemporary Practice of the United States Relating to International Law, Eichensehr Kristen Ed.), American Journal of International Law, vol. 115, issue 1 (2021), pp. 138-140.

${ }^{224}$ Danoti, Jessica. "Biden Administration Ends Sanctions Against ICC Officials, Overturning Trump Policy", The Wall Street Journal, 2 April 2021.

225 "Biden Administration Crafting Plan to Reset US Ties with Palestinians: Sources", The Algemeiner, 3 March 2021.

${ }^{226}$ Para unos comentarios sobre esta cuestión en Israel, véase Auerbach, Jerold. "President Biden: Israel's Friend or Foe?", The Algemeiner, 11 April 2021; y Cohen, Ben. "America Has Made a Serious Mistake on UNRWA", Idem, Berkowitz Adam, Eliahu. "Republicans Block Biden \$150 Million to Palestinians", Israel365 News, 11 April 2021. Una de las razones que invocan para denegarlo es que la Autoridad Palestina utiliza millones de estas ayudas para pagar a los terroristas en la cárcel, y no para el bienestar del pueblo palestino. Y esto lo hacen al considerarlos mártires, lo que está prohibido por la Taylor Force Act, firmada por el presidente Trump el 23 de marzo de 2018. Y es que, durante el último año de la Administración Obama, los Estados Unidos dieron 600 millones de dólares a la Autoridad Palestina, y desde 1993, 6.300 millones de dólares fueron entregados a los palestinos con el fin de que avanzaran en la capacidad de construir un Estado, por un lado, y distanciarlos del terrorismo, por otro. No parece que se haya conseguido ni lo uno ni lo otro.

227 “Joe Biden quelifie Poutine de <<tueur〉>, la Russie rappelle son ambassadeur", Le Temps, 18 mars 2021.

228 Graffenried de Valérie : "Washington ne cède rien face à Pékin”, Le Temps, 19 mars 2021.
} 
americanos, aunque esta estrategia ya se sabe que no podrá ir muy lejos. Y es que, si Joe Biden piensa arrodillar a Rusia y que le obedezca China, está cometiendo un error de bulto, cuyas consecuencias pueden ser muy graves para todos. Este error ya lo cometió Obama con Rusia, y no le fue bien, al negar a Rusia un estatuto de igualdad, considerándola como una simple Potencia regional que amenazaba sus vecinos no por la fuerza que tuviera, sino por su debilidad $^{229}$

\section{6. ¿Qué hará la administración Biden a la luz de estas circunstancias en la zona?}

Los pasos que está dando la administración Biden en su política en torno al Medio Oriente no deja de suscitar ciertos temores en algunos analistas árabes, según los cuales Joe Biden está llevando a cabo actos poco amistosos en relación con sus aliados árabes, mientras que al mismo tiempo apacigua a los enemigos. Y esto, comentan, es el caso con Arabia Saudí, pero también con otros países árabes del Golfo, como los Emiratos Árabes Unidos y Bahréin. No saben a ciencia cierta si es producto solo del asesinato del periodista Yamal Khashoggi, o si hay algo más, aunque se pronuncian más por esto último. Este es el caso del periodista sirio Abduljalid Alsaeid, quien piensa que oficiales de la antigua administración Obama que forman parte ahora de la administración Biden están intentando dañar las relaciones entre los Estados Unidos y Arabia Saudí. La razón que apunta es que "The wing of former President Barak Obama among the Biden team considers itself in a state of hostility with Saudi Arabia because of the Kingdom's diplomacy that succeeded in persuading former President Donald Trump to withdraw from the ill-fated nuclear deal... The Obama wing inside the ruling Democratic Party accepts the Iranian regime and turns a blind eye to Iran's terrorism in Syria, Iraq, Yemen and Lebanon”. Pero es que ahora, además, estos Estados del Golfo se oponen a que los Estados Unidos vuelvan al acuerdo nuclear. En este sentido, y solo por estos hechos, Alsaeid reconoce que Biden “... has the right to talk about America's democratic values, but why have these values not been expanded to hold Hezbollah accountable for the recent killing of [anti Hezbollah Lebanese publisher] Loqman or the slaughter of thousands of thousands of Syrians by pro-iranian groups?" ${ }^{230}$. Otro analista egipcio, Emad El Din Adeeb sostiene que la administración Biden está "rewarding Iranian despotism while punishing Saudi Arabia”"231.

Otros analistas que examinan los detalles de por dónde puede ir la Administración Biden, parten de la premisa de que se está intentando legitimizar la Autoridad Palestina con el fin de conseguir que la existencia de un Estado palestino sea una realidad lo más pronto posible. Uno de estos signos son las presiones que se están ejerciendo al recurrir a proyectos, declaraciones y otras acciones políticas que van en esa dirección, aunque no se vean con precisión su alcance en la actualidad. Y es que la Administración Biden está volviendo a poner el tema palestino en el epicentro de sus preocupaciones, a pesar de que la Autoridad Palestina abandonó las negociaciones que estaban manteniendo con los israelíes, siendo primer ministro Ehud Olmert, en el primer mandato de $\mathrm{Obama}^{232}$. Desde esta perspectiva, cabe mencionar el tema de las elecciones palestinas tras quince años transcurridos desde que tuvieron lugar las últimas. Tanto es así que ya, a mediados de enero del 2021, el presidente palestino Abbas anuncia que habrá elecciones parlamentarias el 22 de mayo de 2021. Pero ¿por qué en este momento y por qué con tanta rapidez? "Very simple, the Biden Administration wants to lay the foundations for a Palestinian state in disregard of Israel's opposition, and there is no better

\footnotetext{
${ }^{229}$ Allgöwer, Marc : "Joe Biden, la forme et le fond", Le Temps, 19 mars 2021.

${ }^{230}$ Toameh, Abu Khaled: “Arabs Warn Biden: We Do Not Want Another Obama”, United with Israel, 4 March 2021.

231 Ibid.

${ }^{232}$ Sobre estas negociaciones, véase Bermejo García, Romualdo y Pozo Serrano, Pilar: Una tierra dos Estados: Análisis jurídico-político del conflicto árabe-israelí, op. cit., pp. 340 y ss.
} 
way to present the State-on-the-way as truly democratic than to have 'all sectors of the Palestinian people' take part in elections-that is even Hamas" ${ }^{233}$.

Pero hay otras dos cuestiones que pueden ser vistas como que algo se está moviendo en la mente de Joe Biden. La primera es Hamás, cuyos líderes tuvieron su época de gloria durante los dos mandatos de Obama, pero que fueron abruptamente excluidos por Trump, pero que ahora están retornando a la Casa Blanca. Prueba de ello es que el 20 de febrero de 2021, Abbas envió una carta oficial a Washington en la que se indica que las organizaciones palestinas, incluida Hamás, deberían crear un Estado palestino basado en las líneas de 1967 (es decir, la Línea Verde) con capital en Jerusalén-Este. Que Hamás y la Autoridad Palestina propongan ahora este planteamiento, cuando Hamás sigue proclamando un Estado palestino desde el Jordán hasta el Mediterráneo, es bastante paradójico. La segunda cuestión atañe a una "Declaración de Libertades", vía Decreto Presidencial, con el fin de reforzar las libertades públicas en ese futuro Estado palestino. La idea de recurrir a las elecciones como medio de legitimación puede venir de Washington. Y la tercera es que los que hacen que Hamás siga existiendo son los "Hermanos Musulmanes", cuyos líderes de esta organización en los Estados Unidos son poderosos y tuvieron unas relaciones muy importantes con la Administración Obama durante sus dos mandatos. Pero Trump los excluyó de venir por la Casa Blanca, y ahora están volviendo con una fuerte influencia en la Administración Biden, que los considera aptos para resolver el conflicto. De ahí que la Autoridad Palestina los haya incluido en las elecciones.

Habrá que ver cuánto dura esta luna de miel entre los dos bandos palestinos, aunque lo que parece claro, es que ambos bandos tienen las puertas abiertas en Washington. Estas ideas de Mordechai Kedar ${ }^{234}$ no se sabe si prosperarán o no, ya que el avispero palestino tiene muchos lugares recónditos. No obstante, interpreta en nuestra opinión correctamente una situación en la que Joe Biden se está enfangando sin saber a ciencia cierta si podrá salir airoso o no, porque lo que tiene enfrente no es baladí, por mucho que Joe Biden se crea que tiene al mundo árabe a sus pies, y que le seguirán los pasos. Eso pensaba también en gran medida Barack Obama, y se estrelló, tanto en sus relaciones con los países árabes al ritmo de sus "Primaveras", como con Israel, al contemplar como Benjamin Netanyahu se le colaba en el Congreso de los Estados Unidos, y sin su autorización, para dar el famoso discurso del 3 de marzo de 2015 en ausencia del presidente Obama, pero consiguiendo que el Congreso se pusiera en pie ${ }^{235}$.

$\mathrm{Ni}$ que decir tiene, que los ataques de los Estados Unidos sobre objetivos iraníes en el noreste de Siria, el 26 de febrero de 2001, han supuesto un marco de confianza entre la administración Biden e Israel, no solo por los ataques en sí, sino porque Israel ha sido informado de los ataques previamente ${ }^{236}$. Este ataque estadounidense era la respuesta al ataque que el 15 de febrero de 2021 llevaron a cabo en Erbil, capital del kurdistán iraquí, en el que murió un contratista civil hiriendo además a un ciudadano americano que prestaba servicio. Este ataque estadounidense revela que, a pesar de que Joe Biden fue vicepresidente con Barack Obama, quizás no sea del todo Obama, un temor que estaba presente en muchos analistas israelíes. No obstante, habrá que ver si ocurren otros acontecimientos similares o no. Y es que Israel se ha prodigado en los últimos tiempos en llevar a cabo ataques en la misma zona contra las milicias apoyadas por Irán, incluyendo las milicias de "Kataib hezbolláh" y las de "Kataib Sayyid al-

\footnotetext{
${ }^{233}$ A este respecto, véase. Kedar, Mordechai: Toward a Palestinian State? The US Confers Legitimacy on the Palestinian Authority and Hamas, The Begin-Sadat Center for Strategic Studies, Besa Center Perspectives Paper $\mathrm{n}^{\mathrm{o}}$ 1,949, 5 March 2021.

234 Ibid.

${ }^{235}$ A este respecto, véase. Bermejo García, Romualdo: "La Política de Trump ante el conflicto israelo-palestino a la luz del Derecho internacional: un balance positivo", Anuario Español de Derecho Internacional, vol. 37 (2021), pp. 9-70, pp. 10-21.

${ }^{236}$ A este respecto, véase "Israel 'very pleased' with US strikes on Iranian targets in Syria, was Informed in Advance", The Algemeiner, 26 February 2021.
} 
Shuhada", que actúan en los límites fronterizos entre Irak y Siria. La respuesta del ministro sirio de Asuntos Exteriores ha sido de condenas de estos ataques, indicando que se supone que “... The Biden Administration is supposed to stick to international legitimacy, not to the law of the

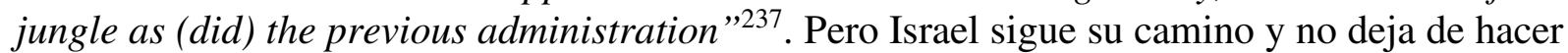
frente a Irán abiertamente tanto en el caso de su programa nuclear como con sus "proxies" situados en Líbano, Siria o Gaza ${ }^{238}$. Sobre estos temas, Benny Ganz ha dicho lo siguiente "The Iranian Nuclear escalation must be stalled. If the world stops them before, it's very much good. But it not, we must stand independently and we must defend ourselves by ourselves" ${ }^{239}$. Por lo tanto, Netanyahu y su ministro de Defensa Benny Gantz van en este tema de la mano ${ }^{240}$.

Por otro lado, la cooperación de Israel con los países árabes en materia antiterrorista ha dado un paso de gigante tras los Acuerdos de Abraham, a pesar de que Irán está buscando el momento, ya lo ha intentado, de dar un buen golpe en cualquier parte del mundo. En la India ha sido acusada de querer perpetrar un ataque contra la Embajada de Israel, y el 15 de febrero de 2021, las autoridades etíopes detuvieron a 16 personas, sospechosas de llevar a cabo un ataque contra la embajada de los Emiratos Árabes Unidos en Addis Abeba. Las autoridades etíopes también han acusado a la célula terrorista iraní de planificar un ataque contra la embajada de los Emiratos también en Sudán. África es el continente considerado como principal objetivo, y los agentes que quieren cometer los atentados son algunos de ellos de doble nacionalidad iraní y de otros Estados europeos ${ }^{241}$.

\section{Pero a Joe Biden le estallan las crisis: Nada de elecciones en Palestina, pero sí guerra de Israel con Hamás}

Algo se barruntaba en el siempre complicado y complejo ajedrez del Medio Oriente, pero no tanto como estamos viendo en estos días. En realidad todo se le ha venido encima al presidente Biden: las elecciones palestinas no han tenido lugar por diversas razones, y una guerra entre Hamás e Israel tal y como se ha iniciado tampoco, aunque esto último se veía venir tras los graves disturbios ocurridos sobre todo durante el Ramadán, y los cohetes que de vez en cuando eran lanzados por Hamás sobre el Sur de Israel para aterrorizar a la población y para mostrar que el enemigo de los sionistas está ahí hasta echarlos al mar como prevé la Carta de Hamás. Respecto a las elecciones solo queremos decir que Joe Biden ha utilizado la teoría de los dos Estados de la que es partidario, al menos así lo propugna, sin darse cuenta de que Palestina no existe ni como Estado ni como otra entidad más o menos homogénea, ya que hoy en día tenemos dos entidades bien diferenciadas: la Autoridad Palestina, que administra ciertas competencias en Cisjordania (Judea y Samaria) tal y como están recogidas en los Acuerdos de Oslo; y Gaza, gobernada y controlada militarmente por la Organización, para muchos terrorista, de Hamás, de la que Israel se retiró en 2005. Esta retirada fue decidida, como se sabe, por Ariel Sharon, aunque encontró una fuerte oposición en el Likud liderada por Netanyahu. Las elecciones

\footnotetext{
${ }^{237}$ Ibid.

${ }^{238}$ A este respecto, véase. "Israel Reveals Iranian Target Map we are ready to fight", World Israel News, 6 March 2021.

239 Ibid.

${ }^{240}$ Ver también Shindman, Paul : "IDF Updating Preparations to Strike Iran Ready to Fight Ourselves", World Israel news, March 5, 2021 ; "Gantz affirme que l'armée reste prête à toute attaque de sites nucléaires d'Iran", The Times of Israel, 5 mars 2021, en el que se recoge la afirmación de Benjamin Netanyahu siguiente : "Je ferai tout ce qui est en mon pouvoir pour empêcher l'Iran de se doter de l'arme nucléaire, et jusqu' à présent: nous y sommes pourvenus". Y refiriéndose a Joe Biden en una entrevista concedida a Fox News, Netanyahu señaló : "Une chose que je crois qu'il comprend et respecte, c'est qu'en tant que Premier Ministre du seul et unique Etat juif nous n'allons pas laisser un groupe d'ayatollahs nous effacer de la surface de la Terre ou nous rayez de la Carte de l'histoire". Esta actitud dura de Netanyahu le ha llevado a él mismo a querer delegar las discusiones sobre Irán a sus cuadros superiores en distintos aspectos con el fin de evitar una viva tensión personal entre él y Joe Biden.

${ }^{241}$ Fard, Erfan: Israeli Intelligence Cooperation with Arab Allies Thwarts Iranian Terrorism, Begin-Sadat Center for Strategic Studies, 8 March 2021.
} 
estaban previstas para el 22 de mayo, pero el presidente de la Autoridad Palestina, Mahmud Abbás las ha suspendido "hasta que se pueda votar en Jerusalén-Este".

Hamás, sin embargo, considera que la suspensión ha sido un "golpe de Estado" que viola flagrantemente lo acordado en El Cairo, y que se han suspendido porque Abás, de 85 años, ha visto que perdería las elecciones, lo que implicaba que Hamás se haría con el Gobierno, también en Cisjordania. Esto, que lo sabía Israel y pensamos que también Joe Biden, no ha impedido a éste apoyar las elecciones, pensando que, como no había habido elecciones desde 2006, apoyarlas ahora le convertiría en una especie de "Libertador" del pueblo palestino, echando además por tierra el famoso "Plan de paz del Siglo" elaborado por la Administración Trump ${ }^{242}$. Estamos, pues, ante una serie de crasos errores de Biden y de su Administración, ya que además todo esto se hacía con una cierta displicencia hacia Israel. Por lo tanto, una acción en la que Biden había puesto todo su empeño, se desmorona por sí sola, sin que él, que quería democratizar al pueblo palestino y presentarlo al mundo como uno de los pilares para convertirlo en un Estado democrático, se derrumba como un castillo de arena. Y es que hay una narrativa que no corresponde a la realidad en torno al deseo palestino de crear su propio Estado. Esto no sería un gran problema si es que quisieran sellar la paz a la que se comprometieron en los Acuerdos de Oslo. Sin embargo, tanto en las listas de Hamás como en las del Frente Popular de Liberación de Palestina, grupo marxista-leninista, se anuncia, cada uno a su manera, expulsar a la entidad sionista. Evidentemente, esto no cuadra con las tesis de Biden, y sin embargo ha propiciado desde el principio estas elecciones que, al final, la Autoridad Palestina viene de anularlas $^{243}$.

Sin embargo, a pesar de la complicada situación que se vivía a nivel interno israelí, desde que el 13 de abril comenzaran los graves disturbios en la Explanada de la Mezquita/Monte del Templo, hasta ahora nunca tan graves, hacía presagiar malos augurios. Estos disturbios se trasladarían después a la Puerta de Damasco, de Jerusalén, a la que empezaron a acudir también grupos judíos extremistas a enfrentarse con los árabes, terminando estos enfrentamientos expandiéndose a otras ciudades mixtas israelíes como Lod, Acre, la zona de Nazareth, Jaffa, cerca de Tel Aviv, etc., algo por otro lado nunca visto, al menos con esa intensidad. Si a esto añadimos, la suspensión de las elecciones por parte de Mahmud Abás, y el desalojo por la Corte Suprema israelí de cuatro familias de Sheik Jarrad, en Jerusalén-Este ${ }^{244}$, Hamás ha encontrado el momento adecuado para iniciar el lanzamiento de cohetes y misiles sobre Jerusalén y el Sur de Israel, así como sobre el Centro del país, desatando evidentemente una contundente respuesta israelí, al amparo del Derecho de legítima defensa. Esta guerra es ya la cuarta desde que Hamás gobierna la Banda de Gaza desde 2007, expulsando del territorio a los partidarios de FATAH, es decir del Frente de Liberación de Palestina. Desde entonces, Israel ha tenido con esta en la que nos encontramos ahora cinco guerras: lluvia de verano ( 28 de junio26 de noviembre 2006); la denominada Operación Plomo Fundido (27 de diciembre 2008; 8 de enero 2009); la del Pilar Defensivo (14-21 noviembre 2012); la del Margen Protector (8 julio26 agosto 2014) y la actual, Guardián de los Muros (10-21 mayo 2021) ${ }^{245}$. En todas ellas, Israel

\footnotetext{
${ }^{242}$ Jeremberg, Batya. "PA Gloats as Biden Team Returns to Old Peace Formula: The Deal of the Century is Dead", World Israel News, 28 January 2021.

${ }^{243}$ Para unos inteligentes comentarios sobre esta cuestión, cfr. Toamed, Khaled Abu. Palestinian Elections: What the Biden Administration Does Not Want to Know, Gatestone Institute, 30 April 2021. De este mismo autor, Biden Administration to Support Palestiniam Dictator-Ship, Gatestone Institute, 17 April 2021, en donde se reprocha a la Autoridad Palestina imponer severas restricciones a las organizaciones cívicas palestinas, para poder ejercer su labor. Se habla incluso de auténtica represión sobre las ONGs locales.

244 Sobre este desalojo, véase supra.

${ }^{245}$ Al margen de estas grandes cinco operaciones militares, hay que apuntar también la "Operación Cinturón Negro", que duró 72 horas, y en la cual fue eliminado el jefe de la Jiad Islámica en la Banda de Gaza Baha Abu al Ata, con un número indeterminado de terroristas, así como importantes infraestructuras de esta organización terrorista. Se calcula que murieron en torno a unos 36 palestinos. El jefe la Jiad Islámica fue atacado mientras
} 
ha invocado el derecho a defenderse ante un ataque armado, tal y como está recogido en el artículo 51 de la Carta de las Naciones Unidas, formando parte obviamente del derecho consuetudinario $^{246}$.

Conviene destacar la actitud tímida, por no decir de rechazo, que Joe Biden ha mantenido frente a la actual crisis que Israel está teniendo tanto a nivel interno ${ }^{247}$ como con Hamás en Gaza, que demuestra un casi abandono de su principal aliado en la zona. Esta actitud está suscitando serias críticas a nivel interno estadounidense, sobre todo por parte de los republicanos, aunque es lo que se esperaba de él, un personaje nebuloso y al mismo tiempo algo soberbio que lo único que proclama es una solución de dos Estados, sin que por el momento haya hecho grandes esfuerzos para convencer a las partes con el fin de encontrar alguna solución, sino solo de criticar lo que hizo Trump. Este no es el camino a seguir, a pesar de que tenga en el propio partido demócrata dos tendencias muy netas en relación con Israel y Palestina, algo que ya se ha apuntado ${ }^{248}$. Este abandono se ve claramente en que tan solo ha sido el 12 de mayo de 2021, cuando el ya conocido Antony Blinken, secretario de Estado, ha anunciado nombrar un "enviado especial" a la zona, es decir, una vez que se había desatado el conflicto con Hamás, cuando ya los ha nombrado para Irán, Libia y Yemen. Es más, solo una vez que ha visto la intensidad del conflicto a causa de la cantidad de cohetes y misiles lanzados por Hamás y la Jihad Islámica sobre Israel, se ha pronunciado al respecto, indicando que "Israel tiene el derecho a defenderse cuando se lanzan sobre su territorio millares de cohetes y misiles"249. Sin embargo, a pesar de este posicionamiento claro en este aspecto del Derecho internacional, reconociendo el derecho de legítima defensa de Israel, todavía no había nombrado ni Embajador ni Cónsul General en Israel. Esto era chocante para los dos mejores aliados en el Medio Oriente, por eso, tras el cese el fuego, Biden ha colmado esta anomalía, aunque solo en parte, ya que, en efecto, el 22 de mayo ha decidido nombrar un alto oficial de

dormía en su casa acompañado con otros miembros del Grupo, de ahí que el primer ministro Benjamin Netanyahu pronunciara esa famosa frase de que "nuestros enemigos han recibido el mensaje. Podemos alcanzar a cualquiera, incluso en sus camas. Espero que esta lección se haya aprendido". Véase "Israel will end attacks if the captures soldier is released", en

http://www.irishexaminer/irishexaminer/pages/story.aspx-qqqg=world-qqqm=world-qqqa=world=qqq.d=7409$\mathrm{qqqx}=1$.asp. El mensaje original en inglés fue el siguiente: "I take personal responsibility for what is happening in Gaza. I want no one to sleep at night in Gaza. I want them to know what it feels like.

${ }^{246}$ Como se sabe, estos conflictos armados, desencadenados todos ellos por Hamás, no existirían sin el apoyo financiero y técnico de Irán, así como del apoyo financiero de Catar que es el que paga los destrozos causados por las guerras, al menos hasta ahora. Para más comentarios sobre este tema, cfr. Toameh, Abu Khaled. "Guerra de Gaza, guerra de Irán", Gatestone Institute, 18 de mayo de 2021. Como apunta este experto, "si no fuera por la ayuda financiera y militar de Irán, los grupos terroristas palestinos no serían capaces de atacar a Israel con miles de cohetes y misiles. Como sus patronos en Irán, Hamás y la YIP (Jiad Islámica) no reconocen el derecho a Israel a existir y están comprometidos con su destrucción”.

${ }^{247}$ Sobre las causas de esta crisis a la luz de las revueltas árabes en ciertas ciudades de Israel, cfr. Karsh, Efraim. Israel's Arabs v. Israel, The Begin-Sadad Center, BES Center perspectives Paper $\mathrm{n}^{\circ}$ 2039, May 14, 2021. Parte de este estudio ya se publicó en Commentary Magazine en diciembre 2003, analizando los orígenes y las causas de las revueltas palestinas en apoyo de Yasser Arafat que se produjeron a partir de octubre de 2000. El autor compara esta situación, que sería el origen de la Segunda Intifada, con los actos violentos producidos sobre todo en las últimas semanas de abril-mayo 2021. No conviene ignorar que es Irán el que financia, arma y entrena a Hamás en Gaza, lo mismo que hace con Hezbolláh. Para más detalles, cf. May, Clifford D. “The Islamic Republic's War on Israel", The Algemeiner, May 19, 2021.

${ }^{248}$ Joffe, Alex. Gaza and the War Between the Democrats, The Begin-Sadad Cente for Strategic Studies, BESA Center Perspectives Paper $n^{\circ}$ 2041, May 16, 2021. Las acerbas críticas, llenas de odio, lanzadas contra Israel por el ala progresista del partido, como Ilhan Omar, de origen somalí, Rashida Tlaib, nacida en los Estados Unidos en el seno de una familia palestina, y Alexandria Ocasio-Cortez, de origen puertorriqueño, están ahí para demostrarlo, de ahí que esta última dijera contra Biden, tras haber este reconocido el derecho a defenderse de Israel que "The president stated that Israel has a right to self-defense. Do Palestinians have a right to survive?"

${ }^{249}$ De Coraffenried, Valérie. "La timide posture de Joe Biden face à Israël”, Le Temps, 13 mai 2021. Ver también Hachuel, Vera: Tres en Uno con Israel, no 2999.8, 17 May 2021; Idem nº 3000.8, 17 May 2021. 
Obama, Michael Ratoney, lo que está bien, pero por lo que se apunta, el nuevo Embajador ha participado de forma activa en los grupos que han intentado desbancar a Netanyahu ${ }^{250}$. En los próximos meses, y si Netanyahu continúa en el Gobierno, veremos, casi seguro, alguna diatriba entre uno y otro, como pasó con Obama. Esto no ha impedido, sin embargo, que los Estados Unidos hayan frenado en tres ocasiones una Declaración común desfavorable para Israel, a pesar de que era defendido por los Miembros europeos del Consejo de Seguridad de las Naciones Unidas, salvo el Reino Unido, es decir Estonia, Francia, Irlanda y Noruega. Ni que decir tiene que esta actitud de la Casa Blanca ha sido criticada expresamente por Donald Trump, acusándole de abandonar a sus aliados.

Hay otros muchos aspectos en los que Biden no ha estado a la altura de lo que se podría esperar. En efecto, si como se ha apuntado ha reconocido "el derecho a defenderse de Israel", en el mismo momento ha señalado que "... The Palestinian people also have de right to safety and security just as israelis do". En realidad, nadie ha dicho lo contrario, pero para eso no deben apoyar el terrorismo ni a los terroristas, cosa que hoy por hoy, y desde hace ya mucho tiempo, no es así. En este contexto, no es extraño que esta respuesta haya sido considerada como "ridícula". Tal es el caso de Eytan Gilboa, experto en la política estadounidense en el Medio Oriente, quien ha responsido a la frase de Biden como “... the most ridiculous and counterproductive statement any American administration would make on violence initiate by two terror organizations supported by Iran against a U.S. ally". Y es que recalca, además, como algo obvio que no haya habido "one Word about Hamas or Islamic Jihad". Es más, señala que al poner como uno de los focos de atención lo que ocurre con unas cuantas viviendas en el barrio de Sheikh Jarrad, y no en Hamás, trae consigo que se interprete como un incentivo hacia organizaciones terroristas como las que actúan en Gaza. Esto ya lo hizo Obama, y parece que su antiguo vicepresidente le es completamente fiel ${ }^{251}$.

Sin embargo, al hilo de cómo se desarrollaban las hostilidades, hay que reconocer que la Administración Biden ha salido de ese mutismo cómplice, haciendo declaraciones contundentes. Este es el caso cuando se le ha preguntado si la respuesta israelí al lanzamiento de misiles era "desproporcionada", aspecto este último en el que suelen coincidir en general muchos Estados europeos. La respuesta ha sido clara, indicando que no le parece que ha habido una "significant overreaction", a lo que ha añadido lo siguiente: "The question is how we get to a point where - they get to a point where there is a significant reduction in the attacks, particularly the rocket attacks that are indiscriminately fired into population centers" 252 . En esta misma línea se ha pronunciado el secretario de Estado, Antony Blinken quien, preguntado sobre la disparidad de bajas de israelíes y palestinos, respondió diciendo que hay una diferencia muy clara entre Hamás, una organización terrorista, que está enviando misiles de forma indiscriminada hacia Israel, de hecho, atacando a civiles, y la respuesta israelí que es defensiva, centrándose en los terroristas que están bombardeando Israel, y evitando causar daños civiles ${ }^{253}$.

\footnotetext{
250 "Biden Sends ex - Obama Official to Israel as Acting Ambassador", World Israel News, 22 May 2021.

${ }^{251}$ Para más detalles sobre estos aspectos, véase. Kasnett, Israel. "Biden is Failing Mideast Test, Response is 'Ridiculous', Analyse Say", United with Israel, 13 May 2021.

252 Biden Says Israel Hasn't Overreacted to Gaza Rocket Attacks", en

https://bloombergquint.com/polities/biden-says-israel-hasn-t-overreacted-to-gaza-rocket-attacks.

${ }^{253}$ Estas respuestas de Blinken se han dado en el momento que se presentaba un Informe sobre la libertad de religión, respuestas que no dejan lugar a dudas, al transcribirla del inglés: "There is first a very clear and absolute distinction between a terrorist organization, Hamas, that is indiscriminately raining down rockets - in fact, targeting civilians - and Israel's response defending itself that is targeting the terrorist who are raining down rockets on Israel”. "Secretary Antony J. Blinken on Release of the 2020 International Religious Freedom Report", Remarks to the Press, en https://www.state.gov/secretaryt-antony-j-blinken-on-release-of-the-2020-internationalreligious-freedom-report/. Desde otra perspectiva, hay analistas que sostienen que vencer a Hamás en el tablero
} 
Pero no es solamente Biden el que ha tardado en reaccionar, no se sabe si por cobardía o convicción. Tenemos en este sentido el mansaje lanzado por Boris Johnson en twitter diciendo lo siguiente: "I'm urging Israel and the Palestinians to step back from the brink and for both sides to show restraint. The UK is deeply concerned by the growing violence and civilian casualties and we want to see an urgent d-escalation of tensions". Se nota que el primer ministro británico quiere guardar una equidistancia entre el agresor y el agredido, lo que refleja una tendencia muy generalizada de muchos gobiernos británicos en relación con este conflicto israelo-palestino desde el Mandato británico sobre la zona, durante el cual el Reino Unido no estuvo, como se sabe, a la altura de las circunstancias. Y es que comparar en este caso, Hamás, organización terrorista, con Israel es un insulto a la inteligencia. Y esto lo sabe, pues su país tiene tras de sí una auténtica lucha contra un grupo terrorista. Esta clase de análisis confunde a la opinión pública, y más que "desescalar" el conflicto puede revigorizarlo, al dar a Hamás un oxígeno que no se merece. Esto no es una exclusividad británica, pues muchos países europeos, no todos, se prestan a este juego peligroso ${ }^{254}$, pues con estas actitudes ambos contendientes, el que se defiende y el que agrede, se encuentran en el mismo $\operatorname{saco}^{255}$. Y esto a pesar de que la comunidad internacional de la época de la Administración Bush presionó a Israel a retirarse de Gaza en 2005, prometiendo no solo el reconocimiento del derecho de legítima defensa en caso de ataques armados, sino también la legitimidad internacional para hacerlo. Sin embargo, Israel parece que solo recibe reproches de "potencia ocupante" y de cometer crímenes. Así las cosas, es evidente que la única desescalada del conflicto es llevando a cabo la obligación que tiene Israel y sus fuerzas armadas de proteger a sus ciudadanos.

Hay que reconocer que en estas circunstancias se comprenden ciertas peticiones hechas por ciertos senadores y congresistas republicanos, una de las cuales consiste en cesar las discusiones con Irán en torno al levantamiento de las sanciones y el asunto nuclear iraní. Desde esta perspectiva, el Senador Marco Rubio ha indicado no comprender por qué se está debatiendo con Irán levantar las sanciones cuando es Irán el principal responsable de que Hamás lance los misiles sobre Israel. En la carta dirigida al presidente Biden, que ha sido firmada por la casi totalidad de los Senadores republicanos, se pide que Washington no contribuya de ninguna manera a enriquecer a los enemigos de Israel. Y es que esto es hoy en día de conocimiento público, una vez que el jefe de Hamás, Ismael Haniyet haya reconocido oficialmente lo que todo el mundo sabe pero que no proclama, como es que Irán es el que provee de recursos

del Medio Oriente no es solo algo que atañe a Israel, sino en general a todos los países árabes. Para más detalles, véase Stephens, Bret: "For the Sake of Peace, Israel Must Rout Hamas", The New York Times, 13 May 2021, en https://www.nytimes.com/2021/05/13/opinion/gaza-hamas-israel.html.

Atrás se quedan ciertas declaraciones de Bernie Sanders, también del partido demócrata, que ha censurado abiertamente "the irresponsible actions of government-allied right-wing extremists in Jerusalem", u otras similares de la también demócrata Rashida Tlaib, cuyas opiniones van en la dirección de que Israel es un Estado racista que practica el apartheid, etc. sin añadir ni una palabra de condena para Hamas.

${ }^{254}$ Como señala Gabriel Albiac, nunca habrá que olvidar que "en el corazón del mar de las teocracias, Israel es una isla de libertad. Europa lleva decenios negándose a entenderlo. En este tiempo que ve la regresión continua de la libertad europea, un país que nació en guerra hace 73 años, y que en guerra sigue, ha logrado perseverar sin abolir jamás libertades ciudadanas", Albiac, Gabriel: "Israel, Israel...", ABC, 13 de mayo de 2021.

${ }^{255}$ Precisamente ha sido esta actitud la que ha suscitado reacciones como la de Stephen Daisley, cuando en relación con esta declaración de Boris Johnson, señala lo siguiente: "Both sides. Hamas does not seek the infidel's praise. It just needs a score draw with the Zionist enemy which is what the UK government and most governments across the West are happy to give it. The pretence of equivalence between the IDF and a Kill-the-Jews terror gang would be offensive if it weren't so risible. Not just because Israel wields far superior fire power (in physical, if not diplomatic, artillery), but because the values of Hamas and the values of Israel don't exist in the same moral universe. Israel at its worst guarantees civil equality and religious freedom even to those who riot for its destruction, to the extent of arresting Jews who try to pray at Judaism's holiest site while facilitating worship and pilgrimage by Muslims from the Palestinian authority and elsewhere. If it's Israeli apartheid you're looking for, take a hike up Temple Mount”. De este autor, "Don't compare Israel to Hamas", The Spectator, 14 mai 2021, en https://www.spectator.co.uk/article/don-t-compare-israel-to-hamas. 
financieros y de armas a Hamás para poder atacar a Israel. Y a pesar de esto, dicen, el equipo de negociadores de Joe Biden se encarga de apaciguar a las partes en las negociaciones de Viena sobre el Acuerdo nuclear para dar a Irán millares de millones de dólares que le permitirán dotarse del arma nuclear ${ }^{256}$.

A esta tesis, Antony Blinken responde categóricamente que no tiene nada que añadir sobre la implicación o no de Irán en lo que ahora está pasando en Gaza “... Mais dans la mesure où il s'agit de l'une des activités malveillantes dans lesquelles l'Iran peut ou non s'être engagé... cela ne fait que souligner à quel point est important que nous fassions tout ce que nous pouvons pour nous assurer que l'Iran ne se procure jamais d'arme nucléaire". Y es que para el secretario de Estado "Un Iran avec une arme nucléaire ou la capacité d'un avoir une à très court terme est un Iran qui est encore plus susceptible d'agir en toute impunité en ce qui concerne ces autres actions,"257.

Las actividades militares continuación a pesar de las llamadas de cese el fuego procedente de Egipto, de las Naciones Unidas y de otros muchos Estados y ONG's ${ }^{258}$. Por su parte, Israel decidió continuar con los ataques al considerar el ministro de Defensa, Benny Ganz, que el ejército israelí tiene todavía millares de objetivos que atacar en la Banda de Gaza, de forma que "... No person, area or neighbourhood in Gaza is immune. We have thousands of more attack targets that are only further accumulating. The IDF has many plans to continue striking Hamas and the fighting won't stop until we bring about complete and long-term calm... The international community also needs to understand that it was the Hamas terror group that opened fire and that is continuing to fire indiscriminately toward civilian populations, and it bears responsibility and is paying the price" "259. A esto ha hecho alusión también Netanyahu en su conversación con Biden, diciéndole que "Israel was determined to complete the operation's goal of restoring security to israeli citizens". Esta fue la respuesta a la afirmación que le dio Biden cuando le dijo que él apoyaba un alto el fuego, y que el Tsahal estaba haciendo las cosas muy bien, refiriéndose a que estaban atacando a objetivos terroristas ${ }^{260}$.

\footnotetext{
256 "Républicains à Biden : cessez les discussions, avec l'Iran, sautien du Hamás", The Times of Israël, 13 mai 2021. Hay que apuntar que hay demócratas sensatos que no están contentos con Irán y su comportamiento en el Medio Oriente en los diversos frentes en los que participa directa o indirectamente. Tal es el caso del Senador Chris Murphy, que en un encuentro con el embajador iraní ante las Naciones Unidas, Majid Takht-Ravanchi, le ha pedido claramente “... la necessité pour les iraniens de s'engager sérieusement et dans les meilleurs délais dans les négociations sur le nucléaire, d'exercer des pressions sur les Houthis pour mettre un terme à la guerre du Yémen, de recommander à Hamas d'accepter un cessez-le-feu et de mettre un terme aux attaques à la roquette visant Israël...”. Magid, Jacob : “Un Démocrate US exhorte l'envoyé d'Iran à convaincre le Hamas de cesser les tirs", The Times of Israël, 19 mai 2021.

${ }^{257}$ Magid, Jacob : "Pourquoi Blinquen refuse de mettre fin aux pourparlers nucléaires avec l'Iran", The Times of Israël, 14 mai, 2021.

${ }^{258}$ Es evidente que este conflicto, como los anteriores, está causando unos destrozos considerables que no esperaba Hamás, por eso lleva ya días instando directa e indirectamente un cese el fuego. Margit, Maya: "Hamas Dealt Blow 'Surprised' by Israeli Response, Analysts Say”, Jewish Journal, 19 May 2021.

${ }^{259}$ Ahronheim, Anna y Kayser, Zachary: “Two Thai Workers Killed in heavy mortar barrage on Israel's south from Gaza", The Jerusalem Post, 18 May 2021. Ver también, Harkov, Lahav. "Ganz to Austin: IDF to continue Gaza campaign to achieve long-term quiet", Ibid.

260 "Netanyahu Warns Biden: Israel Calls the Shots in War with Hamás, Not US", United with Israel, 18 May 2021. Ver también Magid, Jacob. "Biden s'entretient avec Natanyahu et se dit "favourable à un cessez-le-feu", The Times of Israël, 18 mai 2021. Sobre las presiones de Biden a Netanyahu para que este acepte el cese el fuego, véase “Netanyahu Rebuffs Biden's Call for Immediate 'De-escalation' in Gaza”, The Algemeiner, 19 May 2021. En contra del cese del fuego se han pronunciado también los residentes de las comunidades israelíes cercanos a la Banda de Gaza hasta que cesen los lanzamientos de cohetes y misiles, así como la devolución de los prisioneros. A este respecto, véase. Kerstein, Banjamin. "Residens of Israel's South Reject Ceasefire with Hamas Until Rocket Fire Quelled, Prisoners Returned", The Algemeiner, 19 May 2021.
} 
Quizás lo que más sorprende en estos conflictos armados que Israel tiene y ha tenido con Hamás es el no reconocimiento de la estrategia que está siguiendo Israel para derrotar al terrorismo de Hamás y cómo se está respetando el Derecho Internacional Humanitario, a pesar de las numerosas voces que algunos divulgan sin conocimiento de causa, como señala el Coronel británico Richard Kemp ${ }^{261}$, indicando con toda firmeza lo siguiente: "This masterpiece of tactical synchronisation, with all its complex elements, symbolises the IDF's precision attack during this campaign, Operation Guardian of the Walls, which have already inflicted damage from which Hamas will not recover for years. The IDF learnt many lessons from previous engagements in Gaza and since 2014 have vigorously collected intelligence and worked to develop battle plans and technological solutions to deal with Hamas and their Palestinian Islamic Jihad bedfellows". Señala esto tras iniciar su estudio afirmando lo que es evidente, pero que muchos lo ignoran o no quieren reconocerlo, advirtiendo que "Hamas is no match for the IDF and could be quickly and much more cheaply defended by blunt and crushing military force were it not for one thing-the israeli need to minimise loss of civilian law. Hamas know that".

Estas tensiones entre la administración Biden e Israel están produciendo una cierta fractura en el seno del partido demócrata que no se limita a los tres congresistas ya citados, Ilhan Omar, Rashide Tlaib y Alexandria Ocasio-Cortez, más Bernie Sanders, sino que 29 senadores demócratas se pusieron de acuerdo para adoptar un comunicado común exigiendo un alto el fuego inmediato entre Israel y Hamás, criticando además la postura expectante de Joe Biden. En este tema, es evidente que el senador Bernie Sanders es un destacado antiisraelí y sobre todo antiNetanyahu, al señalar que “... nous ne pouvons plus faire l'apologie du gouvernement de droite de Netanyahu et de son comportement antidémocratique et raciste" 262 . Esta fractura, que no era esperada, a pesar de las divisiones evidentes existentes en el partido, no se debe solo a este conflicto de Israel con Hamás, sino que también es producto de las políticas que adopta la administración Biden en ciertos ámbitos, como es el deseo de Biden de levantar las sanciones a Irán para poder volver al acuerdo nuclear, cuando se sabe que el principal aliado de los Estados Unidos en el Medio Oriente, Israel, es atacado por Hamás, una organización terrorista respaldada por Irán ${ }^{263}$.

No parece, sin embargo, que el conflicto se extiende por el Norte, abriendo un segundo frente en la frontera libanesa, a pesar de que algún grupo descontrolado sí que ha lanzado seis cohetes que han caído no sobre suelo israelí, sino sobre el propio Líbano y en las aguas territoriales libanesas, como ha apuntado el Tsahal israelí. Todo apunta a que Hezbolláh no ha olvidado la guerra de 2006, ni los efectos que tuvo sobre el Líbano, con muchos ataques sobre las infraestructuras del país. Ahora la situación que padece el país no está como para desencadenar otra guerra, pues tanto Hezbolláh como el Líbano saben muy bien, lo que les

\footnotetext{
${ }^{261}$ Para un análisis de lo que está ocurriendo en Gaza a la luz del conflicto armado que se está desarrollando ahora, cfr. Kemp, Richard. Trumpets and Tank Engines: A Turning Point in Gaza? Gatestone Institute, 16 May 2021. El autor ha sido coronel en el ejército británico y director del equipo sobre terrorismo internacional del gabinete del Reino Unido.

${ }^{262}$ Para más detalles, véase De Graffenried, Valérie. "Violences au Proche-Orient, la fracture démocrate aux EtasUnis", Le Temps, 18 mai 2021.

${ }^{263} \mathrm{La}$ actitud de Biden en relación con Irán encierra una política de apaciguamiento que acarrea una serie de consecuencias muy peligrosas para todo el Oriente Medio. Kasnett, Israel. "Former Secretary Pompeo Blasts Biden Team for 'Folly' of Appeasing Iran”, United with Israel, 23 May 2021. MAJID. As Iran's Mullahs Incite Hamas Terrorism, Biden Administracion Wants Sanctions Lifted, Gatestone Institute, 18 May 2021. Y es que, como se ha señalado por un grupo de 40 senadores, en una carta al Presidente Biden, publicada en Newsweek, 12 May 2021, "The United States engaging in active negotiations with Iran and potentially providing billions of dollars in sanctions relief will no doubt contribute to Iran's support of Hamas and other terrorist organizations who attack Americans and our allies. We call on you to immediately end negotiations with Iran, and make clear that sanctions relief will not be provided".
} 
esperaría en ese caso, ya que las advertencias al Líbano han sido muy claras de la respuesta militar que podría llegar en ese caso ${ }^{264}$. Pero el conflicto armado con Hamás puede que no sea el definitivo a la luz de lo que ha ocurrido con los anteriores, salvo que se hagan grandes progresos políticos en la zona. Por eso no faltan analistas que se dan ya por satisfechos si en el futuro hay cinco años de calma tras la contienda ${ }^{265}$.

\section{El alto el fuego del 21 de mayo de 2021: ¿Ni vencedores ni vencidos?}

Tras presiones de algunos estados, como los Estados Unidos, Francia, Egipto, Jordania, , y, sobre todo, por parte de las Naciones Unidas que, como siempre con Israel, actúa de forma bastante particular, e incluso arbitraria ${ }^{266}$, las partes en el conflicto aceptaron el alto el fuego a las 2 de la mañana del día 21 de mayo, sin que se hayan producido violaciones, al menos por el momento $^{267}$. El Gabinete israelí ya lo había aprobado el jueves día 20 por unanimidad, una vez que el primer ministro Benjamin Netanyahu y el ministro de Defensa Benny Ganz lo respaldaron. Esta decisión fue transmitida a los mediadores egipcios, que han desempeñado en esta crisis un papel importante. Israel ha considerado que la "disuasión" se ha restablecido una vez más sobre el terreno, aunque habrá que ver por cuanto tiempo.

Todos los medios internacionales se han hecho eco de la noticia tras 11 días de combates y bombardeos, aunque Israel no se ha adentrado con sus tropas terrestres en Gaza. La Banda ha sido objeto de serios ataques ${ }^{268}$ por parte sobre todo de los aviones de combate israelíes, como ha sido el caso de los ataques contra el denominado "Metro" de Gaza, en el que han participado 160 aviones de combate (12 escuadrones) destruyendo en una hora en torno a $100 \mathrm{~km}$ de túneles bien preparados para distintas funciones como protección de los combatientes, depósitos de armas, etc. ${ }^{269}$.

Lo que es obvio es que una vez más la superioridad militar y tecnológica israelí se ha impuesto sobre el terreno, lo que ha permitido que las bajas civiles en Gaza sean muy pocas en relación con la intensidad de los ataques, debido sobre todo a los avisos dados anteriormente a los ataques de que los objetivos iban a ser atacados ${ }^{270}$. En estas cifras no están los milicianos que hayan muerto en los túneles a raíz de esos ataques masivos de los 160 aviones de combate israelíes que tuvieron lugar el 13 de mayo, gracias a una cuidada operación muy bien sincronizada a nivel de inteligencia, vigilancia y conocimiento de las tácticas del enemigo, sorpresa y golpes de fuerza precisa en un pequeño espacio de tiempo, sin olvidar el uso que se hizo para engañar al enemigo. La operación se forjó ordenando el Estado Mayor una movilización importante de reservistas que fueron concentrados en la frontera con tanques, numerosas piezas de artillería y vehículos blindados. Esta concentración de fuerzas fue

\footnotetext{
${ }^{264}$ A este respecto, ver las declaraciones de Benny Gantz en relación con Hezbolláh y el Líbano, advirtiendo que el Líbano temblará si Hezbolláh ataca Israel: "Lebanon Will Tremble if Hezbollah Attacks, Warns Israel", United With Israel, 21 February 2021.

${ }^{265}$ Este es el caso de Gross, Judah Ari. "Tsahal : Le conflit será une <<réussite〉> s'il apporte $<<5$ années de calme >”, The Times of Israël, 19 mai 2021.

${ }^{266}$ Basta con examinar las declaraciones del secretario general, Antonio Guterres, para darse cuenta de ello, mencionando las víctimas que se producían en Gaza, pero no las israelíes, e ignorando los misiles de Hamás y de la Jiad Islámica quienes fueron los que desencadenaron el conflicto armado.

${ }^{267}$ Sobre el cese el fuego, véase. Kerstein, Benjamin. "Israelí Cabinet Approves Ceasefire, Potentially Ending Gaza Operation Against Hamas; IDF Believes Goal, Have Been Achieved”, The Algemeiner, 20 May 2021.

${ }^{268}$ Sobre esta cuestión, cfr. Wrobel, Sharon: "Israeli Army Says Gaza Targets Struck Sets Back Hamas Military Capabilities for Many Years", The Algemeiner, 21 May 2021.

${ }^{269}$ Para amplios comentarios sobre el alto el fuego y sobre las causas del conflicto, véase The New York Times, 21 May 2021, en https://www.nytimes.com/live/2021/victory-in.a-gaza-city-celebration.

${ }^{270}$ Las cifras dadas por los medios son de 240 muertos palestinos en Gaza, de los cuales unos 150 eran combatientes de Hamás o de la Jiad Islámica, frente a 12 israelíes, incluido un soldado. Para un análisis de los muertos y heridos en ambas partes, ver La Razón, 21 de mayo 2021, en el que se recoge, en nuestra opinión, de una forma objetiva los datos que hasta el momento se disponen.
} 
observada no solo por Hamás, sino por los medios internacionales de comunicación, apresurándose a informar de que una operación terrestre de envergadura se iba a llevar a cabo. Ante este anuncio, centenares de combatientes de Hamás buscaron refugio en la red de túneles por ellos construida, viéndose así atrapados en ellos mientras que los aviones lanzaban cientos de misiles de ataque directo anti búnker, haciendo explosionar al mismo tiempo grandes cantidades de municiones, lo que se supone, según algún autor, que podría haber decenas o incluso centenares de muertos ${ }^{271}$. Habrá que ver si estas cifras de muertos en los túneles se revelan ciertas o falsas. Es más, a lo mejor nunca se sabrán, pero lo que nunca se podrá negar es cómo el Tsahal se las ha ingeniado para destruir las infraestructuras de Hamás, hechas precisamente para dar cobijo a sus combatientes, sobre todo ${ }^{272}$.

Estas dudas parece que se están disipando pronto, pues algo ya han descubierto los líderes de Hamás, ya que como señala el profesor Hillel Frisch, "Four days after the end of the offensive and 11 days after the attacks Hamas acknowledged that it had located and extricate the remains of four of its terrorists. The acknowledgement was accompanied by a photo of a crater dozens of meters in diameter and at least five meters deep in the middle of which a large earth-moving tractor was operating. One can safely assume that the final toll will be higher than the 80 or so terrorists Hamas has acknowledged were killed in the offensive as extrications efforts are still ongoing along the many kilometres of tunnels that were attacked and destroyed" 273 .

Pero al margen de las cuestiones que se presentan en esta clase de conflictos asimétricos, hoy en día ya muy conocidas, pues se tiende a exigir más al fuerte que al débil, lo que en nuestra opinión es normal, sorprende que quizás por primera vez se haya reconocido una moral superior en relación con la población civil, al exigirle unos comportamientos más exigentes por ser precisamente una "democracia" viva, en relación con Hamás, considerada como organización terrorista. Esto se descubre en algunas intervenciones tanto de Antony Blinken como de Joe Biden cuando advertían a Israel de que tuviera cuidado con la población civil. Dicho esto, hay que insistir sobre el hecho de que Israel siempre ha tenido en esta materia una alta preocupación, y basta con comparar el desarrollo de los conflictos en los que ha participado Israel y otros conflictos, como el de los Estados Unidos en la antigua Yugoslavia en 1999 o el más reciente de los países de la OTAN en Libia.

El contenido del acuerdo del cese el fuego, cuyos detalles se desconocen por el momento, ha suscitado un gran interés pues se ha convertido en un reto político en Israel con grandes divisiones entre los partidos. Tal ha sido el caso de los partidos que están más a la derecha, que han reprochado a Netanyahu haber hecho concesiones a Hamás en torno a Jerusalén. Pero se piensa que quizás se haya negociado también el regreso de dos rehenes que están en manos de Hamás, así como los cuerpos de dos soldados caídos en la Operación Margen

\footnotetext{
${ }^{271}$ Para más detalles sobre estos ataques y las cifras de muertos, cfr. KEMP, Richard. Trumpets and Tank Engines: A Turning Point in Gaza? Gatestone Institute, 16 May 2021. Ver también "Les tunnels du «<Metro»> de Gazacible principale des frappes israéliennes", The Times of Israël, 21 mai 2021; e "Israel engaña a Hamás con una brillante estrategia para atacar 'El Metro" de Gaza”, Diario Judío México Mas ideas, 14 de mayo de 2021.

${ }^{272}$ A esto hace alusión el primer ministro Netanyahu cuando en relación con el conflicto, ha señalado el mismo día del alto el fuego que "We hit the terror group hard. The public does not know everything yet, nor does Hamas. Our accomplishments will be revealed in time. At this point I can say that we did bold, unprecedented things, without getting drawn into unnecessary adventures... We managed to cause serious harm to Hamas, with minimal harm to Israel”. Beck, Atara. "We Hit the Terror Group Hard'; Netanyahu Says After Ceasefire with Hamas Proclaimed”, United with Israel, 21 May 2021. Ver también "Netanyahu : Israël a atteint ses objectifs à Gaza, a <<changé la règle du jeu>>”, The Times of Israël, 21 mai 2021. En este número de esta revista se incluyen varias cifras de muertos, entre ellas Israel asegura haber matado a 235 terroristas de Hamás y de la Jiad Islámica. No obstante, la prensa israelí sigue planteándose cuestiones en torno al futuro con Gaza. Ibid.

273 The Strategic Genius Behind Allowing Qatari Suitcases of Cash into Gaza, The Begin-Sadat Center for Strategic Studies, BESA Center Perspectives Paper nº 2053, 27 May 2021.
} 
Protector de 2014, aspectos ambos de gran importancia para Israel. Esto trae consigo que el país esté dividido a la hora de analizar los resultados de este conflicto ${ }^{274}$. Esto no es en realidad novedoso, pues ya ocurrió en los anteriores conflictos, salvo en el caso de la "Operación Plomo Fundido", en la que Israel combatió con tal firmeza y superioridad durante los 22 días que duró la Operación, iniciada el 27 de diciembre de 2007, que dejó claro quién era Israel en la zona. La Operación fue dirigida por elgGeneral Yoar Galant, quien sería nombrado poco después jefe de Estado Mayor por Ehud Barak ${ }^{275}$.

No obstante, hay que reconocer que el contexto actual internacional en el que se ha desarrollado este conflicto imponía ciertas dosis de prudencia política, con un presidente en los Estados Unidos, Joe Biden, que suscitaba desconfianza en el gobierno israelí, no solo por los pasos y pronunciamientos que ha dado en torno a los problemas existentes en la zona, que son complejos y diversos, sino también porque él mismo sabe que tiene un trio de personalidades que le estaban vigilando, e incluso acosando, tras haber reconocido expresamente y en voz alta el derecho a defenderse de Israel ${ }^{276}$. Si a estas tres personalidades añadimos el antiisraelí Bernie Sanders, el margen de maniobra del gobierno de los Estados Unidos no era muy amplio, de ahí la prudencia mostrada con el fin de no abrir una grieta en el propio seno del partido demócrata. En esta situación se entiende que haya sido Egipto el que ha liderado las negociaciones para acordar el cese el fuego, por mucho que se haya hablado de las presiones de Biden, presiones que Benjamin Netanyahu ha digerido bien.

Tras anunciarse el alto el fuego ambas partes dan cantos de victoria ${ }^{277}$, como suele ser habitual, pero dejando al margen esta cuestión, lo importante es ver qué les ha llevado al conflicto y cómo este se ha desarrollado. A este respecto, el primer ministro Benjamin Netanyahu ha subrayado en su discurso lo siguiente. Primero, que Israel no inició este conflicto, sino que "fuimos atacados por la organización terrorista Hamás que disparó 4000 cohetes contra nuestra capital y nuestras ciudades. Ningún país se queda de brazos cruzados al ser atacado de ese modo criminal. Israel no es diferente" 278 . Se intenta pues demostrar que, si esto es un derecho de cualquier estado, también lo es de Israel. Benjamin Netanyahu recoge aquí lo que durante el conflicto ha señalado muy claramente el Portavoz del Tzahal israelí, Hidai Ziberman, quien, ante ciertas críticas hechas por ciertas personalidades estadounidenses, apuntó que qué hubiera ocurrido si esos cohetes y misiles hubieran caído sobre Washington. Hecha esta afirmación, el camino estaba abierto para invocar el derecho a defenderse y, en este aspecto,

\footnotetext{
${ }^{274}$ Assouline, Pierre-Simon. "Un cessez-le-feu aux contours flous”, Le Temps, 21 mai 2021.

${ }^{275}$ Para un estudio sobre esta Operación, cfr. Norton Augustus, Richard. "La guerra de Gaza: antecedentes y consecuencias", Real Instituto Elcano, ARI, no 21/2009. Ver también Bermejo García, Romualdo. "Israel en dos frentes: algunas cuestiones jurídico-políticas en torno a la desconexión de Gaza y a la guerra de Hizbolandia, en Ramón Chornet, Consuelo (Coord.) (2008): Conflictos armados y Derecho internacional humanitario, Valencia, Tirant lo Blanc, pp. 171-210.

${ }^{276}$ Hacemos alusión a las ya precitadas Ilhan Oman, Rashida Tlaib y Alexandria Octavio-Cortez, esta última conocida por la sigla AOC.

${ }^{277}$ Esta contienda con Hamás nos demuestra una vez más que Israel gana las batallas, pero el problema de Hamás permanece. Esto implica que a Israel le falta ganar la guerra, no solo en Gaza, sino también en Jerusalén. Hacohen, Gershon: The Gaza War Ended, the Hamas Problem Remains, The Begin-Sadat Center for Strategic Studies, BESA Center Perspectives Paper n ${ }^{\circ}$ 2042, 21 May 2021.

278 "Benjamin Netanyahu defiende el derecho de Israel a proteger a sus ciudadanos", Texto difundido por la Embajada de Israel en México, Diario Judio, 21 de mayo de 2021. Para una acerba crítica de la campaña propagandística en torno a la victoria de Hamás en la Operación "Guardián de los Muros”, véase Toamed Khaled Abu. "Hamas and Iran Turned Gaza into Cemetery for Children, Many Arabs Concede", World Israel News, 7 June 2021. Este conocido analista árabe se mofa de los líderes de Hamás que viven en plan de lujo en Catar, como Hanniyet, estrenando un coche Mercedes nuevo, mientras el pueblo de Gaza está solo y abandonado en la batalla, obligado a ejercer de escudos humanos para proteger a los combatientes. Critica además que pidan dinero a los países árabes del Golfo, cuando él mira sobre todo a Irán, país que es el que se aprovecha de Hamás en su lucha contra Israel, utilizando como rehén al pueblo de Gaza.
} 
agradece el apoyo recibido por los Estados Unidos en este tema, así como el de otros países ${ }^{279}$. Segundo, respecto al cómo, es decir el respeto a las normas del derecho internacional humanitario, Benjamin Netanyahu, consciente y conocedor de lo que es la Banda Gaza, en torno a dos millones de habitantes en $365 \mathrm{~km}^{2}$, pone de relieve que "hemos hecho todo lo posible para evitar víctimas civiles... mientras tratábamos de atacar a los combatientes que estaban tratando de asesinar a nuestros ciudadanos. Lamentamos cada pérdida de vida, pero puedo decirles categóricamente, que no hay ejército en el mundo que actúe de forma más moral que el ejército de Israel".

Y yendo ya al terreno de los combates reconoce que si no hubiera sido por la Cúpula de Hierro (Iron Dome), el sistema antimisil de Israel, "habríamos tenido que realizar una invasión terrestre de Gaza para impedir que dispararan sus misiles y el listado de víctimas se habría disparado a niveles estratosféricos" ${ }^{280}$. He aquí, pues, unos ejemplos que permiten comprender mejor por qué Hamás podría ser aplastada, pero que se dispararían las víctimas en ambos lados. No fue esta preocupación la que estuvo presente en los bombardeos de los países de la OTAN en la antigua Yugoslavia en 1999, siendo los Estados Unidos los que realizaron el $90 \%$ de los ataques aéreos con el objetivo de tener "víctimas" cero. Esto lo hubiera podido hacer Israel en cualquiera de las operaciones militares llevadas a cabo en Gaza, sin embargo, no se ha recurrido a ello ${ }^{281}$. Por otro lado, ya se sabe que la fiscal de la Corte Penal Internacional, Fatou Bensouda,

\footnotetext{
${ }^{279}$ Hay analistas que consideran el papel desempeñado por Joe Biden durante la contienda con Hamás como prudente y sabio, sobre todo si se le compara con Barack Obama, que apartaba siempre a Benjamin Netanyahu o le acosaba como ocurrió durante la Operación Margen Protector de 2014 para que aceptara el alto el fuego. A este respecto, Schnur, Dan: "President Biden's Wise Balancing Act”, Jewish Journal, 24 May 2021. Países como Alemania, la República Checa y Eslovaquia en Europa han sido muy claros en esta cuestión, pero también Australia o Canadá. Conviene recalcar que esta operación militar ha confirmado que hay un cambio radical en Europa a la hora de evaluar el conflicto israelo-palestino, salvo algunos países recalcitrantes, como España, en donde sigue conviviendo una enemistad manifiesta contra Israel, con brotes importantes de simpatía. La manifiesta enemistad hacia Israel y todo lo que representa era uno de los temas a los que recurría el ex - líder de Podemos, Pablo Iglesias, cuyos exabruptos antisemitas fueron objeto de una carta de las comunidades judías de España. Esto no se ve en Austria, Eslovaquia, República Checa, Dinamarca, Países Bajos, etc., reconociendo de una manera o de otra el derecho a defenderse de Israel. Y es que esos sentimientos trasnochados de que Israel es el origen de todos los males en el Medio Oriente no han sido nunca verdad, ni antes ni ahora, por mucho que haya habido mucho iconoclasta con análisis muy simplistas, que dividían el conflicto entre los mártires (los palestinos) y los asesinos genocidas (los israelíes). La realidad ha hecho que esto esté cambiando, salvo en aquellos que continúan lanzando al viento las teorías simplistas conspiratorias, generando de mala fe tergiversaciones históricas cuando no auténticos exabruptos. Sobre esta cuestión, un estudio muy interesante es el de Haddad, Benjamin: "How Europe Became Pro-Israel", Foreign Policy, 20 May 2021, en https://foreignpolicy.com/2021/05/20/how-europebecame-pro-israel.

${ }^{280}$ Ibid. Precisamente el director del UNRWA, Matthias Schmale, ha admitido públicamente en el Canal israelí 12 News, el 25 de mayo, que los ataques aéreos israelíes eran precisos, añadiendo lo siguiente: "I have the impression that there is a huge sophistication in the way the Israeli military struck over the last 11 days”. Es más reconoce igualmente, que con algunas excepciones, “... they didn't hit civilian targets, but the viciousness, ferocity of the strikes was heavily felt”. Estas declaraciones acarrearon inmediatamente una condena de los líderes de Hamás, instándole a que pida disculpas. El director de la UNRWA también señala que, durante las hostilidades, no ha habido serios recortes del aprovisionamiento de medicinas, de agua o víveres. Schindman, Paul. "Hemas Slams UNRWA Chief for Saying IDF Strikes Were Precise", World Israel News, 26 May 2021; ver también, "UNRWH Gaza Director Expresses Regret After Saying IDF Strikes Were 'Precise' and 'sophisticated' Did not Target Civilians", The Algemeiner, 25 May 2021. Estas declaraciones suscitaron serias críticas de los líderes de Hamás y de otros grupos palestinos, y más tarde se disculpó por hacer esos comentarios.

${ }^{281}$ Son conocidas las diatribas del The New York Times contra Israel, como bien lo demuestra INI, Gilead. "As Hamas Fired Rockets, the New York Times Joined the Assault on Israel”, The Algemeiner, 30 May 2021. Ver también Satloff, Robert. "What's Wrong with The NY Times' Report on Children's Deaths? So Much", The Times of Israël, 31 May 2021. Este último estudio se centra en la polémica suscitada por el artículo publicado el 26 de mayo de 2021, en The New York Times con el título "They were only children", en donde había fotos de niños relacionadas con los 69 menores de 18 años (67 palestinos, 2 israelíes, uno árabe y otro judío) muertos durante los 11 días de conflicto. Dos días más tarde, el 28 de mayo, el antiguo director de la Liga anti-difamación, Abraham
} 
estaba bien vigilante para que el ejército israelí no cometiera, según ella, crímenes de guerra, como si no hubiera otros conflictos en el mundo, por ejemplo, en el Tigre (Etiopía) o en Birmania, pero parece que le gusta mirar hacia Jerusalén ${ }^{282}$.

Hechas estas consideraciones en torno al alto el fuego, es conveniente hacer alguna reflexión ¿Hubiera habido un cese el fuego si en vez de tener la superioridad militar Israel la tuviera Hamás? La respuesta es a nuestro entender clara, y es que no habría cese el fuego ni negociaciones sobre el cese el fuego, ya que su deseo es que desaparezca el Estado de Israel, tal y como reza su Carta fundacional. Esta es la superioridad moral de Israel sobre las organizaciones terroristas que, como Hamás, luchan por destruir el Estado de Israel. Esto es no solo que lo piensan, sino que lo publican como si de un arma de guerra se tratara. Y gracias que esto solo forma parte actualmente de la narrativa palestina, y no de la realidad, pero es una corriente que siembra antisemitismo y odio hacia el pueblo judío que hoy en día no se puede tolerar. Por eso, es muy común oír hablar que en estos conflictos entre Israel y estas organizaciones de que no hay "proporcionalidad" en las víctimas, como en este caso, pero a esto hay que responder que la "proporcionalidad" no implica la "equivalencia", diferencia que recoge el Derecho internacional humanitario ${ }^{283}$. Y es que a partir del momento en que Hamás lanza los primeros cohetes o misiles hacia Israel para apoyar a los alborotadores palestinos en Jerusalén y en territorio israelí, y después algunos centenares para llegar a millares, Israel tiene desde los primeros momentos el derecho a defenderse, y más cuando estos van dirigidos a la población civil ${ }^{284}$. Sostener lo contrario no es solo ya un exabrupto jurídico, sino también algo

Foxman, tuiteó que cancelaba la suscripción a este periódico con el que había convivido toda su vida, por "el libelo de sangre de Israel y del pueblo judío que figuraba en la portada y que era bastante". El título que aparecería el 28 de mayo sería el de "They were just children" en la portada, y su desarrollo en las pp. A10-A11. Ni que decir tiene, que este artículo del New York Times ha suscitado una serie de reacciones condenando no solo el contenido del artículo, sino sobre todo el mal periodismo practicado por este diario, al señalar como referencias "las fuentes oficiales palestinas" para plasmar la identidad de los menores, cuando en realidad habían sido dadas por oficiales de Hamás, miembros o simpatizantes.

${ }^{282}$ Desde el punto de vista del derecho internacional humanitario, y a pesar de las desinformaciones que han aparecido en muchos medios, hay que reconocer que comparado con otros conflictos que podrían ser similares, a pesar de las especificidades de cada uno, Israel ha creado una nueva ética de la guerra en esta Operación "Guardián de los Muros". Y es que como recoge Rabbi Daniel Rowe, "The conduct of the Israel Defense Forces vis-a-vis the protection of civilians on both sides has no equal or precedent. Indeed, Israel has set a new standard for the ethics of war". Rowe Rabbi Daniel. "Israel Has Set a New Standard for the Ethics of War", Jews News Syndicate, June 4, 2021, en https://www.jns.org/opinion/israel-has-set-a-new-standard-for-the-ethics-of-war/) Y es que comparándolo con otras operaciones recientes, como los ataques de la coalición contra el Estado Islámico en Mosul, mataron a 320 civiles, y el bombardeo de los Estados Unidos contra el último baluarte del Estado Islámico en Racca mató a 1200 combatientes y 1600 civiles. Para algunos comentarios al respecto, véase. Tres en uno, $\mathrm{n}^{\circ}$ 3010-8, 4 de junio de 2021.

${ }^{283}$ Sobre este aspecto véase French, David: "The Two Wrongs of the Gaza Narrative", The Dispatch, en https://frenchpress.thedispatch.com/p/the-two-wrongs-of-the-gaza-narrative, consultado el 21 de mayo de 2021.

${ }^{284}$ Respecto al derecho de legítima defensa de Israel en esta contienda con Hamás, dos militares estadounidenses y al mismo tiempo Profesores de Derecho, Geoffrey S. Corn y Rachel E. Vamlandingham, se han pronunciado rotundamente sobre esta cuestión, siempre espinosa, planteándose simple pero muy directamente la cuestión siguiente: “... What right does Israel have to respond to this threat, and what measures are justified in response? The answer is clear: Israel has the same right that every sovereign nation has to defend itself from unlawful attacks. Hamas efforts to exploit the explosive civil unrest in Israel by unleashing this rocket barrage-partying itself as a defender of the oppressed and launching rockets against Israeli civilians as a purported show of solidarity in an effort to win Palestinian and international sympathy-is a blatant act of unlawful aggression”. Y una vez reconocida la agresión de Hamás, que no es un Estado, pero es igual, se preguntan qué clase de respuesta puede dar Israel ante esta situación, y dicen lo siguiente: "To be sure, the Israeli response must itself comply with international law-it must include the obligation to use only proportional measures to defend itself. But international law does not restrict Israel to a mere tit-for-tat response; rathere it is the nature of the threat that dictates what self-defence actions are necessary and proportional in any given scenario. This means Israel may already be justified in the determination that the time has come for a much more extensive campaign to destroy Hamas' capability for future attack". Desde el punto de vista del Derecho Internacional Humanitario, estos autores 
más grave, puesto que se quiere imponer una violencia destructiva y sin causa que nos retrae a tiempos primitivos ${ }^{285}$. Por eso, algunos ya han apuntado que mientras que Hamás tenga misiles, cualquier cambio será muy limitado y de corto alcance ${ }^{286}$.

Este es el tema pendiente en relación con Hamas, pero también lo es con Hezbolláh, pues con sus grandes reservas de cohetes y misiles, cada vez más perfeccionados y con mayor alcance, Israel está al capricho de unos líderes que dirigen el terror y la mentira a su antojo. Y los conflictos armados con Hamás lo ponen de manifiesto. Un ejemplo de esto que apuntamos lo tenemos en las declaraciones hechas por el confundador y segundo líder de Hamás, Mahmoud al Zahar, según las cuales expresamente admite que atacan objetivos civiles ${ }^{287}$. Es decir, se insiste y se publican fotos de edificios destruidos por la aviación israelí vacíos, porque antes advierten de que salgan los civiles, y en los que hay estructuras militares de diversa índole, acusando a Israel de atacar objetivos civiles, la población civil, etc., mientras que Hamás lanza 4.400 cohetes y misiles directamente contra la población civil, y no se condenan estos ataques en general salvo por unos cuantos Estados, y ahora sale uno de los líderes de Hamás, afirmando que sí, que atacan objetivos civiles y a la población civil. ¿Qué haría ahora la Fiscal de la Corte Penal Internacional, Fatou Bensouda? ¿Qué hará el secretario general de las Naciones Unidas, António Guterres, que lo menciona solo cuando se equivoca? Este es el drama del conflicto israelo-palestino, con cuya confusión y tergiversación estamos conviviendo desde 1948, o incluso antes. Esto no quiere decir, sin embargo, que las operaciones han fracasado, sino que después de haber sido derrotados militarmente, hay Estados que los rearman con gran generosidad y esto es lo que se ve claramente que hace Irán $^{288}$, y en parte Catar, al utilizar los recursos humanitarios para las actividades armadas, y esto mismo se comenta de la ayuda que

condenan la práctica generalizada del uso de los escudos humanos, lo que lleva a Israel a mitigar sus ataques, mientras que Hamás no solo ataca deliberadamente a la población civil israelí, sino que también expone a sus civiles a consecuencias mortales que generan las hostilidades. De estos autores, cfr. "The Illegitimate Instinct to Delegitimaze Israel Opinion", Newsweek, 24 May 2021, en https://www.newsweek.com/illegitimate-instinetdelegitimize-israel-opinion-1592640.

285 Para un análisis de estas cuestiones, véase Dunner, Pini. "Searching for Peace in the Middle East", The Algemeiner, 21 May 2021.

${ }^{286}$ Esto es lo que ha señalado el que fue Enviado de los Estados Unidos a Oriente Medio, Denis Ross, en el Jerusalem Post, en https://www.jpost.com/arab-israeliconflict/ross-as-long-as-hamas-has-rockets-there-can-onlybe-a-short-ter\%com-truce-668679.

${ }^{287}$ A este respecto, cfr. "Hamas Leader Admits Targeting Civilians with Rockets in Exclusive Interview", Israel Video Network, 25 May 2021, en

https://mail.google.com/mail/a/O/\#inbox/FMfcgcGKXScZVFTpnbhmhlFWDLtsB/Dw.

Estas declaraciones las ha hecho el líder de Hamás a la Sky News de Gran Bretaña en donde además señala que quiere conectar con Biden, Véase "Hamas Leader Wants to Connect With Biden", Israel365 News, 25 May 2021. ${ }^{288}$ Pero Irán no solo apoya a Hamás financieramente hablando sino también militarmente, dirigiendo sus operaciones incluso en algunos casos, como ha ocurrido en esta Operación. A este respecto, véase Wrobel, Sharon. "Report: Hamas Coordinate Gaza War with Iran, Hezbollah in Join Military Room", The Algemeiner, 30 May 2021. En este artículo se señala que durante la Operación “Guardián de los Muros”, Hezbolláh y Hamás tenían una sala común en Beirut para las operaciones militares. Ver también, "Hezbollah, IRGC, Hamas Established Chamber of Military Operations in Beirut during israelí War on Gaza: Report”, AlmanarnewsEn, 28 May 2021, en https://english.almanar.com.lb/1352914. El comandante de la "IRGC's Al-Quds Force", el General Esmail Qaani, asistió en dos ocasiones a estas reuniones. Para más detalles sobre esta cuestión, que demuestra un entendimiento entre Hezbolláh y Hamás a nivel de la asistencia militar, véase Berkowitz Adam Eliyahu. "Report: Iran helping Hamas to Fire Rockets at Israel while Negociating with Biden Administration", Israel365 News, 31 May 2021. En este informe se señala que "Hezbollah transmitted weaponry and ammunition to Gaza and moved a number of Palestinian Resistance officers out of the Strip during the aggression... the Islamist Resistance also provided the Palestinian factions with the needed data about the movements, of the Israeli occupation military, which frustrated the enemy's plot to ambush the Palestinian fighters near the Gaza border, adding that drones were employed to reach this goal". Dejando al margen la cuestión de saber si esta información es verdadera o no, lo cierto es que Irán ha apoyado el lanzamiento de misiles contra Israel, tal y como ha reconocido el líder de Hamás Yahga Sinwar. 
viene de las Naciones Unidas, al menos en parte. Y es que, como se sabe, la corrupción es ley, y el pueblo está secuestrado ${ }^{289}$.

Pero dejando al margen estas cuestiones, los comentarios sobre el éxito militar de la Operación son casi generalizados, reconocidos por cualquiera que tenga un mínimo de conocimiento. Pero también desde el punto de vista del Derecho internacional humanitario, por mucho que algunos intenten tergiversarlo, exagerando las víctimas civiles, y ocultando el concepto de escudos humanos, así como las advertencias israelíes transmitidas por diversos medios, incluso por teléfono, para que desalojen las instalaciones la población civil tras comunicarles que van a ser atacadas. Es más, el éxito militar lo anuncian los servicios militares de inteligencia, poco propensos a hacer estas afirmaciones que dan datos que nadie niega ${ }^{290}$. Otros analistas consideran que la Operación ha sido desde el punto de vista militar única, y que Gaza sigue atascada ${ }^{291}$. Y es que las operaciones militares llevadas a cabo por el Tzahal se estudiarán en las academias militares, como el asalto aéreo que, en una hora, 160 aviones de combate destruyeron unos $100 \mathrm{~km}$ del "Metro", tal y como lo han denominado las fuerzas israelíes. Es más, la precisión con la que han llevado a cabo los ataques, están ahí para demostrarlo, de ahí las pocas víctimas civiles. De todo esto, Hezbolláh habrá tomado buena nota, y habrán recordado los ataques de 2006, y las amenazas recientes hechas por altos mandos militares israelíes, incluidas las de Benny Gantz, apuntadas supra. Por otro lado, en muchas ocasiones los medios comentan la extrema pobreza de la población de Gaza, pero que no impide una guerra con Israel ${ }^{292}$.

En estas circunstancias, lo que es indudable es que Hamás es bien consciente de la superioridad militar y moral de Israel. No obstante, habrá que apuntar que esto podría ser fácilmente reconocible por Hamás, y en este caso cabe preguntarse por qué inició estas hostilidades lanzando misiles contra Israel. Sobre esta cuestión, algunos han apuntado que Hamás, a pesar de su inferioridad militar, se lanzó a esta campaña militar para demostrar su apoyo a los alborotadores y sus líderes que dirigían los disturbios, lo que podía ser interpretado no solo como una división en la sociedad israelí, sino como indicios de que podía haber una guerra civil. Otro aspecto apuntado es que Hamás ha generado en la sociedad israelí un sentimiento de inseguridad en la población civil, al estar durante los 11 días que ha durado el conflicto preocupado y, en la medida de lo posible, cerca de los refugios. Por último, no cabe duda de que Hamás se ha hecho una gran publicidad en el mundo, a pesar de los reveses militares que clara y contundentemente han recibido ${ }^{293}$.

Dicho esto, es obvio de que el hecho de que Hamás sea una organización terrorista, no quiere decir que sean unos insensatos, aunque, en algunos casos lo parezcan o, incluso lo sean. Desde esta perspectiva es normal que estén reflexionando sobre unas conversaciones directas con Israel ${ }^{294}$. Hasta ahora Israel siempre se ha negado a hablar directamente con Hamás, al ser una organización terrorista. Sin embargo, pasar de unas negociaciones indirectas a directas, no sería el primer país en hacerlo, como es bien sabido, y esto lo han hecho en Europa varios

\footnotetext{
${ }^{289}$ Sobre este aspecto de que los palestinos son rehenes, véase Fatah Tarek, Fatah. "Palestinians Die as Hostages of Hamas", Toronto Sun, 19 May 2021, en https://torontosun.com/opinion/columnists/fatah-palestinians-die-ashostages-of-humans.

290 "IDF: Most Main Target, in Gaza have been hit", en https://www.netnews.com/article/ryDnE27cO.

${ }^{291}$ Katz, Yaakov. "Israel's Gaza War is Like no Other Military Operation in History-Opinion", The Jerusalem Post, 21 May 2021. Ver también “As Israel-Hamas Cease-Fire Holds, Gazans Survey Wreckage”, The New York Times, 25 May 2021.

292 Niresntein, Fiamma. "Its Iran Stupid”, The Algemeiner, 19 May 2021.

${ }^{293}$ Sobre estos aspectos, ver el interesante artículo de Herman, Peter C. "Hamas vs. Israel: Who won?", Jewish Journal, 28 May 2021.

${ }^{294}$ A este respecto, véase Jeremberg, Batya. "Hamas Mulling Direct Talks with Israel”, World Israel News, 23 May 2021.
} 
Estados, como España o el Reino Unido, sin olvidar a los Estados Unidos que han negociado con los propios talibanes. Sin embargo, muy claras tienen que tener las ideas para que este sueño se convierta en realidad, aunque en política todo es posible. Por el momento, un primer paso está ya dando al proponer algunos líderes de Hamás la eliminación de los intermediarios y negociar ellos directamente. Si son de buena fe, la idea no es mala, pero buscando qué puede haber detrás de esta idea, solo se nos ocurren dos cosas: a) negociar directamente porque piensen que esto les refuerce a nivel internacional, al sentar en la mesa a israelíes; y b) utilizar esta idea para rearmarse otra vez y reiniciar las hostilidades por cualquier motivo como siempre lo han hecho. Si este último es el caso, Israel advierte que responderá con dureza ${ }^{295}$.

El tiempo nos proporcionará quizás algo de luz, y si no, ya se sabe, se volverá a los túneles. Pero antes de ir a los túneles, Israel deberá saber que tiene dentro una "Quinta Columna" que puede resultar peligrosa ${ }^{296}$. Y es que hay que recalcar que la gran novedad de este conflicto no es en sí los cohetes y los misiles de Hamás, por mucho que estos se hayan desarrollado tecnológicamente, y lo seguirán haciendo, sino las movilizaciones árabes dentro de Israel, con ataques crueles y sangrientos a la población judía. Este es quizás uno de los principales retos que Israel va a tener que resolver en el futuro ${ }^{297}$. Pero constatando la importancia de esta "Quinta Columna", es obvio que Israel tiene una "Sexta Columna", que es Irán, que se ha convertido en una especie de Banco económico, de desarrollo, financiero y militar de muchas de estas organizaciones que actúan en contra de Israel. Si a esto añadimos el tema nuclear, considerado por Israel como el peligro número uno actualmente para su existencia, los retos que tiene Israel ya no son solo palestinos, sino que van mucho más allá, estando siempre presente en cualquier tema relacionado con la seguridad de Israel. Y el tema nuclear iraní se lo ha recordado últimamente Netanyahu al secretario de Estado Antony Blinken en la visita que ha realizado a Jerusalén el 25 de mayo de 2021 diciéndole claramente que espera que los Estados Unidos "Will not go back to the old JCPOA, because we believe that deal paves the way for Iran to have an arsenal of nuclear weapons with international legitimacy". Le recuerda además que "Whatever happens, Israel will always reserve the right to defend itself against a regime committed to our destruction, committed to getting the weapons of mass destruction for that end" ${ }^{\prime 298}$. Y es que se está anunciando que el programa nuclear iraní está avanzando de forma que, si no se corrige, la bomba nuclear es inevitable ${ }^{299}$. De esto toma nota también el diario Financial Times, al señalar el director de la AIEA, el argentino Rafael Grossi, que Irán está enriqueciendo unario a niveles que solo lo hacen los países que fabrican armas atómicas. Rafael Grossi dijo al Financial Times que "un país que enriquece uranio al $60 \%$ es algo muy serio, ya que solo los países que fabrican bombas están alcanzando este nivel. Y es que el $60 \%$ es casi ya el grado para fabricar armas". Recuérdese que el Acuerdo nuclear de 2015 preveía solo un 3,67\%. Para salvar la cara, Irán ha respondido que ese enriquecimiento tenía solo fines de investigación y médicos ${ }^{300}$. También se ha hablado de forma general del

\footnotetext{
${ }^{295}$ Dan, Gavriel. "If Hamas Breaks The Calm and Attacks Israel Our Response Will Be Very Powerful”, Breaking Israel Video, en

https://www.israelunwired.com/hamas-heavy-

price/8utm_source=ActiviCampaign\&utm_medium=email\&utm_content="If + Hamas + Breaks + The + Calm + And + Attacks+Israel\%2C+Our+response+Will+Be+Very+Powerful, consultado el 25 de mayo 2021.

296 FRISH, Hillel. Israel's Top Priority: Immediate Confiscation of Illegal Weapons amongst Israeli Arabs, The Begin-Sadad Center for Strategic Studies, BESA Center Perspectives Paper n ${ }^{\circ}$ 2041, 21 May 2021. Para más detalles, Greenfield, Larry. “Can Civil Discourse Prevent Our Second Civil War?”, Jewish Journal, 28 May 2021.

${ }^{297}$ Karsh, Efrain. Hamas' Relentless Jiad. BESA Center Perspectives Paper no 2044, 23 May 2021. Ver también Dromi, Uri. "The Civil Riots in Israel Are a Warning to Prevent a Dark Future”, Jewish Journal, 24 May 2021.

298 Savin, Aryeh. "Is US Rejoinst Nuclear Deal, Israel will reserve the right to defend itself", World Israel News, 25 May 2021.

299 "IAEA Director Admits an Iranian Nuclear Weapon Inevitable”, Israel365 News, 26 May 2021.

${ }^{300}$ Englad, Andrew. "IAEA Chief Sounds Alarm over Iran's Nuclear Program”, en
} 
Derecho a defenderse de Israel, incluido el Acuerdo nuclear, tal y como se ha recogido en el comunicado de prensa ${ }^{301}$. Y es que en relación con el tema nuclear se están planteando serias dudas sobre la buena voluntad de Irán para resolver pronto el asunto o no ${ }^{302}$. A día de hoy, con elecciones en este país el 18 de junio, todo apunta a que las negociaciones nucleares de Viena se prolongarán por algún tiempo.

Así las cosas, y tras el alto el fuego se pueden plantear muchas cuestiones, pero dos las consideramos muy importantes. Como ya se sabe, Antony Blinken no solo ha visitado a Netanyahu y el presidente del Israel Reuven Rivlin, sino que también ha estado en Ramallah, con Mahmud Abbas, defendiendo la teoría de dos Estados, habiéndose producido importantes manifestaciones en su contra, lo que puede ser para algunos chocante. Sin embargo, no lo es, ya que lo que le están recordando a Antony Blinken que está perdiendo el tiempo, pues la teoría de dos Estados no es aceptada por Hamás, que no renuncia a ningún territorio de lo que ellos consideran Palestina, ni quiere reconocer a Israel, pues eso sería una traición ${ }^{303}$.

La segunda cuestión atañe al control de los recursos financieros que en los últimos días ciertos Estados como Catar ${ }^{304}$, Egipto, los Estados Unidos, más las Naciones Unidas han prometido para la reconstrucción de Gaza. Conocedores de lo que ocurre en Gaza, tanto Israel como Egipto, quieren que estos recursos no estén controlados por Hamás, pues saben que los recursos que pasen por las manos de Hamás se utilizarán no para la población civil que ha sido afectada, sino sobre todo para reponer los líderes y sus familias, así como para renovar las pérdidas de armas e infraestructuras militares de Hamás. Dicho de otra forma, los 1.300 millones de dólares prometidos no quieren que vayan ni directamente ni indirectamente a Hamás $^{305}$. Y es que lo que se pretende es prolongar a largo plazo la situación de calma en la zona, de forma que si estas conversaciones que se tendrán también con los Estados Unidos (Egipto hablará de este tema directamente con Hamás) no prosperasen, Israel estaría dispuesto a reiniciar los ataques en una semana. Sin embargo, Israel sí que aceptaría que esos recursos se gestionaran por la Autoridad Palestina. Por otro lado, resultaría extraño que los 350 millones de dólares prometidos por los Estados Unidos terminaran en manos de Hamás, considerados

https://www.ft.com/content/add04cf8f-1740-4022-9119-114b6bd66c4b.

301 Para más detalles, véase https.//www.state.gov/secretary-antony-j-blinken-and-israel-prime-ministerbenjamin-netanyahu-statements-to-the-press/.

302 "Secretary Antony A. Blincen on CNN's Fareed Zakaria GPS with Fareed Zakaria", Interview, Antony J. Blinken, Secretary of State, May 23, 2021, en https://www.state.gov/secretary-antony-j-blinken-on-cnns-fareedzakaria-gps-with-fareed-zakarina/. En esta interview, Antony Blinken duda de que Irán esté hacienda lo necesario para volver al cumplimiento del acuerdo nuclear, y se pregunta: ¿Está Irán preparado para ello?

${ }^{303}$ Para más detalles sobre esta cuestión, y sobre el viaje de Blinken a Ramallah, cfr. Toamed, Khaled Abu. The Palestinian Voices Blinken Won't Hear, The Gatestone Institute, 24 May 2021. Este autor apunta además que en una reciente encuesta el $57 \%$ de los palestinos se oponen a la teoría de los dos Estados, y un 6890 desea que Mahmud Abbas dimita. No parece que ni Blinken ni Biden estén muy bien informados de la situación en la zona, y si lo están, no apuntan muy bien. Y es que los manifestantes palestinos gritaban consignas anti-estadounidenses, como "Estados Unidos es la cabeza de la serpiente", etc. De este mismo autor, palestino y que vive en Jerusalén, ver también "Palestiniens Protest against Blinken's Visit to Ramallah", The Jerusalem Post, 25 May 2021. Tampoco conviene olvidar que Hamás lo que pretende ahora es alzarse como única organización que defiende y representa los intereses palestinos, y no el Fatah. Para más detalles sobre esta cuestión, Gupta, Anoop Kumar. Figuring Out Hama's Strategy, The Begin-Sadat Center for Strategic Studies, BESA Center Perspectives Paper $n^{\circ}$ 2050, 26 May 2021.

${ }^{304}$ Parece que Catar no se cansa de financiar a Hamás, que ha visto cómo volaban por los aires en 40 minutos los mil millones de dólares invertidos últimamente en la organización, al atacar Israel los túneles en Gaza, financiados en gran medida por el Emir de este pequeño Estado. A este respecto, Frisch, Hillel. The Strategic Genius Behind Allowing Qatari Suitcases of Cash into Gaza, The Begin-Sadat Center for Strategic Studies, BESA Perspectives Paper $n^{\circ}$ 2053, 27 May 2021. Conviene apuntar que algunos de estas transferencias han sido autorizadas por Israel, sin examinar muy bien cuál era su destino.

${ }^{305}$ Para un análisis de esta cuestión, cfr. Shindman, Paus. "Egypt, Israel Turning the Financial Screws on Hamas, 'Not So fast' for the \$1.3 billion to Gaza”, World Israel News, 27 May 2021. 
por los Estados Unidos como organización terrorista, por eso los gestionará también la Autoridad Palestina.

\section{La Operación “Guardián de lo Muros” ante el Consejo de Derechos Humanos de las Naciones Unidas}

Hay que reconocer que Hamás ha ganado la guerra de la propaganda y de la desinformación, como ya se ha apuntado, al presentarse no como "agresor", que es lo que ha sido, sino como víctima, difundiendo las consecuencias del conflicto y sus víctimas, dando la imagen de un pueblo aplastado y sometido por la superioridad militar israelí. Pero como la ingenuidad también existe, y sobre todo en algunos órganos onusianos, no es extraño que el Consejo de Derechos Humanos, encargado en teoría de que se protejan y garanticen estos derechos, haya caído en la trampa de la propaganda de Hamás, organización terrorista que ha encontrado un protector en este órgano, lo que no es tan extraño conociendo ya sus andadas en relación con Israel. Y es que uno tiene la impresión de que muchos políticos que terminan en el cementerio onusiano su carrera política, tienden a perder el Norte, siendo realmente del Sur, lo que puede parecer normal, aunque esto no ocurre a todos, evidentemente. Decimos esto, porque la actual Alta Comisionada del Consejo de las Naciones Unidas para los Derechos Humanos, la chilena Michelle Bachelet, ha acusado a Israel de haber iniciado el recién conflicto con Gaza, al instigar los disturbios y la violencia en Jerusalén. Sobre esto, el 27 de mayo de 2021, este Órgano de las Naciones Unidas, compuesto de 47 miembros, ha adoptado una resolución ${ }^{306}$, con 24 votos a favor ${ }^{307}, 9$ en contra (entre los que se encuentran Alemania, Austria, Bulgaria, la República Checa y Reino Unido, Uruguay) y el resto se abstuvo ${ }^{308}$. La resolución ha establecido la creación de una Comisión Independiente Permanente de Investigación con carácter de urgencia para que investigue las presuntas violaciones y abusos de los derechos humanos desde el 13 de abril de 2021, inicio del Ramadán, en Israel y en lo que denominan territorios ocupados, así como las causas que originaron los disturbios y tensiones. Para la Alta Comisionada, los ataques de Israel sobre Gaza durante la "Operación Guardián de los Muros" podrían constituir crímenes de guerra, mientras que los misiles de Hamás contra Israel habrían violado el Derecho internacional humanitario ${ }^{309}$.

La adopción de esta resolución es un claro ejemplo de que Israel es el "principal objetivo" de este Órgano, cuyo antisemitismo es bien conocido, por eso el Ministerio de Asuntos Exteriores de Israel ya ha indicado que no cooperaría en la investigación, añadiendo además que "Israel will continue to defend itself against the terrorism of Hamas and against politicised international bodies that seek to delegitimize our lawful and just actions... Any resolution that fails to condemn the firing of over 4.300 rockets by a terror organization Hamas, is nothing more than a moral failure and a stain on the international community and the UN... Israeli security forces acted with the highest ethical standard in accordance with international law, in defending our citizens from Hamas indiscriminate rocket fire" ${ }^{310}$. Por su parte, el

\footnotetext{
${ }^{306}$ La resolución fue presentada por Pakistán y Palestina en nombre de los 57 Estados miembros de la Organización para la Cooperación Islámica. A/HRC/S-30/L1.

${ }^{307}$ La mayoría de estos países son islámicos, excepto Argentina, Cuba, Filipinas, México, Rusia y Venezuela.

${ }^{308}$ Entre las abstenciones, y dentro de los países europeos, conviene apuntar a Francia, Holanda e Italia, mientras que Brasil y Japón también se abstuvieron. Esta resolución se adoptó en el marco de la trigésima sesión extraordinaria de este Órgano. 30th special sesión of the Human Rights Council on the grave human rights situation in the Occupied Palestinien Territory, including Eas-Jerusalem-, 27 May 2021 (A/HRC/S-30/L 1), en https://www.ochhr.org/EN/HRBodies/HRC/Specialsessions/session30/Pages/30thSpecialSession.aspx, Conviene apuntar que el $30 \%$ de las sesiones extraordinarias de este Consejo se han dedicado a Israel.

309 “UN Rigts Chief: Israel's Airstrikes on Gaza May Constitute War Crimes”, The Times of Israel, 27 May 2021. Ver también Baños, Jordi Joan, La Vanguardia, 28 de mayo de 2021.

310 Wrobel, Sharon. "Israel Rejects 'Outrageous' Probe Approved by UN Rights Council After Gaza Conflict", The Algemeiner, 27 May 2021.
} 
presidente de Israel, Reuven Rivlin, que siempre ha destacado por su prudencia a la hora de hacer declaraciones, esta vez la ha roto, al decir: "The world turned upside down... Instead of the free world speaking out clearling against Hamas and its terror leaders, the UN Human Rights Council makes an inexplicable decision against Israeli citizens who faced the criminal fire of thousands of missiles against innocent civilians" 311 . La resolución también hace un llamamiento a los Estados a cortar el aprovisionamiento de armas a los contendientes.

Hay que reconocer que sorprende constatar como un Órgano de las Naciones Unidas como este se lanza a confundir y a tergiversar la situación reinante en la zona, lo que acarrea un gran desprestigio a esta clase de instituciones onusianas, sobre todo cuando son ellos los que no cumplen con el mandato por el que han sido creados. Que quieran hacerse publicidad en esta clase de asuntos, cuando tienen enfrente a una organización terrorista cuyos objetivos son bien conocidos, revela una pasmosa debilidad que perjudica no solo a este Órgano, sino a las Naciones Unidas, en su conjunto. Es más, intentan adoptar de una forma vergonzosa actos ultra vires, pues todos sabemos las competencias de estos órganos. Y es que parece haber entre ciertos órganos onusianos una especie de carrera para ver quien condena más a Israel, y por mucho que se diga lo contrario, esto es antisemitismo. Esto no quiere decir que no se pueda criticar a Israel por actos que puedan ser considerados como ilícitos, o poco éticos o morales, pero otra cosa es señalarlo continuamente por violaciones de los derechos humanos, o incluso crímenes de guerra de cualquier clase o condición, que es lo que más se hace. La Comisión creada para investigar los presuntos crímenes lo tendrá muy difícil para obtener pruebas, no solo porque Israel no colabore, sino porque no ha habido crímenes. Claro, el Consejo de Derechos Humanos querrá ya levantar la moral a la Corte Penal Internacional que se ha declarado competente para investigar crímenes de guerra en otros contextos. Es decir, parece que en Israel no solo está plagado de tecnologías y de nanotecnología de alta gama, reconocidas a nivel mundial, sino también de criminales de guerra... ¿O será quizás porque solo son nueve millones y medio de habitantes, y no más de mil?

Una vez más, el Consejo, mal llamado, de Derechos Humanos se ha equivocado rotundamente errando el tiro, practicando una equivalencia entre un Estado democrático y un grupo terrorista, y los errores de esta índole son graves. Una vez más Israel, a quien los Estados democráticos han reconocido el derecho a defenderse, en diferentes términos cada uno de ellos, vuelve a estar en el punto del día de este Órgano, a pesar de tener el derecho de legítima defensa y haber respetado el Derecho internacional humanitario, diga lo que diga el Consejo. Parece que solo él no lo entiende, ya que en unos momentos en que se está recrudeciendo el antisemitismo, adoptar la celebración de una sesión extraordinaria para tratar esta cuestión, revela que no saben dónde van, pues como dice Ron Malkas, diplomático y Embajador israelí en la India, "The only parties that will gain from de UNHRC session are haters of Israel and supporters of terrorism, as will as the totalitarian regimes around the world" ${ }^{312}$. Es más, preguntado el 26 de mayo, es decir un día antes de que tuviera la sesión el Consejo de Derechos Humanos, sobre qué podría adoptar este Órgano, sin dudar un momento acierta a rajatabla en

\footnotetext{
${ }^{311}$ Ibid. Por su parte, el Embajador israelí ante las Naciones Unidas y los Estados Unidos, Gilad Erdan, ha calificado esta resolución de "outrageous" y "antisemitic”. Sobre esta cuestión, ver también Schindeman, Paul. "Immoral Equivalence: UN Council Blasted for again Singling out Israel for Alleged War Crimes", World Israel News, 27 May 2021. Esta expression de "Immoral Equivalence" está también recogida en la respuesta que dio, la Embajadora israelí ante la sede de las Naciones Unidas en Ginebra, Meirav Eilon Shahar, al indicar que una vez más, el Consejo de Derechos Humanos se ha presentado con una "a false moral equivalence”, recalcando, además, que está practicando una "... inmoral equivalence, between Israel, a democracy that seeks peace and abides by international law, and a murderous, extreme terrorist organization". Ibid. Es más, haciendo comparaciones señaló además sarcásticamente “ ¿qué harían ustedes si esos misiles fueran disparados a Dublín, París o Madrid?”.

312 Malka, Ron. "UNHRC Special Session Won't Benefit Anyone-Israel, Palestinians or the Middle East", The Print, 26 May 2021, en https://theprint.in/opinion/unhre-special-session-wont-benefit-anyone-israel-palestiniansor-the-middle-east/666030/.
} 
el pronóstico, cuando dice: "Firs, without a doubt, another anti-Israel decision will be passed. And whatever decision is taken or resolution passed during the special session will constitute a travesty of justice. Given de history of UNHRC, Israel can have little to no hope of a fair decision". Y Continuando con su análisis se pregunta: "Could any reasonable person possibly believe that democratic Israel, whatever its faults, is equally deserving of scrutiny as all the authoritarian regimes around the world combined? ${ }^{313}$.

Desde esta perspectiva, no es extraño que traiga a colación la explotación persistente de los civiles como escudos humanos, para después censurar a Israel por las víctimas civiles deliberadamente expuestas por Hamás. Es más ¿Acaso no ha sido Hamás el que ha impedido dos veces el paso de los convoyes humanitarios cargados con petróleo y ayuda alimenticia para la población, recurriendo a fuego de morteros sobre los camiones? Sobre esta cuestión, algunas de las primeras informaciones atribuían a Israel estos ataques, hasta que los militares israelíes probaron al mundo que los tiros de morteros procedían de Gaza.

\section{Conclusión}

En estos momentos no parece fácil vislumbrar las sendas que elegirá el presidente Biden para cumplir con lo que venía insinuando desde que anunciara las directrices que iba a seguir si ganaba las elecciones en la revista Foreign Affairs, de marzo-abril 2020. Habló de que quería unificar el país, pero cuando fue investido, lo primero que hizo fue empezar a adoptar órdenes ejecutivas en plan autoritario causando extrañeza en el mundo. No obstante, no podrá conseguir lo que quizás a él le hubiera gustado, como podría ser el anular el traslado de la embajada de los Estados Unidos de Tel Aviv a Jerusalén, pues ya ha dicho que no tocará ese asunto.

Más resuelto se le ve a la hora de volver al acuerdo nuclear de 2015, y está haciendo hasta ahora todo lo que puede por conseguirlo. Irán no se lo está poniendo fácil, y las negociaciones se están desarrollando en un clima político complicado debido a las sanciones que impuso Trump al salirse del acuerdo, pero también debido a las elecciones iraníes del 18 de junio, algo a lo que no se le ha dado la importancia que tiene. Y es que, al ganar el candidato del ala radical, las negociaciones se endurecerán, y el precio a pagar por parte de los Estados Unidos será alto. Otro problema que tiene Joe Biden en esta materia es la seria oposición de Israel a que se integre en el acuerdo tal y como está ahora, dejando claro que velará por su seguridad, vigilando unilateralmente que Irán no obtenga el arma nuclear, recurriendo incluso al uso de la fuerza si fuera necesario. Todo ello en medio de una nueva situación internacional creada por el desarrollo balístico y nuclear de Corea del Norte, cuyos lazos y acuerdos con Irán son perfectamente conocidos, pudiendo utilizar medidas de retorsión en este campo. La permanencia y consolidación de Corea del Norte como país nuclear de facto es un factor también fundamental distorsionador que difumina el rigor de múltiples análisis sobre esta negociación y este acuerdo. ${ }^{314}$

Respecto al conflicto israelo-palestino, lo primero que conviene remarcar es que el conflicto, tras estar controlado durante el mandato de Trump, que guste o no es una realidad, ha vuelto a resurgir con Joe Biden, a pesar de los Acuerdos de Abraham y la nueva realidad existente con los países árabes de la zona. Esto se debe en gran medida a que Joe Biden, a pesar de que ha reconocido lo positivo que ha sido la celebración de los Acuerdos de Abraham, siempre lo ha dicho con la boca pequeña, demostrando además muy poca cordialidad, cuando

\footnotetext{
${ }^{313}$ Ibid.

${ }^{314}$ Marquina Antonio: "Los conflictos internacionales con Irán y Corea del Norte (I): el proceso negociador”, UNISCI Discussion Papers, $\mathrm{n}^{\circ} 13$ (Enero / January 2007), en http://www.unisci.es/wpcontent/uploads/2017/05/Marquina13.pdf; Marquina Antonio: "The US Relations with the two Koreas" en Parc Jimmyn, Yang EunSook, Ranger Stephen (eds.) (2020): South Korea's International Relations with its Neighbors. Madrid, UNISCI, pp. 107-172.
} 
no enemistad, con el país poderoso de la zona, Arabia Saudí, hasta no hace mucho el principal pilar de los Estados Unidos, obviamente tras Israel. Esto ha sido interpretado por los palestinos, y sobre todo por Hamás y la Jiad Islámica, como el momento apropiado para lanzarse a la aventura, primero instigando los disturbios dentro de Israel, y sobre todo en Jerusalén, pero también en otras ciudades mixtas en donde han convivido pacíficamente, al menos hasta ahora, ambas comunidades, la árabe y la judía. Y es que la administración Biden y el Partido Demócrata, donde hay, como se ha apuntado, personalidades que han mostrado abiertamente no ya una oposición a la política israelí, sino claramente "odio" hacia Israel y los judíos, ha abierto el camino a esta situación, ya que si Kamala Harris, Alexandria Ocasio-Cortez, Bernie Sanders, etc., tenían carta blanca para atacar a Israel y a los judíos, guardando el presidente un silencio cómplice, esto ha abierto la espita de los disturbios, y rápidamente la apertura de las hostilidades por parte de Hamás, lo que ha traído consigo el inicio de las hostilidades. Así las cosas, no conviene olvidar que el conflicto israelo-palestino sigue por el momento paralizado donde estaba, sin que el nuevo gobierno israelí haya dado pasos significativos al respecto. Y es que, para el actual primer ministro israelí, Naftali Bennet, no es el momento ni se dan las circunatancias de reconocer un Estado palestino.

Pero iniciadas las hostilidades, Hamás ha tenido que hacer frente a algo inesperado, que ha sido la contundente respuesta israelí, demostrando a Hamás y a sus aliados, no solo lo que Israel ha hecho, sino también lo que podría hacer, pero que no ha hecho, intentando hacerles comprender que Israel está ahí, dispuesto a defenderse solo. En este caso, Joe Biden ha salido al paso de forma decidida, reconociendo a Israel el derecho a defenderse de los misiles lanzados por Hamás contra las zonas civiles, mientras Israel, haciendo alarde de una ética jurídica ejemplar, ha respetado las normas del derecho internacional humanitario, distinguiendo objetivos civiles, de los militares. Esto ha sido así, por mucho que no le guste al Consejo de Derechos Humanos de las Naciones Unidas. Y es que una democracia viva tiene savia para hacer frente al terror, venga de donde venga.

Un problema que puede tener la administración Biden es el carácter de su presidente. Y es que el desaguisado que Joe Biden preparó con Putin al llamarle "killer" en un alarde de soberbia poco común, ya le ha costado caro al consentir el "Nortd Stream 2" y al mismo tiempo la renuncia a las sanciones a la empresa del citado oleoducto y su director ${ }^{315}$. Esto demuestra su carácter impulsivo que le lleva a cometer errores que demuestran que su administración no es tan perfecta como él prometía ${ }^{316}$. Ha reconocido que seguir adelante e imponer sanciones ahora es contraproducente en términos de sus relaciones con los países europeos. Si a esto añadimos que el proyecto está acabado al 95\%, y que el gas llegará desde Rusia a Berlín, uno

\footnotetext{
315 Se trata de la empresa suiza "Nortd Stream 2 AG", y su director ejecutivo el alemán Matthias Warnig.

${ }^{316}$ El exabrupto pronunciado por Joe Biden a Vladimir Putin al calificarle de "killer", nos recuerda aquella comparación que hizo entre Trump y el nazi Joseph Goebbels, comparación que fue muy aplaudida por muchas personalidades demócratas, destacando su ironía. Para unos ejemplos de las críticas que los medios internacionales, que fueron muchos, hicieron a este exabrupto de Joe Biden. Véase Bailey, Beth. "Joe Biden compared Trump to Joseph Goebbels. Where is the ADL's Condemnation?", Washington Examiner, September 28, 2020, en https://www.washingtonexaminer.com/opinion/joe-bgoebbels-wheren-is-the-adls-condemnation. El autor recoge muchas críticas publicadas al respecto, pero también señala que "Many Democrats, on the other hand, applauded Biden's jab for its alleged accuracy". Y el autor recoge la idea de que "The Democratic Party playbook of comparing Trump to various Nazi figureheads continues to be employed because it works thanks to ignorance of Naci atrocities". Ver también Mansfield, Mollie. "Fighting Words Joe Biden Shockingly compares Trump to Hitler's Nazi propagandist Joseph Goebbels in Wild Attack", The Sun, 22 September 2020, que recoge literalmente la frase de Biden: "He's sort of like Goebbels. You say the lie long enough, Keep repeating it, repeating it, it becomes common Knowledge, they think", en

https://www.thesun.co.uk/news/12779891/joe-biden-donald-trump-joseph-goebbels/. Para un mayor desarrollo sobre esta cuestión, véase "Joe Biden compare Donald Trump au Nazi Joseph Goebbels", The Times of Israel, 27 September 2020.
} 
de los sancionados sería Alemania, que es precisamente uno de sus mejores aliados en Europa. No es fácil comprender como es posible que se metiera en un terreno tan pantanoso y peligroso, pues Rusia no es cualquiera, asunto que ahora parece que lo reconoce al haber aceptado la cumbre que ha tenido lugar en Ginebra el 16 de junio $2021^{317}$.

Por otro lado, hay declaraciones por parte de algunas personalidades de la administración Biden que hablan de paz, pero lo que pueden traer es más guerra. Tal es el caso de Antony Blinken, quien ha advertido al gobierno israelí que la reclamación de viviendas por parte de judíos cuyos títulos de propiedad son correctos, pero de las que fueron desalojados en 1948 por Jordania (que están situadas en el barrio de Sheik Jarrah, de Jerusalén) generaría "tensión, conflicto y guerra" si continúan con sus reclamaciones ante la Justicia ${ }^{318}$. Habrá que preguntar a Antony Blinken qué significa para él el "derecho de propiedad", y si lo que propone que se haga en Israel, que se haga también en los Estados Unidos. No parece que su propuesta sea muy respetuosa con el estado de derecho de un país democrático. Si hay controversia en torno al derecho de propiedad de las citadas viviendas tendrán que ser los jueces los que lo decidan. Cuestión distinta es que se pueda negociar entre las partes la solución del caso, incluso a nivel político, para poder encontrar una solución. Y eso es posiblemente lo que pretende Antony Blinken... ${ }^{319}$.

\section{Bibliografía}

"A Shock for the Saudis: Joe Biden Puts Saudi Arabia on Notice", The Economist, 5 de febrero de 2021.

"As Israel-Hamas Cease-Fire Holds, Gazans Survey Wreckage", The New York Times, May 25, 2021.

“Aviv Kochavi comdamne l'enquéte de la Cour pénale internationale”, The Times of Israël, 22 mars 2021.

"Biden Admin Silent about Alleged Massive National Security Breach by Kerry", Breaking Israel Video, en https://mail.google.com/mail/u/O/\#inbox/FMfcgxwLtVTzgcSDThKgQXdmFXcDvZ.

"Biden Admits Iranian Nukes a 'Serious Threat', but Supports JCPOA Talks", World Israel News, 2 May 2021.

"Biden Repudiates Trump on Iran, ready for Talks on Nuke Deal", World Israel News, 19 February 2021.

\footnotetext{
${ }^{317}$ La cumbre no ha sido solo buena para Putin y Rusia, sino también para Alemania, ya que el gasoducto transportará hasta 55.000 millones de metros cúbicos de gas al año, tras pasar por las aguas territoriales o zonas económicas exclusivas de Alemania, Dinamarca, Finlandia, Rusia y Suecia. Este gasoducto rompe con las esperanzas de los Estados Unidos de vender gas en Europa, contando al efecto con el apoyo de países como Letonia, Lituania y sobre todo Polonia, muy dependientes de las exportaciones rusas, pero que se oponían también al "Nord Stream 2". Para más detalles, véase "Biden defiende la renuncia a las sanciones contra Nord Stream 2 y señala que serían <<contraproducentes〉>, El Periódico de la energía, 26 de mayo de 2021.

318 “Jews Reclaiming Jerusalem Homes Will Cause new 'war', says Blinken”, World Israel News,30 May 2021.

${ }^{319}$ Esta cuestión ciertamente ha generado discordias y tensiones que él mismo reconoce, y que convendría evitar. A este respecto, señala: "We raised the concerns that we have on all sides with actions that in the first instance could spark tension, conflict and war and also ultimately undermine even farther the difficult prospects for two states", Ibid.
} 
"Biden Sends ex - Obama Official to Israel as Acting Ambassador", World Israel News, 22 May 2021.

"Biden: No Easing of sanctions until Iran Complies with Nuclear Deal", Israel365 News, 8 February 2021.

"Bidens Desire to Reach out to Iran, Sparks Israel's Potential Attack on Iran", Breaking Israel, 27, January 2021.

"Gantz affirme que l'armée reste prête à toute attaque de sites nucléaires d'Iran", The Times of Israel, 5 mars 2021

"Government, IDF Working on Budget for Potential Iran Strike Plan-Report", The Jerusalem Post, February 2, 2021, en https://www.jpost.com/Israel-news-government-idf-working-onbudget-for-potential-iran-strike-plan-report-657505?

"Hamas Leader Admits Targeting Civilians with Rockets in Exclusive Interview", Israel Video Network, 25 May 2021, en https://mail.google.com/mail/a/O/\#inbox/FMfcgcGKXScZVFTpnbhmhlFWDLtsB/Dw

“Hamas Leader Wants to Connect with Biden”, Israel 365 News, 25 May, 2021.

"Hezbollah, IRGC, Hamas Established Chamber of Military Operations in Beirut during israelí War on Gaza: Report", Almanarnews en, 28 May 2021, en https://english.almanar.com.lb/1352914,

"IAEA Director Admits an Iranian Nuclear Weapon Inevitable", Israel365 News, 26 May 2021.

"IDF Chief: strike on Iranian Nuclear Sites is on 'on the Table". Israel Defence Forces Chief of Staff Aviv Kochavi told the Biden Administration that Renegotiating the Iran Nuclear Deal it is not the Right Thing to Do, United with Israel, 27 January 2021. en https://unitedwithisrael.org/idf-chief-hit-on-iraniannuclear-sites-is-on.the

table/?utm_source=newsletters_unitedwihtisrael_org\&utm_medium=email\&utm_content=ID F+strike+on+Iran+Nukes+is+on+the+Table\%3B+Israel\%27s+Arab+Allies+Promote+Holoca uste.

"IDF: Most Main Target, in Gaza have been hit", en https://www.netnews.com/article/ryDnE27cO.

"Iran Accord sur le nucléaire: des négociations <<positives〉>", Centre-Presse, en https://www.centre-presse.fr/article-787417-iran-accord-sur-le-nucleaire-des-negociationspositives.html.

"Iran Bans 15 People from Travelling Over Zarif Leak, Official Resigns", Reuters, 29 April 2021, en https://www.reuters.com/world/middle-east/iran-bans-15-people-travelling-overzarif-leak-official-resigns-2021-04-29/

“Iran celebrates 'Nuclear Day' by firing up Advance Centrifuge Iran's IR-9 Centrifuge is 50 Times Quicker than the First Iranian Centrifuge, the IR-1", World Israel News, 10 April 10, 2021.

"Iran Nuclear Agreement is Implemented Notwithstanding Expressions of Distrust by Iran and the U.S. Congress" (Contemporary Practice of the United States Relating to International Law), vol. 108, nº 1, American Journal of International Law, 2014, pp. 343-347.

"Iran: la fuite-d'un audio vise à crér la <<discorde>> pendant les négociations", The Times of Israël, 28 avril 2021. 
“Iran's Foreign Minister in Leaked Tape, Says Revolutionary Guards Set Policies", The New York Times, 25 April 2021, en

https://nytimes.com/2021/04/25/world/middleast/Iram-suleimani-zarif.html.

"Iran's President-Elect Refuses to Meet Biden, Digs in on Ballistic Missiles", World Israel News, 21 June 2021.

"Israel 'very pleased' with US strikes on Iranian targets in Syria, was Informed in Advance", The Algemeiner, 26 February 2021.

"Israel engaña a Hamás con una brillante estrategia para atacar 'El Metro" de Gaza”, Diario Judío México Mas ideas, 14 de mayo de 2021.

“Israel Reject, ICC Probe into IDF 'War Crimes', Saying it Lacks Jurisdiction”, World Israel News, 8 April 2021.

"Israel Reveals Iranian Target Map we are ready to fight", World Israel News, 6 March 2021.

"Israel will end attacks if the captures soldier is released", en http://www.irishexaminer/irishexaminer/pages/story.aspx-qqqg=world-qqqm=world-

qqqa=world=qqq.d=7409-qqqx=1.asp. El mensaje original en inglés fue el siguiente: "I take personal responsibility for what is happening in Gaza. I want no one to sleep at night in Gaza.

I want them to know what it feels like.

"Israel's Secretive Dim one Nuclear Facility Under goes Major Project. What the Construction is for, however, Remains Unclear. The Israeli Government did no Respondent to Detailed Questions about the Wok", World Israel News, 25 February 2021.

"Joe Biden compare Donald Trump au Nazi Joseph Goebbels", The Times of Israel, 27 September 2020.

“Joe Biden quelifie Poutine de «tueur », la Russie rappelle son ambassadeur", Le Temps, 18 mars 2021.

"John Kerry Accused of Sharing Israel's Vital Security Information with Iran”, Breaking Israel, 27 April 2021, en

https://mail.google.com/mail/u/O/\#imbox/FMfcgxwLtkSCegKpWgRBfRJVVTQxTJvb

"Krauss Joseph. Israel Rejects ICC Probe, Saying it Lacks Jurisdiction", The Washington Post, 8 April 2021.

“L'Iran annonce qu'il « va commencer à enrichir l'uranium à $60 \%$ »”, The Times of Israël, 13 avril 2021.

'L'Iran et l'AIEA annoncent un accord 'temporaire' de surveillance des activités nucléaires", en https://www.france24.com/fr./moyen-orient/20210221-nucleaire-I-iran-salue-desdiscussions-fructueuses-avec-I-aiea

"Lebanon Will Tremble if Hezbollah Attacks, Warns Israel", United with Israel, 21 February 2021.

“Les Etats-Unis multiplient les gestes à l'égard de l'Iran”, Le Temps, 19 février 2021.

"Les tunnels du "Metr" de Gaza-cible principale des frappes israéliennes", The Times of Israël, 21 mai 2021.

"Moscou promet des contre-sanctions visant Etats-Unis et convoque l'ambassadeur", L'Orientle Jour, 15 avril 2021. 
"Netanyahu to Austin: Israel Won't Allow Iran to Carry Our Goal of Nuclear Genocide", Jewish Journal, 13 April 2021.

"Netanyahu Warns Biden: Israel Calls the Shots in War with Hamás, Not US", United with Israel, 18 May 2021.

"Netanyahu: Israël a atteint ses objectifs à Gaza, a « changé la règle du jeu »", The Times of Israël, vendredi 21 mai 2021.

“Netanyahu: Israël ne vas pas « coopérer» avec la CPI”. The Times of Israël, 9 avril 2021.

“Nucléaire iranien : Des négociations 'positives' après des tensionc en série”, The Times of Israël, 15 avril 2021.

"Nucléaire: l'Iran se dote de centrifugueuses nouvelle génération, dont l'utilisation lui est pourtant interdite", Le Monde, 10 avril 2021.

"Olmert: La bombe de Natanz en Iran pourrait avoir été placée il y a 10 ou 15 ans", The Times of Israël, 14 avril 2021.

“ONU: L'Iran enfreint l' accord et installe de nouvelles centrifugeuses à Natanz”, The Times of Israel, 3 février 2021.

"Our Warplanes Can reach Iran, Israel Minister Warms Amid Nuclear Talks", Reuters, 29 April 2021.

"Pretende Rusia invadir Ucrania?", Fundación FAES, 7 de abril de 2021, en https://fundacionfaes.org/es/contenido/47405/a-pretende-rusia-invadirucrania?et=t0\&mc_eid=2e37ba5/5d\&mc_eid=28a8e=bd18.

"Républicains à Biden: cessez les discussion, avec l'Iran, sautien du Hamás", The Times of Israël, 13 mai 2021.

"Rohani ordonne une enquête après des propos du chef de la diplomatie ayant fuité", The Times of Israël, 27 avril 2029.

"Situation in the State of Palestine", no ICC-01/18, 5 February 2021, en https://icc-cpicpi.int/CourtRecords/CR2021_01165.PDF.

“Un 'apagón' sospechoso en una instalación nuclear de Irán”, SWI, 11 de febrero de 2021, en https://www.swissinfo.ch/spa/afp/un--apagón--sospechoso-en-una-instalación-nuclear-deirán/46522156.

"UN Rigts Chief: Israel's Airstrikes on Gaza May Constitute War Crimes", The Times of Israel, 27 May 2021. Ver también Baños, Jordi Joan, La Vanguardia, 28 de mayo, 2021.

"United States Fails to Secure Multilateral Snapback Sanctions Against Iran" (Contemporary Practice of the United States Relating to International Law Eichonsehr Kristen Ed.), American Journal of International Law, vol. 115, n 1 (2021), pp. 140-146.

"United States Imposes Economic Sanctions and Visa Restrictions on International Criminal Court Officials" (Contemporary Practice of the United States Relating to International Law, Eichensehr Kristen Ed.) American Journal of International Law, vol. 115, n ${ }^{\mathrm{o}} 1$ (2021), pp. 138140.

"United States Pursues Non-proliferation Agenda at NPT Review Conference, Agrees to 2012 Conference on Nuclear-Free Middle East", (Contemporary Practice of the United States), American Journal of International Law, vol. 104, n 3 (2010), pp. 520-524. 
"Blinken : Si l'Iran continue d'enfreindre l'accord, elle pourrait avoir la bombe", The Times of Israël, 1 février 2021.

"Nucléaire : Téhéran demande aux Européens de jouer les médiateurs avec Washington", Le Temps, 2 février 2021.

Agencia DPA: "Rusia/EEUU. Rusia convoca al embajador de EEUU tras el anuncio de sanciones y promete una respuesta contundente", en

https://www.clarin.com/agencias/dpa-rusia-ecun-rusia.convoca-embajador-eeuu-anuncio-

sanciones-promete-respuesta-contundente-_O_evbFKHLqf.html.

Ahronheim, Anna y Kayser, Zachary: “Two Thai Workers Killed in heavy mortar barrage on Israel's south from Gaza”, The Jerusalem Post, 18 May 2021.

Albiac, Gabriel: "Israel, Israel...", ABC, 13 de mayo de 2021.

Allgöwer, Marc : "Joe Biden, la forme et le fond”, Le Temps, 19 mars 2021.

Assouline, Pierre-Simon : “Un cessez-le-feu aux contours flous”, Le Temps, 21 mai 2021.

Auerbach, Jerold. "President Biden : Israel's Friend or Foe ?", The Algemeiner, 11 April 11, 2021.

Bailey, Beth: "Joe Biden compared Trump to Joseph Goebbels. Where is the ADL's Condemnation?", Washington Examiner, September 28, 2020, en: https://www.washingtonexaminer.com/opinion/joe-bgoebbels-wheren-is-the-adlscondemnation (consultado el 26 de enero de 2021).

Beck, Atara: "We Hit the Terror Group Hard; Netanyahu Says After Ceasefire With Hamas Proclaimed", United with Israel, 21 May 2021.

Beilin, Yossi: "Israel Should cooperate with the ICC", Israel Hayom, 12 February 2021, en https://www.israelhayom.com/opinions/cooperating-with-the-icc-to-fight-for-justice/

Benzion, Yakir. "Netanyahu warns that U.S. reentering the Iran Nuclear Deal would lead to 'nightmare' of other states seeking nuclear weapons", United with Israel, 15 January 2021.

Bergman, Ronen, Gladstone, Rick y Fassihi, Farnaz. "Blackout Hits Iran Nuclear site in What Appears to Be Israeli Sabotage”, The New York Times, 11 April 2021.

Berkowitz Adam, Eliahu: "Republicans Block Biden \$150 Million to Palestinians", Israel365 News, 11 April 2021.

Berkowitz Adam, Elisyu. "Iranian Ayatollah I want Peace with Israel, to Pray with them at Western Wall”, Israel365 News, 31 January 2021.

Berkowitz, Adam Eliahu: “Iran's Main Nuclear Site Mysteriously Suffers Power Outrage Right After Advanced Centrifuges go online”, Israel 365 News, 11 April 2021.

Berman, Lazar: "Si Teherán et Washington s'accordent, Israël a besoin d'une nouvelle approche", The Times of Israël, 27 avril 2021

Berman, Lazar : 'L'ouverture d'un bureau diplomatique tchèque à Jérusalem dénoncée par l'AP", The Timesw of Israël, March 14, 2021. Ver también, "El Primer Ministro checo inaugura una oficina diplomática en Jerusalén”, Aurora, 11 de marzo de 2021.

Bermejo García, Romualdo: "De Trump a Biden: ¿Ruptura o continuidad en la política exterior de los Estados Unidos”, en: Fernández Liesa, Carlos y López-Jacoiste Díaz, Eugenia (Coords) (2021): Nuevas dimensiones del Desarrollo sostenible y los derechos económicos sociales y culturales, Cizur Menor 
Bermejo García, Romualdo: "La política de Trump ante el conflicto israelo palestino a la luz del Derecho internacional: un balance positivo", Anuario Español de Derecho Internacional. vol. 37, (2021), pp. 9-70.

Bermejo García, Romualdo "Cuestiones claves del Próximo y Medio Oriente”, en: Gutiérrez Espada, Cesáreo y Cervell Hortal, Ma José (dir) (2016): La Unión Europea como actor global de las relaciones internacionales: retos y problemas seleccionados, Valencia, Tirant lo Blanch, pp. 9-122.

Bermejo García, Romualdo y Gutiérrez Espada, Cesáreo: "Del programa nuclear iraní de la República Islámica de Irán y de su evolución (Política y Derecho)”, Anuario Español de Derecho Internacional, vol. 31 (2015), pp. 7-63.

Bermejo García, Romualdo y Gutiérrez Espada, Cesáreo: "El programa nuclear iraní en el ojo del huracán”, Revista Española de Derecho Internacional, vol. 57, nº 1 (2005), pp. 105-119.

Bermejo García, Romualdo y López-Jacoiste Díaz, Eugenia: La ciberseguridad a la luz del Jus ad Bellum y del Jus in Bello, Pamplona, Eunsa, 2020, 224 p.

Bermejo García, Romualdo: “¿Es Palestina un Estado? Reflexiones a la luz del Derecho internacional y de la práctica europea sobre los acontecimientos recientes en torno al reconocimiento de un Estado palestino", Revista de Estudios Europeos, nº 65 (2014), pp. 9-40.

Bermejo García, Romualdo: "El futuro de Israel y Palestina tras el reconocimiento de esta como 'Estado Observador' no miembro en las Naciones Unidas", Revista Española de Derecho Internacional, vol. 65, $\mathrm{n}^{\mathrm{o}}$ 1(2013), pp. 262-369

Bermejo García, Romualdo: "Israel en dos frentes: algunas cuestiones jurídico-políticas en torno a la desconexión de Gaza y a la guerra de Hizbolandia, en Ramón Chornet, Consuelo (Coord.) (2008): Conflictos armados y Derecho internacional humanitario, Valencia, Tirant lo Blanc, pp. 171-210.

Biden, Joseph Jr.: "Why America Must Lead Again Rescuing U.S. Foreign Policy After Trump”, Foreign Affairs, vol. 99, nº 2 (March/April, 2020), pp. 64-76.

Bob Yonad Jeremy: "IDF Chief Kochavi: return to Iran 2015 Nuclear Deal is Strategic Mistake", The Jersusalem Post, 27 January 2021.

Bob Yonah, Jeremy, Lahar, Harkov y Joffre, Tzivi: "Mossad Behind Attack on Iran's Natanz Nuclear Facility”, The Jerusalem Post, 13 April 2021.

Bob, Vomah Jeremy: "ICC Prosecutor to Decide Cyprus File Before Exist", The Jerusalem Post, 18 February 2021.

Bob, Vomah Jeremy: "ICC Prosecutor to Decide Cyprus File before Exit. Case Could Have Implications for Israeli Settlement”, The Jerusalem Post, 18 February 2021.

Brewer, Eric: "A clean return to the Iran nuclear deal should be Biden's first option", Bulletin of the Atomic Scientist, 75 years and counting, 11 January 2021, en https://thebulletin.org/2021/01/a-clean-return-to-the-iran-nuclear-deal-should-be-bidens-firstoption/

Calumani Quilca, Milagros: "Implicancias de la salida natural de los Estados Unidos del Acuerdo Nuclear con Irán”, Anuario Mexicano de Derecho Internacional, vol. XX, (2020), pp. 655-685.

Clemenceau, François : “Jean-Yves Le Drian : L'insurrection aux Etats-Unis nous enseigne qu'il faut rester vigilants”, Journal du Dimanche, 16-17 janvier 2021. 
Cohen, Ben. "America Has Made a Serious Mistake on UNRWA" The Algemeiner, 11 April 2021.

Conde de los Rríos, Augusto: Las implicaciones de la llegada de Biden para Irán, IEEE, Documento de Opinión 23/2021, 25 de febrero de 2021.

Cooper, Abraham: "The ICC Opens a New Front in the War Against Israel. Why We Must Fight", Jewish Journal, 9 February 2021, en https://jewishjournal.com/commentary/332735/the-icc-opens-a-new-front-in-the-war-againstisrael-why-we-must-fight/.

Dan, Gavriel: "If Hamas Breaks The Calm and Attacks Israel Our Response Will Be Very Powerful", Breaking Israel Video, en https://www.israelunwired.com/hamas-heavyprice/8utm_source=ActiviCampaign\&utm_medium=email\&utm_content="If + Hamas+Breaks + The+Calm+And+Attacks+Israel\%2C+Our+response+Will+Be+Very+Powerful

Danoti, Jessica: "Biden Administration Ends Sanctions Against ICC Officials, Overturning Trump Policy", The Wall Street Journal, 2 April 2021.

De Coraffenried, Valérie : "La timide posture de Joe Biden face à Israël", Le Temps, 13 mai 2021.

De Graffenried, Valérie : "Violences au Proche-Orient, la fracture démocrate aux Etas-Unis", Le Temps, 18 mai 2021.

Dekkiche, Vanis : "Rétablissement des relations diplomatiques sur fond de reconnaissance de la souveraineté mavocaine sur le Shara Occidental", Chronique des faits internationaux, Revue générale de droit international public, $\mathrm{n}^{\circ} 1$ (2021), pp. 89-93.

Dromi, Uri: "The Civil Riots in Israel Are a Warning to Prevent a Dark Future", Jewish Journal, 24 May 2021.

Dunner, Pini: "Searching for Peace in the Middle East", The Algemeiner, 21 May 2021.

Egozi, Arie: "Mossad Head Briefs Biden Admin on Iranian Nukes, Missiles", Breaking Défense, 13 January 2021, en https://breakingdefense.com/2021/01/mossad-head-briefs-bidenadmin-on-iranian-nukes-missiles

Englad, Andrew: "IAEA Chief Sounds Alarm over Iran's Nuclear Program", en https://www.ft.com/content/add04cf8f-1740-4022-9119-114b6bd66c4b

Fard, Erfan: Antisemitisme Is Inseparable from Khomeinism, The Begin-Sadat Center for Strategic Studies, BESA Center Perspectives Paper nº 1999, 16 April 2021.

Fard, Erfan: Biden's CIA Director and Iran, The Begin-Sadad Center for Strategic Studies, BESA Center Perspectives Paper nº 1965, 14 March 2021.

Fard, Erfan: Israeli Intelligence Cooperation with Arab Allies Thwarts Iranian Terrorism, Begin-Sadat Center for Strategic Studies, BESA Center Perspectives Paper $n^{\circ}$ 1954, 8 March 2021.

Fatah Tarek, Fatah: "Palestinians Die as Hostages of Hamas", Toronto Sun, 19 May 2021, en https://torontosun.com/opinion/columnists/fatah-palestinians-die-as-hostages-of-humans.

French, David: "The Two Wrongs of the Gaza Narrative”, The Dispatch, 14 May 2021, en https://frenchpress.thedispatch.com/p/the-two-wrongs-of-the-gaza-narrative

Frisch, Hillel: Is the Phrase "State of Palestine" Catching on? The Begin-Sadat Center for Strategic Studies, BESA Center Perspectives Paper nº 1931, 15 February 2021. 
Frisch, Hillel: The Strategic Genius Behind Allowing Qatari Suitcases of Cash into Gaza, The Begin-Sadat Center for Strategic Studies, BESA Perspectives Paper nº 2053, 27 May 2021.

Frish, Hillel: Israel's Top Priority: Immediate Confiscation of Illegal Weapons amongst Israeli Arabs, The Begin-Sadad Center for Strategic Studies, BESA Center Perspectives Paper nº 2041, 21 May 2021.

Gadi Eizenkot indicando que "Israel finally realises that Arabs should be accountable for their leaders' acts", Yediot Ahronoth, 10 June 2008.

Geoffrey S. Corn and Rachel E. Vamlandingham: "The Illegitimate Instinct to Delegitimaze Israel Opinion”, Newswek, 24 May 2021, en https://www.newsweek.com/illegitimate-instinetdelegitimize-israel-opinion-1592640.

Gilead, Ini: "As Hamas Fired Rockets, the New York Times Joined the Assault on Israel”, The Algemeiner, 30 May 2021.

Glic, Caroline: “The Price of Friendship with Biden's Washington: Analysis”, World Israel News, 7 June 2021.

Gold, Dore: "Israel Should Fight Back", Jews New Syndicate, 14 February 2021, en https://www.jns.org/opinion/israel-must-fight-back-against-the.icc/.

Goldberg, Richard y Dubowitz, Mark. "Why Biden's Plan to Rejoin the Iran Deal Makes No Sense", Foreign Policy, 8 January 2021.

Graffenried de Valérie : “Washington ne cède rien face à Pékin”, Le Temps, 19 mars 2021.

Greenfield, Larry: "Can Civil Discourse Prevent Our Second Civil War?", Jewish Journal, 28 May 2021.

Gross, Judah Ari. "Le chef de Tsahal fait allusion aux attaques présumées d'Israël contre l'Iran", The Times of Israel, 11 avril 2021.

Gross, Judah Ari. "Le complexe nucléaire de Natanz touché par un acte de 'terrorisme' dit Teheran", The Times of Israel, 11 avril 2021.

Gross, Judah Ari. “Tsahal : Le conflit será une « réussite » s’il apporte « 5 années de calme »”, The Times of Israël, 19 mai 2021.

Gupta, Anoop Kumar : Figuring Out Hama's Strategy, The Begin-Sadat Center for Strategic Studies, BESA Center Perspectives Paper nº 2050, 26 May 2021.

Hacohen, Gershon: The Gaza War Ended, the Hamas Problem Remains, The Begin-Sadat Center for Strategic Studies, BESA Center Perspectives Paper nº 2042, 21 May 2021.

Hacohen, Gershon: Lt.-Gen. Aviv Kochvi's Land mark speech, The Begin-Sadat Center for Strategic Studies, BESA Center Perspectives Paper nº 1912, 2 February 2021.

Hacohen, Gershon: Not an Existential Threat - A Vital national Interest, The Begin-Sadat Centre for Strategic Studies, Besa Center Perspectives Paper nº 1898, 22 January 2021.

Haddad, Benjamin. "How Europe Became Pro-Israel", Foreign Policy, 20 May 2021, en https://foreignpolicy.com/2021/05/20/how-europe-became-pro-israel.

Harkov, Lahav. "Ganz to Austin: IDF to continue Gaza campaign to achieve long-term quiet", The Jerusalem Post, 18 May 2021.

Harkov, Lahav. "Germany, Hungary Join States Opposing ICC Probe of Israel”, The Jerusalem Post, 9 February 2021. 
Harkov, Lahav: "Israel, in first Comment, Says Troubled by US Position ahead of Iran Talks", The Jerusalem Post, April 5, 2021.

Harkov, Lahav: "US, Iran Head to Vienna for Indirect Nuclear Deal Talks", The Jerusalem Post, 3 April 2021.

Herman, Peter C. “Hamas vs. Israel: Who won?”, Jewish Journal, 28 May 2021.

Hershco, Tsilla. Israel-France Relations in Light of the ICC Decision, 8 April 2021.

Imbert, Louis. "Israël met en garde contre un retour à l'accord sur le nucléaire iranien", Le Monde, 28 janvier 2021.

Isaac, David. "Haley reacts to Kerry's Iran Leak: Disgusting on Many Levels", World Israeli News, 27 April 2021.

Isaac, David. "Israel behind Natanz Nuclear Mishap? IDF Cheaf of Staff Says Our Actions Are not Hidden from enemy Eyes", World Israel News, 11 April 2021.

Isaac, David. "Netanyahu: We Will not be bound by an Iran Deal that Threatens to Destroy Us", World Israel News, 7 April 2021.

Isaac, David. "Nikky Haley: Biden 'snubbing Israel' While crying up to enemies by Iran", World Israel News, 7 February 2021.

Isaac, David. "No Accident: Israel Behind Iran Nuclear Incident, Intel Sources Say”, World Israel News, 11 April 2021.

Isaac, David. "Undiluted anti-Semitism: Netanyahu Outraged at ICC for Investigating Israel", World Israel News, 3 March 2021.

Isaac, David: “Ted Cruz warns Biden's Iran Policy Could Threaten Israel's very existence”, World Israel News, 20 January 2021.

Jaccottet, Aline : “Au coeur de Natanz, la mise en garde israélienne”, Le Temps, 13 avril 2021. Jeremberg, Batya: "Hamas Mulling Direct Talks with Israel”, World Israel News, 23 May 2021. Jeremberg, Batya. "PA Gloats as Biden Team Returns to Old Peace Formula: The Deal of the Century is Dead", World Israel News, 28 January 2021.

Jerenberg, Batya: "Biden source: Israel Will be Consulted Before U.S. Reenters Nuclear Deal with Iran”, World Israel News, 17 January 2021.

JNS. “Former Israeli Ambassadors Say Kerry's History of Conflict with Israel Lends Weight to Iranian Accusation", Israel 365 News, 30 April 2021.

Joffe, Alex: Gaza and the War Between the Democrats, The Begin-Sadad Cente for Strategic Studies, BESA Center Perspectives Paper nº 2041, 16 May 2021.

Joffre, Tzivi y Bob Yonah, Jeremy: "Natanz Attack it is 50 Meters Underground Destroyed Most of the Facility", The Jerusalem Post, 13 April 2021.

Karsh, Efraim: Israel's Arabs v. Israel, The Begin-Sadad Center, BESA Center perspectives Paper $n^{\circ}$ 2029, 14 May 2021.

Karsh, Efrain: Hamas' Relentless Jiad, The Begin-Sadad Center, BESA Center Perspectives Paper n 2044, 23 May 2021.

Kasnett, Israel: "Biden is Failing Mideast Test, Response is 'Ridiculous', Analyse Say", United with Israel, 13 May 2021. 
Kasnett, Israel: "Former Secretary Pompeo Blasts Biden Team for 'Folly' of Appeasing Iran", United with Israel, 23 May 2021.

Katz, Yaakov: "Israel's Gaza War is Like no Other Military Operation in History-Opinion", The Jerusalem Post, 21 May 2021.

Kedar, Mordechai: Toward a Palestinian State? The US Confers Legitimacy on the Palestinian Authority and Hamas, Besa Center Perspectives Paper n 1949, 5 March 2021.

Kemp, Richard: "The International Criminal Court Threatens Middle East Peace", Gatestone Institute, 11 February 2021, en

https://www.gatestoneinstitute.org/17051/international-criminal-court-threatens-peace

Kemp, Richard: Trumpets and Tank Engines: A Turning Point in Gaza? Gatestone Institute, 16 May 2021.

Kemp, Richard: Trumpets and Tank Engines: A Turning Point in Gaza? Gatestone Institute, 16 May 2021.

Kerstein Benjamin: "Blinken to US House Committee: 'It Remains Unclear' whether Iran Prepared to Comply with Nuclear Deal Limits", The Algemeiner, 7 June 2021.

Kerstein, Banjamin: "Residens of Israel's South Reject Ceasefire with Hamas Until Rocket Fire Quelled, Prisoners Returned”, The Algemeiner, 19 May 2021.

Kerstein, Benjamin: "Ahead of Vienna Talks, US Envoy Says Iran's Missile Programm, Regional Activities Should Be Addressed in 'Follow-On' Deal”, The Algemeiner, 6 April 2021.

Kerstein, Benjamin: “IDF's Point Man on Iran Says Israel 'Definitely' Has Capacity to Destroy Nuclear Program, Biden Administration Keeping Its Promises So Far", The Algemeiner, 30 March 2021.

Kerstein, Benjamin: "Iran's top Nuclear Official Calls Major Malfunction at Natanz Facility, Attributed to Israel, an Act of Nuclear Terrorism", The Algemeiner, 11 April 2021.

Kerstein, Benjamin: "Israelí Cabinet Approves Ceasefire, Potentially Ending Gaza Operation Against Hamas; IDF Believes Goal, Have Been Achieved”, The Algemeiner, 20 May 2021.

Kerstein, Benjamin: "Netanyahu Sends Message to White House, Iran: We Are Not Pinning Our Hopes on Any Agreement with an Extremist Regime", The Algemeiner, 23 February 2021.

Kerstein, Benjamin: "Netanyahu will seek to Avoid a Confrontation with Biden on Iran Nuclear Issue-Report", The Algemeiner, 27 January 2021.

Keyser, Zachary: "UK Notes Opposition to ICC probe Into Alleged Israeli War Crimes", The Jerusalem Post, 14 April 2021.

Khoshnood, Ardavan: The Attack on Natanz and the JCPOA, The Begin-Sadat Center for Strategic Studies, BESA Center Perspectivas Paper nº 1997, 14 April 2021.

Khosnood, Arvin: The Dangers of Lifting Sanctions on the Islamic Region of Iran, The BeginSadat Center for Strategic Studies, BESA Center Perspectives Paper nº 1907, 28 January 2021.

Landslide, Vatory: "Senate Votes 97-3 to Make US Embassy Move to Jerusalem Permanent, United with Israel", 5 February 2021.

Lappin, Yaakov: "New report Exposes how Iran is Entrenching itself into southern Syria", en: https://www.jns.org/new-eport-exposes-how-iran-is-entranching-itself-into-southern-syria

Lasserre, Isabelle: "Iran: la fuite en avant vers la bombe", Le Figaro, 12 février 2021. 
Limor, Yoav: "Israel has the Ability to completely Destroy Iran's Nuclear Program", Israel Hayom, 29 March 2021.

Ludvik, Jan. "Closing the window of vulnerability: Nuclear Proliferation and Conventional Retaliation”, Security Studies, vol. 28, no 1 (2018), pp. 87-115.

Lynch, Colum: "Despite U.S. Sanctions, Iran Expands its Nuclear Stockpile", Foreign Affairs, 8 May 2020, en https://foreignpolicy.com/2020/05/08/ran0advances-nuclear-program-withdrawal-jcpoa/

Magid, Jacob: "Biden s'entretient avec Natanyahu et se dit "favourable à un cessez-le-feu", The Times of Israël, 18 mai 2021.

Magid, Jacob : "Pourquoi Blinquen refuse de mettre fin aux pourparlers nucléaires avec l'Iran", The Times of Israël, 14 mai, 2021.

Magid, Jacob : “Un Démocrate US exhorte l'envoyé d'Iran à convaincre le Hamas de cesser les tirs", The Times of Israël, 19 mai 2021.

Majid. As Iran's Mullahs Incite Hamas Terrorism, Biden Administration Wants Sanctions Lifted, Gatestone Institute, 18 May 2021.

Malka, Ron: "UNHRC Special Session Won't Benefit Anyone-Israel, Palestinians or the Middle East", The Print, 26 May 2021, en https://theprint.in/opinion/unhre-special-sessionwont-benefit-anyone-israel-palestinians-or-the-middle-east/666030/.

Mansfield, Mollie: "Fighting Words Joe Biden Shockingly compares Trump to Hitler's Nazi propagandist Joseph Goebbels in Wild Attack", The Sun, 22 September 2020, en https://www.thesun.co.uk/news/12779891/joe-biden-donald-trump-joseph-goebbels

Marcus, Lauren: "Iran Admits Nuclear Sabotage Was 'Beautiful': Remoted-controlled Bomb Caused Explosion”, World Israel News, 13 April 2021.

Marcus, Laurent: "If Biden adopts Obama's plan, there's nothing to talk about: Israel Gears up for Clash on Iran", World Israel News, January 2021, en https://worldisraelnews.com/if-biden-adopts-obamas-plan-theres-nothing-to-talk-about-israel-gears-up-for-clash-on-

iran/?utm_source=centent=israel+Rea...

Marcus, Laurent: "Mysterious 'accident' reported at Iranian Nuclear Facility", World Israel News, 11 April 2021.

Marcus, Laurent: “'Prepare for Iran Nuclear Facility Strike', Says Israeli Official after Election of 'Butcher of Tehran", World Israel News, 20 June 2021.

Margit, Maya: "Hamas Dealt Blow 'Surprised' by Israeli Response, Analysts Say”, Jewish Journal, 19 May 2021.

Mark, David: "IDF Prepares First Strike Options Against Iran”, Israel Unwired, 15 January 2021, en https://www.israelunwired.com/idf-prepares-attack-iran/

Marquina Antonio: "Los conflictos internacionales con Irán y Corea del Norte (I): el proceso negociador", UNISCI Discussion Papers, $\mathrm{n}^{\mathrm{o}} 13$ (Enero/January 2007), en http://www.unisci.es/wp-content/uploads/2017/05/Marquina13.pdf;

Marquina Antonio: “The US Relations with the two Koreas" en Parc Jimmyn, Yang EunSook, Ranger Stephen (eds.) (2020): South Korea's International Relations with its Neighbors. Madrid, UNISCI, pp. 107-172.

Mars, Amanda: "Joe Biden, en su primera cumbre internacional: Estados Unidos ha vuelto", El País, 20 de febrero de 2021. 
May, Clifford D.: “The Islamic Republic's War on Israel”, The Algemeiner, 19 May 2021.

Mekelberg, Yossi: "Is the Biden Presidency an Opportunity or a Threat to Israel?". Chatham House, 18 November 2020, en https://www.chathamhouse.org/2020/11/five-key-questionsbidens-middlecast-policy.

Mekelberg, Yossi : "The Role of the Arab States in Israeli-Palestinian Peacemaking", 20 February 2019, en https://www.chathamhouse.org/events/all/research-event/role-arab-statesisraeli-palestinian-peacemaking

Mousavian Seyed, Hossein: "Sanctions Make Iran's Coronavirus Crises more Deathly", Aljazeera, 8 May 2020.

MUR, Robert: "Rafael Grossi, el argentino más atómico", La Vanguardia, 27 de febrero de 2021.

Navarro, Beatriz: "La rutina vuelve a casa", La Vanguardia, 29 de enero de 2021.

Niresntein, Fiamma: "Its Iran Stupid”, The Algemeiner, 19 May 2021.

Norton Augustus, Richard: "La guerra de Gaza: antecedentes y consecuencias", Real Instituto Elcano, ARI, n 21/2009, 13 de febrero de 2009.

Ofek, Raphael: Signs that Iran Might Be continuing its Nuclear Weapons Program, The BeginSadat Center for Strategic Studies, BESA Center Perspectives Paper nº 1937, 19 February 2011.

Oren, Michael y Halevi, Yossi Klein: "The Case Against the Iran Deal. Reviving the JCPOA will ensure either the emergences of a nuclear Iran or a desperate war to stop it", The Atlantic, 21 January 2021, en

https://www.theatlantic.com/ideas/archive/2021/01/case-against-iran-deal/617755/

Pellicer, Luis y Mars, Amanda: "Estados Unidos e Irán dan el primer paso para salvar el acuerdo nuclear", El País, 6 de abril de 2021.

Plank, Josh: "Iran warns Biden: Return to Old Nuclear Deal if you want a seat at the Table", World Israel News, 25 January 2021.

Plank, Josh: "Kerry's Reported Leaks to Iran about Israel Lead to Calls for his Dismissal", World Israel News, 27 April 2021.

Pozo Serrano, Pilar: "La retirada de los Estados Unidos del Plan de Acción Integral conjunto y la reimposición de sanciones a Irán: aspectos jurídicos y políticos”, Anuario Español de Derecho Internacional, $\mathrm{n}^{\circ} 35,2019$, pp. 219-259.

Prieto Arellano, Fernando: "El desafío de Biden en Oriente Medio. Del Acuerdo del Siglo a los Acuerdos de Abraham y el pragmatismo de la nueva geopolítica regional", IEEE, Documento de Opinión 15/2021, 9 de febrero de 2021.

Rafizadeh, Majid: “On Iran, Biden Administration Ready to Undo Former Administration's Work, whether it is Good for the World or Not?”, Gatestone Institute, 14 April 2021.

Razaian, Jason: “Opinión: Don't Sanction Iran - Trade with it”, The Washington Post, 1 November 2018.

Rowe Rabbi Daniel: "Israel Has Set a New Standard for the Ethics of War", Jews News Syndicate, 4 June 2021, en https://www.jns.org/opinion/israel-has-set-a-new-standard-for-theethics-of-war/)

Ruíz Miguel, Carlos: "Colapso del proceso de paz en el Sahara Occidental y vuelta a la guerra”, Razón Española (enero-febrero 2021), pp. 71-81. 
Sahuquillo, María R.: "Moscú amenaza con una respuesta contundente al castigo de Estados Unidos", El País, 16 de abril de 2021.

Samuel Greene: "Pour Joe Biden, la Russie ne détient aucune solution aux problèmes du monde", Le Temps, 15 avril 2021.

Sánchez Arreseigor, Juan: dudas sobre la verdadera trascendencia y eficacia de los Acuerdos de Abraham, Documento Opinión 41/2021, IEEE, 13 de abril de 2021,

Sánchez Vallejo, Ma Antonia: "Biden impone duras sanciones a Moscú por los ciberataques y la injerencia en las relaciones", El País, 15 de abril de 2021.

Satloff, Robert: "What's Wrong with The NY Times' Report on Children's Deaths? So Much", The Times of Israel, 31 May 2021.

Savin, Aryeh: "Is US Rejoinst Nuclear Deal, Israel will reserve the right to defend itself", World Israel News, 25 May 2021

Schindeman, Paul: "Immoral Equivalence: UN Council Blasted for again Singling out Israel for Alleged War Crimes", World Israel News, May 27, 2021.

Schindman, Paul: "Biden Administration Changes Policy, says it is now Prepared to Lift Sanctions before Iran Stops its violations of the Nuclear Deal", World Israel News, April 8, 2021.

Schindman, Paul: "Biden Administration Willing to Lift Terror Sanctions on Iran", World Israeli News, April 22, 2021.

Schindman, Paul: "Hemas Slams UNRWA Chief for Saying IDF Strikes Were Precise", World Israel News, May 262021

Schnar, Dan: “Biden's Status Quo Middle East Policy”, Jewish Journal, February 1, 2021.

Schnur, Dan: “A Symbolic Impact”, en

https://mail.google.com/mail/a/0/\#inbox/FMfcgzGkXwDNqDFKmKMBDflTrrfVsbbc,

Schnur, Dan: “President Biden's Wise Balancing Act”, Jewish Journal, 24 May 2021.

Seill, Isabel (2021): "How Biden Can Rebuild a Divided and Distrustful Nation. Americans Must Get to Know Another Again”, Foreign Affairs, vol. 100, nº 1, 4 January 2021.

Shindman, Paul: “Golan Will Always Remain Israeli: Netanyahu Responds Forcefully to Biden Team's Wishy-Washy Answer on Heights Sovereignty Secretary of State Dodges Question When Asked if Biden Administration Recognizes Israeli Sovereignty, Calling it a "Legal Question"”, World Israel News, February 9, 2021.

Shindman, Paul: "IDF Updating Preparations to Strike Iran Ready to Fight Ourselves", World Israel news, 5 March 2021.

Shindman, Paul: "Iran Admits Top-secret Nuclear Facility was attaqed 5 Times", World Israel News, 2 May 2021.

Shindman, Paus: "Egypt, Israel Turning the Financial Screws on Hamas, 'Not So fast' for the $\$ 1.3$ billion to Gaza", World Israel News, 27 May 2021.

Sonnenfeld, Daniel: "Israeli Officials Likely on Damage Control Mission as Iran Nuclear Deal Revival Nears. Biden, Blinken and Sullivan Have All Met in Washington with Israeli Security Officials in the Last Week", Jewish Journal, 4 May 2021.

Stephen Daisley: "Don't compare Israel to Hamas", The Spectator, 14 May 2021, en https://www.spectator.co.uk/article/don-t-compare-israel-to-hamas. 
Stephens, Bret: "For the Sake of Peace, Israel Must Rout Hamas", The New York Times, 13 May 2021, en: https://www.nytimes.com/2021/05/13/opinion/gaza-hamas-israel.html.

Suissa, David: "What Does Iran's New Leader Mean for the Iran Deal? Jewish Journal Round Table, June 22, 2021.

Tavakol, Mohsen: "Iran's Economiy and the Burden of Multiple Exchange Rates", Atlantic Council, 12 May 2020, en

https://www.atlanticcouncil.org/blogs/iransource/irans-economy-and-the-burden-of-multipleexhange-rates/

The Algemeiner Staff: “Khameini Criticizes Iran's Foreign Minister Over Leake Remarks”, The Algemeiner, 2 May 2021.

The Algemeiner Staff: “Gantz: ICC's Probe into Israel's Alleged War Crimes Blind and Unjust”, The Algemeiner, April 9, 2021.

The Algemeiner Staff: "German Foreign Minister Rebuked After Saying Sabotage of Iranian Nuclear Facility Not a Positive Contributions", The Algemeiner, 12 April 2021.

The Algemeiner Staff. "Netanyahu: Israel Will Defend Itself Against 'Existential Threat' Regardless of Iran Nuclear Deal", The Algemeiner, 7 April 2021.

The Algemeiner Staff. “Nuclear Deal Possible Soon if Iran Takes 'Political Decision' Says US Official”, The Algemeiner, 6 May 2021.

The Algemeiner Staff. "UNRWH Gaza Director Expresses Regret After Saying IDF Strikes Were 'Precise' and 'sophisticated' Did not Target Civilians", The Algemeiner, 25 May 2021.

The Algemeiner Staff. "White House: Israeli Delegation Will Not Sway Biden into Abandoning Iran Nuclear Deal", The Algemeiner, 25 April 2021.

The Algemeiner Staff. "Biden Administration Crafting Plan to Reset US Ties with Palestinians: Sources", The Algemeiner, 3 March 2021.

The Algemeiner Staff. "Biden Informs Mossad Chief That US Is Far from Returning to Iran Deal: Report”, The Algemeiner, 3 May 2021.

The Algemeiner Staff. "Concern in Israel Over Us Announcement Welcoming Nuclear Talks with Iran", The Algemeiner, 19 February 2021.

The Algemeiner Staff. "Intelligence Website Releases 3D Reconstructed Images of Iran's Fordow Nuclear Facility", The Algemeiner, 30 May 2021.

The Algemeiner Staff. "Iran Deepens Breach of Nuclear Deal at Underground Enrichment Site", The Algemeiner, 2 February 2021.

The Algemeiner Staff. "Iran Enriching Uranian with New Advanced Machine Type at Underground Plant: IAEA". The Algemeiner, 16 March 2021.

The Algemeiner Staff. "Iran Says Nuclear Talks Not at Impasse, but Difficult 'Issues' Remains”, The Algemeiner, 1 June 2021.

The Algemeiner Staff. 'Netanyahu Rebuffs Biden's Call for Immediate 'De-escalation' in Gaza", The Algemeiner, 19 May 2021

The Algemeiner Staff. "Reports of Kerry Disclosure to Zarif on israelí Strikes 'Disturbing' Says Algemeiner Editor-in-Chief”, The Algemeiner, 29 April 2021.

The Strategic Genius Behind Allowing Qatari Suitcases of Cash into Gaza, The Begin-Sadat Center for Strategic Studies, BESA Center Perspectives Paper no 2053, 27 May 2021. 
The White House. Press Briefing by Press Secretary Jen Psaki and Secretary of the Interior Deb Haaland, 23 April 2021, en https://www.whitehouse.fov/briefing-room/speechesremarks/2021/04/23/press-briefing-by-press-secretary-jen-psaki-and-secretary-of-the-interiordeb-haaland-april-23-2021/.

Times of Israel Staff : L'ancien chef du Mossad met en garde l'Iran et défend Netanyahu", The Times of Israël, 11 juin 2021, en https://fr.timesofisrael.com/en-interview-tv-lancien-chef-dumossad-met-en-garde-liran-et-defend-

netanyahu/?utm_source=A+La+Une\&utm_campaign=a-la-une-2021-06-

11\&utm_medium=email.

Toamed Khaled Abu: "Hamas and Iran Turned Gaza into Cemetery for Children, Many Arabs Concede", World Israel News, 7 June 2021.

Toamed, Khaled Abu: Biden Administration to Support Palestinian Dictator-Ship, Gatestone Institute, 17 April 2021,

Toamed, Khaled Abu.: Palestinian Elections: What the Biden Administration Does Not Want to Know, Gatestone Institute, 30 April 2021.

Toamed, Khaled Abu: The Palestinian Voices Blinken Won't Hear, The Gatestone Institute, 24 May 2021.

Toameh, Abu Khaled: "Arabs Warn Biden: We Do Not Want Another Obama”, United with Israel, 4 March 2021.

Tobin, Jonathan S.: "Opinion: Israel has no choice but to Act on Its Own to Stop Iran", World Israel News, 27 April 2021.

Tzahi, Hanegbi : “Washington n’attaquera jamais l'Iran ; Israël pourrait agir seul”, The Times of Israël, 3 février 2021.

Vahid, Farid : "Iran : les possible conséquences de la fin de l'embargo sur les armes”, Revue Défense Nationale, vol. 2, nº 837 (2021), pp. 109-114.

Vakil, Sanan: "How is a Biden Victory Perceived Across Both Sides of the Gulf?", Chatham House, Five Key Questions on Biden's Middle East Policy, en htps://www.chathamhouse.org/2020/11/five-key-questions-bidens-middleeast-policy

Watch: "Investigate Kerry over Leaks to Iran about Israeli Airstrikes, Demand Republicans", World Israel News, 8 May 2021.

Wilkenfeld, Yon: "Israel Says US 'Very Considerate' of its Concerns on Iran Threat After Week of High-Level Talks", The Algemeiner, 30 April 2021.

Wilkenfeld, Yoni: "ICC Decision on Israel 'Obstructs the Path to Peace' Say Top US Jewish Leaders", The Algemeiner, 12 February 2021.

Wolf, Albert: "Why Hasn't Anyone Attacked Iran's Nuclear Sites?” The Begin-Sadad Center for Strategic Studes, Besa Center Pespectives Paper nº 1878, Bar-Ilan University, 11 January 2021.

Wrobel, Sharon: "Israel Keeping close Eye on Vienna Nuclear Talks Between Iran and World Powers, Experts Say”, The Algemeiner, 7 April 2021.

Wrobel, Sharon. 'Israel Rejects 'Outrageous' Probe Approved by UN Rights Council After Gaza Conflict”, The Algemeiner, 27 May 2021.

Wrobel, Sharon: "Israeli Army Says Gaza Targets Struck Sets Back Hamas Military Capabilities for Many Years", The Algemeiner, 21 May 2021. 
Wrobel, Sharon: "Israeli Security Officials Head to Washington to Share Iran Threat Intel as White House Says It Can’t Be Swayed on Nuclear Deal”, The Algemeiner, 26 April 2021.

Wrobel, Sharon: "Report: Hamas Coordinate Gaza War with Iran, Hezbollah in Join Military Room", The Algemeiner, 30 May 2021.

Wrobel, Sharon: "Report: Tens of Thousands of Allied Fighters Serve as Iran's Four-Pronged Network of Proxy Forces", The Algemeiner, 16 April 2021.

Wrobel, Sharon: "Netanyahu Says Israel Has Four More Peace Agreements in Region on the Way", The Algemeiner, 16 March 2021.

Zarif Mohammed Javad: "Iran Wants the Nuclear Deal it Made. Don't Ask Tehran to Meet New Demands", Foreign Affairs, 22 January 2021. 